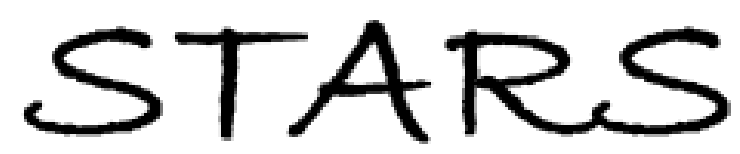

University of Central Florida

STARS

2015

\title{
Conditions Associated with Increased Risk of Fraud: A Model for Publicly Traded Restaurant Companies
}

\author{
Elizabeth Yost \\ University of Central Florida
}

Part of the Education Commons, and the Hospitality Administration and Management Commons Find similar works at: https://stars.library.ucf.edu/etd University of Central Florida Libraries http://library.ucf.edu

This Doctoral Dissertation (Open Access) is brought to you for free and open access by STARS. It has been accepted for inclusion in Electronic Theses and Dissertations, 2004-2019 by an authorized administrator of STARS. For more information, please contact STARS@ucf.edu.

\section{STARS Citation}

Yost, Elizabeth, "Conditions Associated with Increased Risk of Fraud: A Model for Publicly Traded Restaurant Companies" (2015). Electronic Theses and Dissertations, 2004-2019. 1196.

https://stars.library.ucf.edu/etd/1196

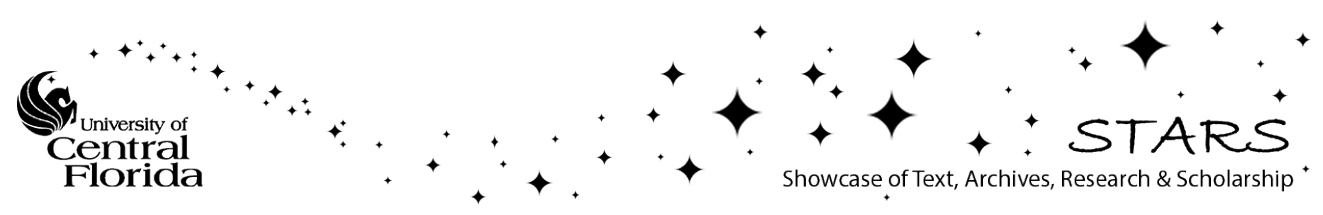




\title{
CONDITIONS ASSOCIATED WITH INCREASED RISK OF FRAUD: A MODEL FOR PUBLICLY TRADED RESTAURANT COMPANIES
}

\author{
ELIZABETH A. YOST \\ M.S.A. University of Central Florida, 2003 \\ B.S. University of Florida, 2000
}

\begin{abstract}
A dissertation submitted in partial fulfilment of the requirements for the degree of Doctor of Philosophy in the College of Education and Human Performance at the University of Central Florida Orlando, Florida
\end{abstract}

Spring Term

2015

Major Professors: Robertico Croes and Denver Severt 
(C) 2015 Elizabeth A. Yost 


\begin{abstract}
The central focus of this dissertation study is to understand the impact of the SarbanesOxley Act and the factors that contribute to increased risk of fraud in order to determine why fraud may occur despite the imposed regulation of the Sarbanes-Oxley Act. The main premise of the study tests the application of the fraud triangle framework constructs to publicly traded restaurant companies during the time period of 2002-2014, using proxy variables defined through literature. Essentially, the study seeks to identify the factors that may provide the optimal criteria to engage in fraudulent or opportunistic behavior. The fraud triangle theoretical framework is comprised of the constructs of pressure, opportunity and rationalization, and has mostly been utilized by external auditors to assess the fraud risk of various companies. It has never been applied to the restaurant industry, and the proxy variables selected have never before been tested in a comprehensive model. Thus, a major contribution of this study may enable executive managers to assess the fraud triangle conditions according to the model in order to afford conclusions regarding increased risk of fraud.

The study first hypothesized that the Sarbanes-Oxley Act has had a significant impact on detecting increased risk of fraud for publicly traded restaurant companies. Additionally, the study controlled for and tested the proxy variables of the fraud triangle constructs to determine if any of the variables had a significant impact on detecting increased risk of fraud for publicly traded restaurant companies. The variables tested included company size, debt, employee turnover, organizational structure, international sales growth, executive stock compensation, return on assets, the Recession, and macro-economic factors of interest, inflation, and unemployment rates.
\end{abstract}


The research study adopted an exploratory research design using the case of publicly traded United States restaurant companies in order to provide a better understanding of the characteristics that may contribute to increased fraud risk. The study assumed a binary distribution of the dependent variable, increased fraud risk, measured by the incidence of a reported internal control deficiency over the testable time period. Specifically, the study employed a probit model to estimate the probability that an entity or company will be at an increased risk of fraud based on the independent variables that support and are linked to the fraud triangle framework. Additionally, the model assumes equal weight to the variables of the fraud triangle framework.

Through use of the probit model, the major findings of the study were as follows: First, the Sarbanes-Oxley Act does have a significant impact on highlighting areas of increased fraud risk for publicly traded restaurant companies. Second, for the total population of restaurant companies, only the Recession, interest rates, inflation rates and unemployment rates are significant indicators of increased fraud risk. None of the internal variables were significant. However, once the data was segmented by type of restaurant, the results revealed significance of both internal and external variables.

These results imply a couple of theoretical notions: first, that the Sarbanes-Oxley Act is an effective means for detecting risk of fraud for publicly traded restaurant companies when considering variables that support the fraud triangle; second, that the fraud triangle is contextual when applied to the restaurant industry because only the variables that are outside of managements control were significant. Finally, from a managerial perspective, the study provides evidence that macro-economic conditions that might affect consumer demand may increase the risk of fraud for publicly traded restaurant companies. 
This dissertation is dedicated to my wonderful husband, my extraordinary mother and my beautiful mother in law.

Matt, throughout the LONG process of my pursuit of this degree, you have always been by my side. Without your support, I don't think I could have ever finished! From the time you gently mentioned that I should stop playing Angry Birds and write my dissertation, to the many mornings you would bring me a cup of coffee while I sleepily got ready for work, and to your patience of waiting for me each night when I said "I just need another 30 minutes and then I'll come watch our shows with you", your support and understanding made this almost unbearable process so much easier. I love you so much!

Mom, I never would have made it through this process without the skill set that you taught and bestowed upon me. My perseverance is directly attributed to you!! You always taught me that I could do anything I put my mind to, and that I could do anything for a short time. I am and always will be inspired by the way you live your life, and your dedication to our family. You taught me to live my life with integrity and purpose, to always do the right thing, and to always reach for my dreams. My compassion and strength comes from you, and your belief in the benefits of higher education helped me to recognize the importance of achieving this degree. You are the best mom in the whole world!! I'm so thankful for everything you have ever done for me and for our family. I love you!!

Sharon, I know you are watching over all of us and would be so proud to see me finish this degree. We love and miss you every day! I think it's fitting that graduation is also your birthday weekend. We will celebrate! 


\section{ACKNOWLEDGMENTS}

I never thought I would see the day when I would be able to write the acknowledgments to my dissertation! To say that this process has been arduous is an understatement. I began my PhD coursework when I was 28 years old. At that time, I had no idea my path to earning these three little letters after my name would be met with such beautiful and also sorrowful events. At the darkest times, I wanted to quit. However, in my heart, I knew that this was one goal I could not abandon. This would not have been attainable without the following individuals, with whom I am eternally grateful and thankful for their time, commitment and compassion to seeing me complete this degree.

- To Dr. Robertico Croes: Thank you for your amazing leadership, mentorship and dedication to leading me to completing a successful dissertation. You taught me the foundation of being a scholar - building me up from the blueprint to forming the house (and even adding a few window treatments) ;-). Thank you for your service as my Chair, and from the bottom of my heart, I couldn't have done this without you.

- To Dr. Denver Severt: Thank you for your mentorship, leadership and dedication. Through all of the ups and downs, you were there for me. You gave me space when I wasn’t ready, yet you pushed me when needed. You always believed in me and never lost faith that I would one day finally graduate!

- To Dr. Kelly Semrad: You are one of the most important people in my life! I honestly don't know what I would do without your collaboration, mentorship and friendship. You have helped me to become a better scholar, thinker and person. Thank you for everything! 
- To Dr. Kevin Murphy: Thank you for your practical and theoretical expertise, your real world perspective and your kind support! I'll never forget what you told me when life was at its worst for me. You said, “I promise, you won’t feel like this forever”. I carry that nugget of wisdom with me all the time. And for the record, you were right!

- To Dr. Paul Rompf: Thank you for doing such a wonderful job as program director and supporting me and all of my fellow PhD Candidates. You looked out for me and all of us, and I'm eternally grateful for your assistance in helping me to finish my PhD. I'm holding you to your promise that you will come out of retirement to attend my graduation!

- To Dr. Leonard Jackson: Thank you for serving as my external committee member and traveling from Georgia to be at my defenses. Your commitment to scholarship and service is beyond admirable and your smile and kind words exude support. Thank you for your service, support, expertise and kindness.

- To Dr. Mike Robinson: Thank you for your support and the support of the College of Education!

Finally, to all of my family (Grandma, Jon, Keirstin, Norah, Bev, Stacey, Jay, Chris, Shawna, Ed, Karen) and friends (Jackie, Nickie, Jami, Denise, Michelle, Elise and countless others) thank you for your support, love and understanding! The pursuit to my PhD has been one long roller coaster ride. You all helped and inspired me to work hard, never quit and to smile and laugh when it all just goes to heck. 


\section{TABLE OF CONTENTS}

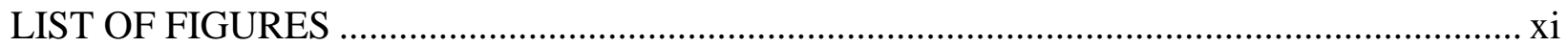

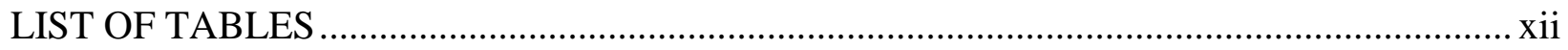

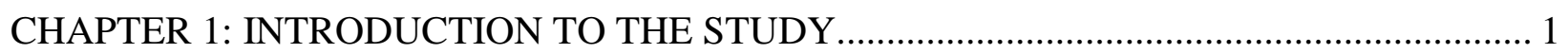

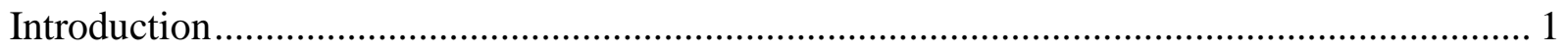

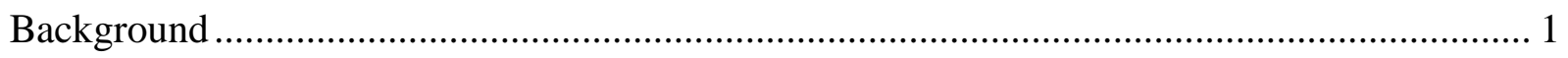

Evolution of the Sarbanes-Oxley Act of 2002 …………........................................................... 4

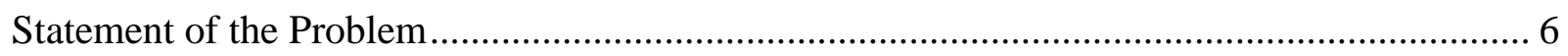

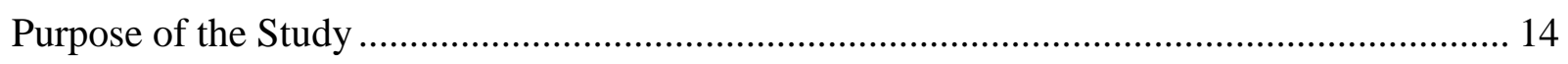

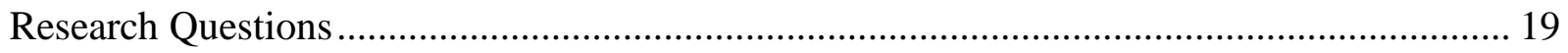

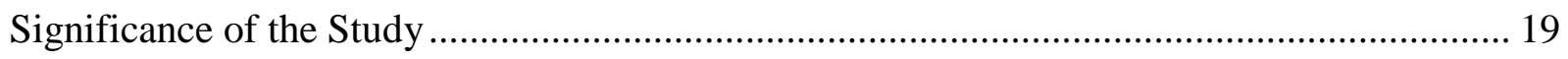

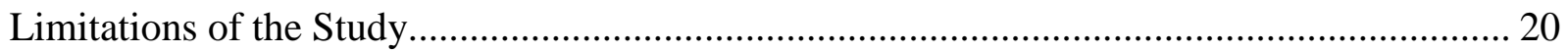

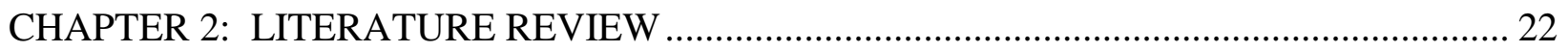

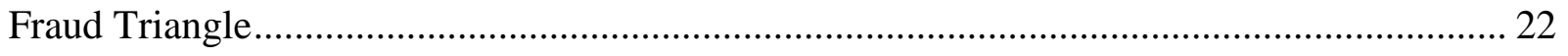

Fraud Triangle Construct - Pressure/Motivation.................................................................... 28

Fraud Triangle Construct - Opportunity ............................................................................... 35

Fraud Triangle Construct - Rationalization........................................................................... 38

Industry Characteristics and Increased Fraud Risk................................................................... 43

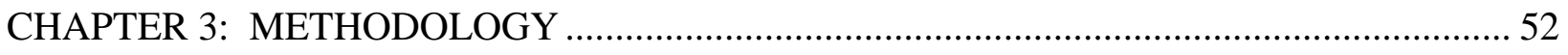

Research Questions and Hypotheses .................................................................................. 52

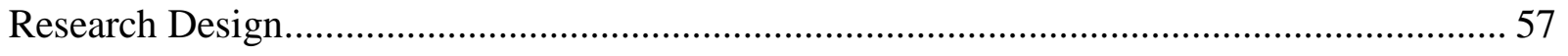

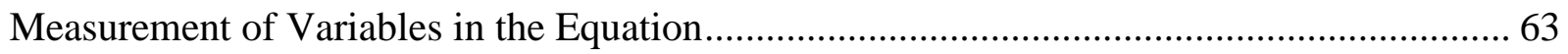

Population and Sample of Study ..................................................................................... 74 


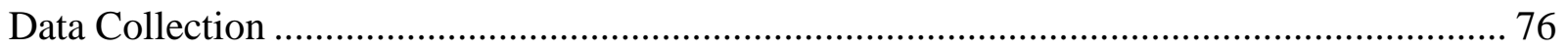

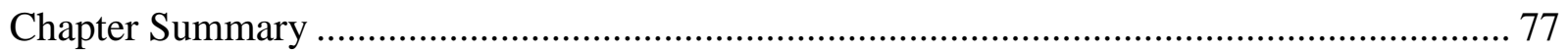

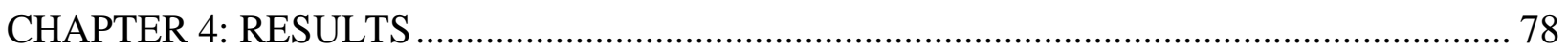

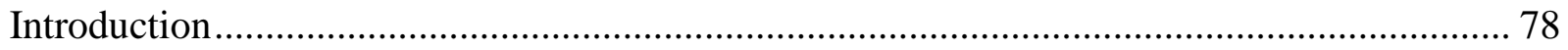

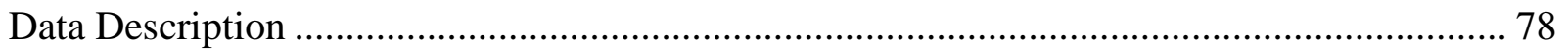

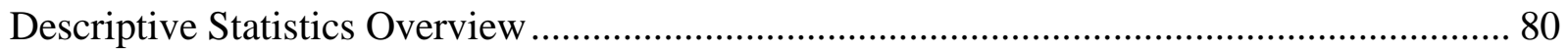

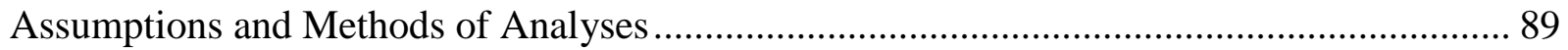

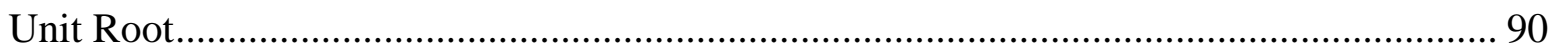

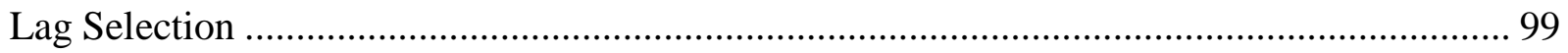

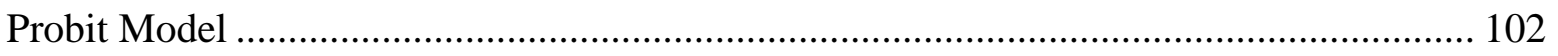

Likelihood of Increased Fraud Risk.................................................................................... 106

Research Objective \#1: Company Size............................................................................. 106

Research Objective \#2: Debt ......................................................................................... 107

Research Objective \#3: Employee Turnover .......................................................................... 108

Research Objective \#4: Organizational Structure ................................................................ 109

Research Objective \#5: International Sales Growth .............................................................. 110

Research Objective \#6: Stock Compensation ...................................................................... 110

Research Objective \#7: Return on Assets ........................................................................... 111

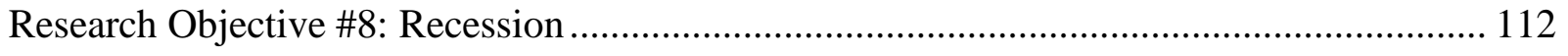

Research Objective \#9: Macroeconomic Factors …………………………………............. 113

Results: Type of Restaurant Segment ................................................................................. 115

Quick Service Restaurants Results ........................................................................................ 115

Fast Casual Restaurants Results................................................................................. 118 
Casual Dining Restaurants Results ................................................................................... 121

Fine Dining Restaurants Results .................................................................................... 125

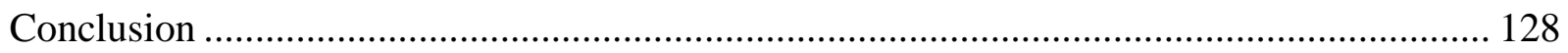

CHAPTER 5: CONCLUSIONS AND IMPLICATIONS ....................................................... 129

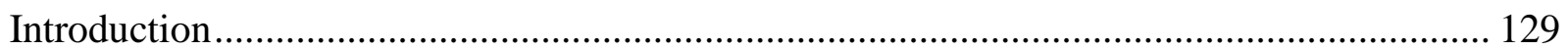

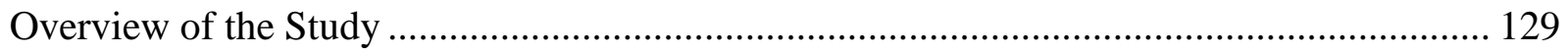

Objective One: Sarbanes-Oxley Act............................................................................. 130

Objective \#2: Company Size ……………………………................................................. 133

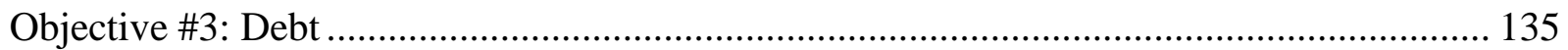

Objective \#4: Employee Turnover........................................................................................ 137

Objective \#5: Organizational Structure ............................................................................ 139

Objective \#6: International Sales Growth ......................................................................... 142

Objective \#7: Stock Compensation................................................................................... 144

Objective \#8: Return on Assets............................................................................................. 146

Objective \#9: Recession and Macroeconomic Factors .......................................................... 149

Conclusions Regarding the Overall Model.......................................................................... 151

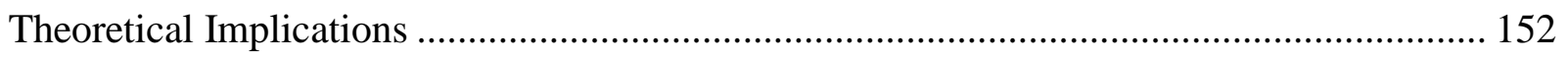

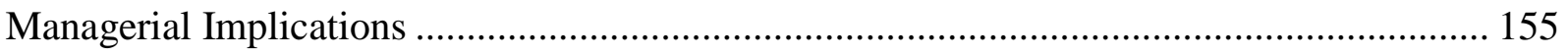

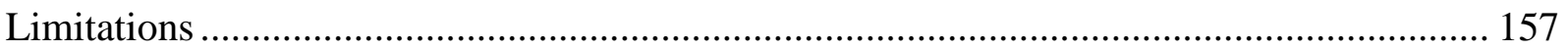

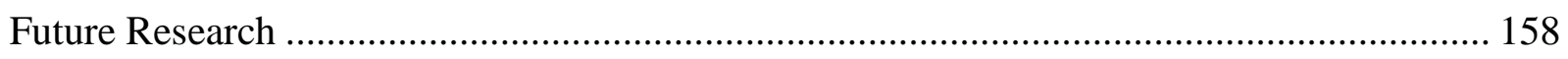

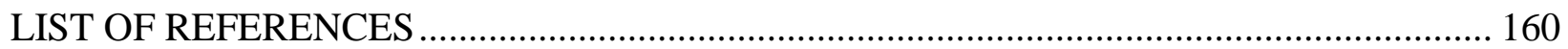




\section{LIST OF FIGURES}

Figure 1: The Fraud Triangle .......................................................................................... 16

Figure 2: Proposed Model of the Fraud Triangle Framework in the Restaurant Industry........... 49

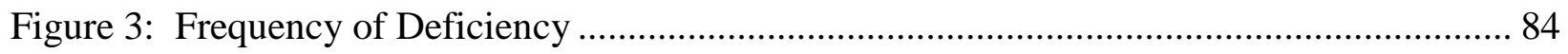

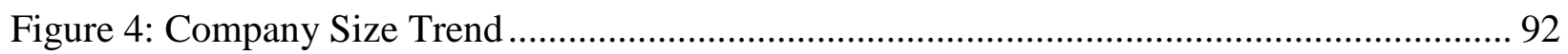

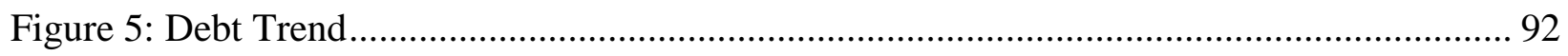

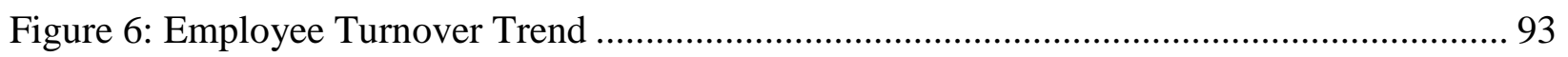

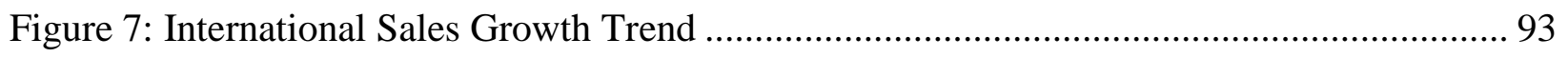

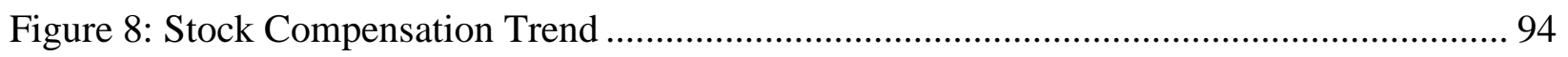

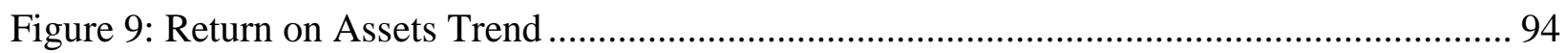

Figure 10: Interest Rate Trend ...................................................................................... 95

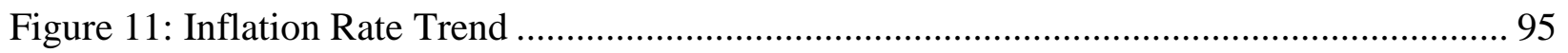

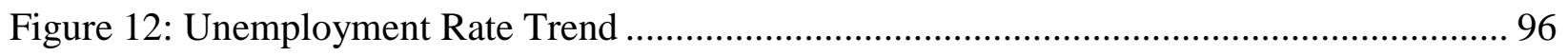

Figure 13: Components of the Fraud Triangle................................................................ 154 


\section{LIST OF TABLES}

Table 1. Applications of the Fraud Triangle Framework ................................................... 27

Table 2. Summary of Fraud Triangle Constructs - Results/Conditions .................................. 41

Table 3: Research Questions and Hypotheses ................................................................. 54

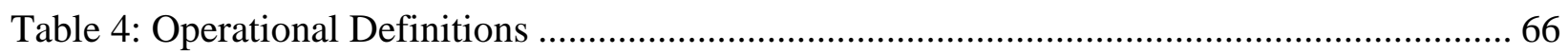

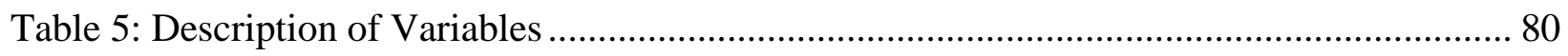

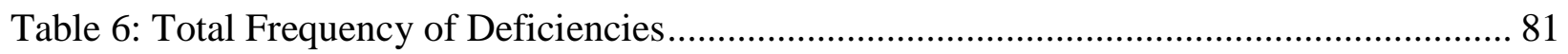

Table 7: Frequency of Deficiency, by Year ...................................................................... 83

Table 8: Summary Statistics of the Continuous Independent Variables................................... 87

Table 9: Summary Statistics of the Categorical Independent Variables.................................... 88

Table 10: Summary Statistics of the Independent Categorical Variables and the Categorical

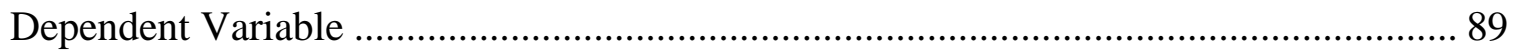

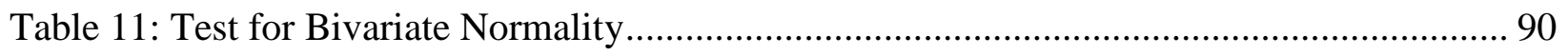

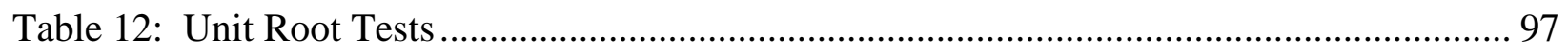

Table 13: Akaike's Information Criterion and Bayesian Information Criterion ........................ 100

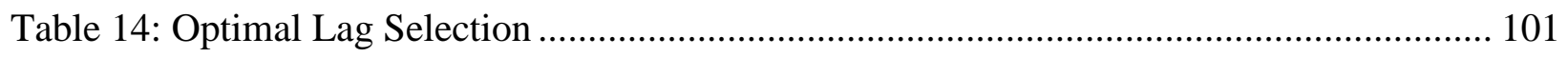

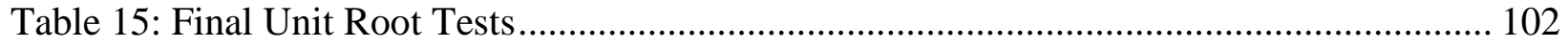

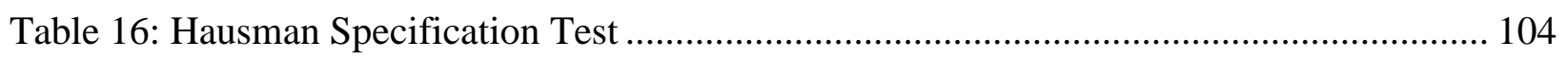

Table 17: Level and First Difference Form Probit............................................................. 105

Table 18: Final Probit Model (form and identified lags included) ....................................... 105

Table 19: Research Objective 1 Hypothesis ..................................................................... 107

Table 20: Research Objective 2 Hypothesis ..................................................................... 107

Table 21: Research Objective 3 Hypothesis .................................................................... 108 
Table 22: Research Objective 4 Hypothesis ................................................................................... 109

Table 23: Research Objective 5 Hypothesis ............................................................................ 110

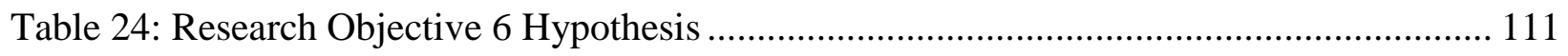

Table 25: Research Objective 7 Hypothesis .......................................................................... 112

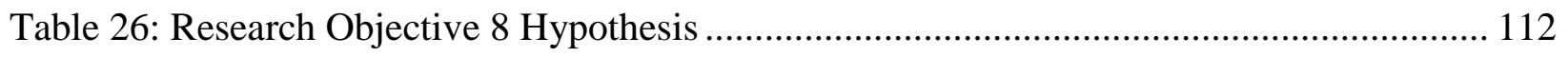

Table 27: Research Objective 9 Hypothesis ........................................................................... 114

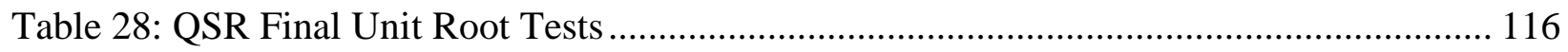

Table 29: QSR Final Probit Model (form and identified lags included) .................................... 117

Table 30: Fast Casual Final Unit Root Tests ............................................................................. 119

Table 31: Fast Casual Final Probit Model (form and identified lags included).......................... 120

Table 32: Casual Dining Final Unit Root Tests....................................................................... 122

Table 33: Casual Dining Final Probit Model (form and identified lags included) ..................... 123

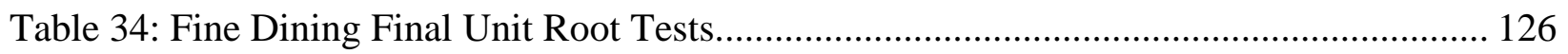

Table 35: Fine Dining Final Probit Model (form and identified lags included) ........................ 127 


\section{CHAPTER 1: INTRODUCTION TO THE STUDY}

\section{Introduction}

The purpose of this research study is to examine opportunistic behavior conditions highlighted through variables that might be associated with internal control deficiencies reported for publicly traded U.S. restaurant companies, since inception of the 2002 Sarbanes-Oxley Act, or SOX. The 2002 SOX Act was the Securities and Exchange Commission's (SEC) answer to the great decline in investor confidence as a result, among other things, of the accounting scandals that occurred in the early 2000s (Hammersley, Myers, Shakespeare, 2008).

Chapter one provides background information that provides a broad overview regarding the accounting scandals that permeated the market and the consequences of these scandals affecting organizations’ performance, particularly in the restaurant industry. The vulnerability of the restaurant industry to weaknesses in internal control and increased risk of fraud is also reviewed, followed by a statement of the research problem and the purpose of the study. The research problem is embedded in the fraud triangle theoretical framework which provides a model for understanding pressures, opportunities and rationalization that all contribute to increased fraud risk. After a concise explanation of the relevant theoretical framework, the research questions are provided along with a brief summary of the methods to be used in the study. Lastly, the significance of the study is noted with respect to its potential theoretical and practical contributions, followed by a discussion of the study’s limitations.

\section{Background}

Publicly traded companies today are under growing pressures from both passive and active investors to constantly increase their stock value in a dog-eat-dog world where meeting 
performance goals are necessary to maintain a competitive edge (SEC, 2014). Due to these pressures, the current business environment may be one of increased susceptibility to fraud and abuse (Martinek, 2005). To meet targets, it is typical for companies to put additional stresses on their internal control structures by reducing head counts, requiring employees to perform more than one job, and re-arranging risk profiles (Langevoort, 2006).

A weakened internal control structure is more susceptible to an increase in internal control deficiencies (COSO, 2000), which increased for public companies after initial compliance with the Sarbanes-Oxley Act (Ashbaugh-Skaife et al., 2006). Additionally, as companies make changes to their business structures (e.g., get bigger or smaller from acquisitions or dispositions) and enter into complex accounting treatments and ventures, opportunities for deficiencies increase (Bryan \& Lilien, 2005). Deficiencies are often observed through review of the main business cycles: revenue and receivables, purchasing and payables, treasury and stock, and financial reporting (Vallens \& Cook, 2001).

Examples of deficiencies that may be noted in a revenues and receivables cycle stem from policies and the tone at the top, and include an incomplete credit check; lack of review of a point of sale report; improper accounting personnel making journal entries, or a culture with weak corporate governance activities. Similar deficiencies exist for the purchasing and payables cycle. For example, such deficiencies may involve a lack of approved payable reconciliations; buying product without an approved purchase order or documentation; or personnel capitalizing purchases when they should be expensed (Geller, N, 1991; Schmidgall, 2006). In the treasury cycle, most control deficiencies are reported when an appropriate segregation of duties doesn't exist. For example, if management had a policy that allowed for petty cash withdrawals without documentation, the susceptibility of a deficiency being reported is high. Additionally, allowing a 
single employee to take cash to the bank and deposit it without a review may create a control deficiency (Hogan \& Wilkins, 2008).

In the financial reporting business cycle, deficiencies occur mostly due to management's philosophy and operating style - which is the main driver of effective internal control systems (COSO, 1992). Management is responsible for the month end close process and has the capability to exercise either a conservative (recommended) or aggressive attitude towards making year end journal entries (Krishnan \& Visvanathan, 2007). A reported control deficiency at this level highlights the amount of influence management has over a company’s financial records (Kim, Song \& Zhang, 2009). Additionally, management decisions relating to acquisitions/divestitures and treatment of such major transactions are reflected in the financial reporting cycle (Hogan \& Wilkins, 2008). Aggressive or non-compliance with accounting regulations as a result of such transactions may result in reported deficiencies (Lord \& Benoit, 2007). It's important to note that within each business cycle the incidence of a reported deficiency highlights a significant issue that has been found by the company’s external auditors. A growing body of professional and academic literature has indicated that companies with reported internal control deficiencies often pay for it through both lower returns through stock price and a higher cost of capital (Ashbaugh-Skaife et al, 2006; Lord \& Benoit, 2007). Further, the incidence of a reported deficiency, together with internal and external pressures and rationalizations by employees, may result in increased fraud risk (Levisohn, 2009). The implication of these studies is that companies with strong levels of transparency will prevail and be rewarded, while those without regard for corporate governance will suffer. Specifically stated, shareholders will benefit when companies perform checks on their internal controls, in accordance with provisions expressed in the SOX Act of 2002 (Bryan \& Lilien, 2005). 


\section{Evolution of the Sarbanes-Oxley Act of 2002}

When the corporate scandals of the early 2000s occurred, the actual standards and requirements for internal controls were quite narrow in scope (Geiger \& Taylor, 2003). In fact, the FCPA, also known as the Foreign Corrupt Practices Act of 1977 was the main legislative parameter that dictated any type of regulation over controls. Further, a requirement to disclose significant control deficiencies in a company's 8-K was only mandated when a company made a change to their independent audit firm (Geiger \& Taylor, 2003; Krishan, 2005).

In 2002, in response to the accounting and corporate scandals that plagued Enron and Arthur Andersen, the Sarbanes-Oxley Act created new reporting requirements that mandated new disclosures about, and assessments of, internal control. The downfall of both of these companies led to bankruptcies, severe stock losses, and a public loss of confidence in the stock market. There are two main sections of the Act that affect the disclosure requirements and assessments of internal control: 302 and 404. Section 302 of the Act imposed a much larger accountability on public company executives. Specifically, section 302 now requires executives to certify that they have reviewed and reported their conclusions about the effectiveness of internal controls. The certification is presented in several statements and must occur in the periodic reports that are to be filed with the Securities and Exchange Commission. If executives are aware and conclude that there are material weaknesses in their controls, they must disclose the identified deficiency and are also prohibited from reporting that the overall controls are effective (SEC, 2002, 2004). The incentive for executives to comply with the section is enforced by section 906 of the Act, which details criminal penalties upwards of \$5,000,000 and 20 years of jail time for executives who certify that controls are effective when they have evidence that 
they are not. This constitutes a violation of the requirements mandated by the Sarbanes-Oxley Act and does not comply with the provisions of effective internal control (Ge \& McVay, 2005).

Additionally, section 404 demands that companies obtain an in depth understanding of their internal controls at all levels in the organization as well as taking responsibility for maintaining adequate internal control. The provision specifically includes a required assessment of the procedures and overall effectiveness of the structure of internal controls by management in each annual report, which must also be reviewed and approved by the company's public auditors (Doyle, Ge and McVay, 2007[b]). Finally, executives and their companies must disclose all significant deficiencies and weaknesses that relate to their internal controls in their public filings.

The intent of sections 302 and 404 of the Sarbanes-Oxley Act was to afford investors and users of financial statements early cautions regarding potential concerns relating to company financial performance that may result from poor internal controls (Hammersley, Myers \& Shakespeare, 2008). The SEC's view of the imposed requirements of internal control reporting is that these reforms have the best ability to improve investor and public reliability on financial reporting. By certifying to the public that a company has effective internal controls that are free from weakness, public confidence in the market may strengthen and additionally encourages public investment in various markets (Nicolaisen, 2004).

Evaluation of an internal control system's strengths and weaknesses has been established by the Generally Accepted Auditing Standards (GAAS) in the United States (Doyle, Ge and McVay, 2007(a)). Three types of internal control deficiencies have been identified by the auditing standards. The deficiencies are noted as: significant deficiencies, control deficiencies and material weaknesses, listed in order of severity (PCAOB, 2004; Ge and McVay, 2005). Material weaknesses are the most concerning of the internal control deficiencies because they 
indicate problems with internal controls that are probably going to result in materially misstated financial statements (PCAOB, 2004; Ge \& McVay, 2005, Doyle, Ge \& McVay, 2007(b), Hammersley, Myers \& Shakespeare, 2008). Regardless of the classification of the deficiency, the mere identification of a control deficiency indicates a lack of controls sufficient to produce precise financial statements which, in turn, may cause a loss of confidence by investors and may subsequently decrease the market price of a company's common stock (Ashbaugh-Skaife et al, 2006).

\section{Statement of the Problem}

It is now known that millions of dollars were misappropriated during the reign of corrupt and deceptive business practices of corporations during the early 2000s. Enron and WorldCom caused publicly traded US companies losses upwards of $\$ 7$ trillion in market value due to the corporate fraudulent reporting scandals. The deceptive and corrupt business practices of these companies and others resulted largely from a failure of corporate governance and lack of ethical business practices, in which internal control mechanisms were circumvented by conflicts of interest that enriched executives and damaged shareholders (Free, Stein \& Macintosh, 2007). With these recent disclosures, it is essential that companies work to minimize internal control deficiencies and material weaknesses, which appear to offer the greatest opportunity for fraud to occur (Maijoor, 2000). Many academic studies and industry examples provide evidence that as a

firm's internal control structure weakens and deficiencies are found, the opportunity to engage in fraudulent financial reporting increases significantly (Baker, 1998; Geller, 1991; Rezaee, 2005).

The Sarbanes-Oxley Act was intended to reestablish public assurance in the way corporate America manages its business processes and activities by addressing, at its core, the 
issue of business ethics. Companies utilize the concept business ethics to ensure that a certain level of trust is maintained between employees and shareholders, through the management of ethical practices and a corporate governance framework (Hess, 2007). The Act, among other things, attempted to improve public company business ethics at the highest level in organizations by requiring disclosure of "honest and ethical conduct” (section 406 (a)) through a Code of Ethics that applies to the most senior executives, with additional provisions designed to increase whistle blowing (SEC, 2002; Hess, 2007), as well as additional required disclosures about the effectiveness of internal controls. All publicly traded companies in all industries were subject to the regulations of the Sarbanes-Oxley Act, and since inception, SOX has had far-reaching implications, although questions to its effectiveness still exist (Coates, 2007; Srinivasan \& Chandra, 2014).

The Sarbanes-Oxley Act was enacted to increase investor confidence by requiring companies to make assessments about the effectiveness of their internal controls, as well as deterring fraudulent behavior by imposing civil and criminal penalties to those who knowingly violate provisions of the Act. Criminal penalties and jail time are stipulated in section 906 of the Act, imposing fines starting at \$1,000,000 and jail time of 10 years (Karpoff, Lee \& Martin, 2005). However, a general problem exists because despite intent, enforcement, heavy fines, jail time and reputational demise of individuals and companies, fraud and misrepresented financial statements continue to occur (SEC, 2008). For example, as recent as March 2014, three top executives of a law firm were charged with grand larceny, scheme to defraud, securities fraud and falsifying business records in a \$200 million book cooking operation (New York Times, 2014). Additionally, in 2013, JP Morgan was forced to pay approximately \$614 million and constrict their oversight controls in order to reconcile charges that the company conned the 
government into guaranteeing defective home loans. With these very recent examples of fraud and many more since inception of the Act, it does not appear that the hefty penalties are sufficient deterrents to those committing the fraud. Therefore, the heart of this problem seeks to understand the impact of the Sarbanes-Oxley Act and the factors that contribute to increased risk of fraud in order to determine why fraud may occur despite the imposed regulation of the Sarbanes-Oxley Act.

A deeper dive into this problem seeks to understand if there are specific industries that may be more susceptible than others to fraud and reported internal control deficiencies. Some research has been conducted in this area, and findings suggest that companies in the telecommunications, technology, financial and services industries experience the most difficulty with initial Sarbanes-Oxley compliance efforts due to increased risk of fraud from industry risk factors (AICPA, 2009). The restaurant industry, a key player in the services industry, is particularly subject to increased fraud risk because executives and management control the key sources of revenue through operations, credit and market assessment (Boulton, 2013). So, if executives and management have a business plan that promotes aggressive financial reporting, then fraud risk is increased. Additionally, it should be noted that the restaurant industry is comprised of companies that operate as cash businesses with a large volume of transactions, are heavily dependent on supplier partner relationships, incredibly competitive, and sensitive to changes in macroeconomic conditions (Bernardi \& Pincus, 1996). Each of these characteristics provides opportunities for increased fraud risk through related variables, which will be discussed subsequently. In other words, the restaurant industry is often susceptible to deficiencies due to its inherent characteristics and high control risk (Rezaee, 2005). 
Examining industry risk factors that may lead to fraud in the restaurant industry, specifically, through the occurrence of control deficiencies is a meaningful research problem. Corporate scandals, misappropriation of assets and financial statement misstatement are all very real threats to the restaurant industry. According to the NRA, or National Restaurant Association, fraud conditions amount to approximately $4 \%$ of industry sales, which is anywhere from \$23 - \$26 billion dollars (Garber \& Walkup, 2004). Internal controls are often the first avenue of protection in safeguarding assets and thwarting and discovering errors and fraud (Arad \& Jamshedy-Navid, 2010), however, if fraud is going to occur, research has shown that motivation and rationalization are key factors that contribute to fraud (Krippel, Henderson, Keene, Levi, \& Converse, 2008). Therefore, pressure resulting from expectations of financial performance, opportunity to circumvent internal controls and rationalization coupled with certain inherent industry factors may contribute to increased risk of fraud (Fikes, 2009).

Since the restaurant industry is susceptible to increased fraud risk because its inherent general industry characteristics provide opportunities for unethical behavior and fraud, further examination and assessment of these characteristics is warranted. As noted, opportunity to engage in unethical behavior may stem from the macro environment, the operational features, and the specific nature of the business cycles (Allen, 2008) in the restaurant industry. First, it is noted that companies in restaurant industry may have difficulty in finding additional time and resources to design and evaluate internal control systems due to the intense focus on development and opening of restaurants and financial reporting deadlines (Schmidgall, 2006; Ge and McVey, 2005). For example, corporate restaurant companies operate on stringent timelines to open a restaurant quickly in order to begin to pay back debt as a result of construction loans and contribute to earnings as quickly as possible. If there are delays in the process, 
rationalization to cut corners may materialize in the form of circumvented processes, controls and reported numbers (Whitfield, 2013). In addition to this, implementation of certain key controls may not be a cost effective option for the company, for example, if they are working within various budget constraints. Restaurant companies performing poorly may reduce department expenditures and decide to "cut out" certain processes to save time and money (McMillan, 2006), resulting in less controls in place.

Second, the restaurant industry has a high-turnover rate (Allen, 2008), often due to a large variation in workforce diversity, which may create an increased risk of fraud, especially in the area of staffing and appropriate employment roles at corporate and field offices (Davis \& Albright, 2000; Geller, 1991). For example, while a restaurant company is searching for a new candidate to fill an open position, there may be an identified weakness in internal controls because job duties are blurred (Davis \& Albright, 2000; Geller, 1991), creating opportunity for fraud to occur. This blur in job duties is also a common situation for restaurant companies that are undergoing some form of restructuring due to changes in operations (Mulherin \& Boone, 2000). Often, restaurant companies require employees to take on extra responsibility during periods of change and restructuring (Ainsworth, 2010), and acquisitions are looked at as a way to increase their market share in an environment of high competition and high development costs (Garg, 1999). In fact, restaurant companies have engaged in acquisitions three times as much as other services based companies (Pany \& Whittington, 2001). Additionally, divestitures are common as companies change their business plan initiatives in response to current operating performance and the macro environment (Rui \& Yip, 2008). In terms of increased fraud risk, these types of dealings often involve complex material transactions, and therefore must have numerous knowledgeable and committed personnel with a keen understanding of implemented 
controls and process to work through the transaction. Otherwise, increased risk of fraud through opportunity may ensue.

Finally, another general characteristic of the industry involves the "culture at the top", or the "control environment" of a restaurant company (Hope \& Fraser, 2003). If the executives in the organization are so focused on earnings, to the point that aggressive tactics are utilized and control procedures are ignored, then the company may not be concerned with setting up control procedures in the first place. Classic red flags or characteristics that may indicate a weak culture or tone at the top include a complex organizational structure (indicated by aggressive acquisitions/growth as noted above), rapid or steady increases in gross performance margin compared with the prior performance of the company in conjunction with industry norms (Hope \& Fraser, 2003).

Additionally, from an operating perspective, the restaurant industry encompasses several operating factors that render it relatively more vulnerable to increased risk of fraud and deficiencies in internal controls (Geller, Ilvento, and Schmidgall, 1990; Geller, 1991). First, the industry is dependent on increasing guest counts in order to drive profitable restaurant operations (Dick and Basu, 1994; Oliver, 1999). In order to increase same store restaurant sales, executive management and operations leaders must meet guest expectations through consistent delivery of service and product, which in turn is dependent on corporate supply chain relationships and strong corporate internal processes and controls. As noted by Cromer (2003), a top risk of fraud is often in the areas of purchasing and procurement and finance and accounting. Fraud perpetrated through supply chains takes form through kickbacks and bribes, falsified labor and inflated bills, and contracts that don't tie to source purchase orders due to third party involvement. In addition to financial statement concerns, supply chain issues may create product 
inconsistencies (Deloitte \& Touche, 2014). All of these concerns may result in reputational risk, which may ultimately affect guest perception and count (Main, 2013).

A second factor that contributes to the susceptibility of the restaurant industry to fraud and weaknesses in internal control is the accessibility of cash and the volume of transactions that involve cash. Without proper controls surrounding cash, misappropriation of this asset is common (Boulton, 2013). For example, cash reconciliations for certain divisions may involve skimming off the top in order to avoid tax payments, or experiencing higher than estimated costs and debt related to opening a new restaurant, which may provide an opportunity to circumvent controls and apply cash from our sources.

A third factor to consider in the restaurant industry is that the related assets in place are commodity assets, which are susceptible to increased risk of fraud due to third party management and complicated supply chain systems (Allen, 2008; Geller, 1991; Geller, Ilvento, and Schmidgall, 1990; Eisenhardt, 1989). For example, in a tight economy, when faced with debt and high expenses, inventory and return on assets are common items to misappropriate, especially when overall cost of goods sold is inflated related to sales and cost carried on the balance sheet (Eisenhardt, 1989). Additionally, rationalization of the company coupled with the type of product available in restaurants provides an increased risk of misappropriation of the assets (inventory). This risk area has been noted recently to account for a major impact to a company’s net income. Public United States companies lost $\$ 2.4$ billion on average to fraud relating to inventory fraud in 2007 (PricewaterhouseCoopers, 2007). Based on these figures, the investment of additional funds to secure proper record keeping, proper process with third party management and documentation of the assets is essential to mitigating fraud and protecting profit and the bottom line. 
A fourth operating factor for consideration of the pervasiveness of fraud and internal control deficiencies in the restaurant industry is the size of the company (Galbraith, 2004). Although fraud and dishonesty can occur in big and small businesses alike, small businesses (comprised of fewer than 100 employees) demonstrated both a greater percentage of overall frauds and a larger average loss than their larger colleagues (AFCE, 2008). It appears that asset misappropriation involving cash received and disbursed is the greatest area of concern for the smaller businesses. The premise for the increased risk of fraud in smaller companies is due to lack of sophisticated controls and lack of sufficient personnel (Geller, 1991). However, it should also be noted that as companies get larger and more complex, the risk of fraud also increases (Ge \& McVay, 2005).

Based on both the general industry and operating characteristics and factors, the restaurant industry appears to be susceptible to increased risk fraudulent behavior. Because of this potential for fraudulent behavior on the company, shareholders, and the public, examining the conditions that prompt fraudulent behavior is necessary for the efficiency of the restaurant industry, and namely, for those passive and active investors that are relying on the financial statements to be true and accurate (Kincaid, 2002; Rezaee, 2005). Ultimately, faith in an investment is what all investors seek, and history has shown that the impact of fraud can have a significant impact on financial investments. Quality of life and the standard of living are natural outcomes and goals of financial investments, and severe cases of fraud can derail both (Kincaid, 2002).

Literature regarding increased risk of fraud in the restaurant industry has traditionally focused on the impact of the fraudulent behavior on the company or investors. For example, Wanhill (1994) looked at the impact of fraud on the viability of a company through analysis of 
the operating statement. Hjalagar (2008) reviewed the economic importance and employment consequences of various fraud acts that commonly occur in the industry. Kincaid, Baloglu and Corsun (2008) have started to explore how to stop unethical practices by instilling a sense of "ethical optimism” from the managers at the highest level of the organization. However, the central theme of all of these studies showcases how companies deal with unethical behavior; they don't address what contributes to the unethical behavior in the first place. If unethical behavior is still pervasive despite the law, the question becomes why the law is not effective in deterring fraud. The relationship between law and fraud is surprisingly under researched, and so discovering conditions that provoke or prevent unethical or fraudulent behavior in the restaurant industry would better the understanding of the effectiveness of control mechanisms in the industry.

\section{Purpose of the Study}

The purpose of this study is twofold: (1) to discover conditions that prompt or deter fraudulent behavior in the restaurant industry; and (2) to identify the relationship between these conditions and increased risk of fraud. This study will seek to identify the conditions that prompt or deter fraudulent behavior by using reported internal control deficiencies as a measure of increased fraud risk. The study will investigate the factors that may provide the optimal criteria to engage in opportunistic behavior according to the Fraud Triangle framework, and will evaluate such factors using the incidence of a reported internal control deficiency as a measure of increased fraud. The definition of internal control deficiencies is provided in section 404 of the Sarbanes-Oxley Act, defined as an instance "when the design or operation of a control does not allow management or employees, in the normal course of performing their assigned functions, to 
prevent, or detect and correct misstatements on a timely basis.” (Sarbanes-Oxley Act, 2002). For example, a control insufficiency may be an absence of segregation of duties for key departments of the business or the lack of controls over safeguarding of assets.

In order to achieve the objectives of the study, this research will first canvas the incidence of internal control deficiencies in the restaurant industry from 2004 and 2013. The deficiencies will be grouped in one category defining the unit of analysis for the study. For this purpose, the study will only investigate public traded restaurant companies. The reason for selecting public traded restaurant companies is because of the material effect of fraud on the restaurant industry. Not only is the restaurant industry a high risk area for fraud, but the cost is staggering for an industry that often struggles during the economic downturn (Allen, 2008). Reviewing incidences of reporting internal control deficiencies may help managers pinpoint areas of focus to mitigate the risk of fraud.

The second step is to assess the overall characteristics of publicly traded restaurant companies. These characteristics are identified as company size, amount of debt, organizational structure, executive stock compensation, macroeconomic factors, the Recession, percent of international sales and return on assets during the period of time from 2004-2012. The characteristics will be analyzed and grouped according to the fraud triangle framework. The fraud triangle was established by Cressey (1950) who noted that fraud occurs when pressure, opportunity and rationalization exist for an individual or a company. Pressure refers to a motive or reason to compel the fraudulent occurrence, opportunity refers to an ability to enable the fraudulent act through a lack of internal control or a weakness in internal control and finally, rationalization refers to the attitude or belief in the reason for committing the fraudulent act (Kassem \& Higson, 2012). 
The study will complement the fraud framework with concepts from hospitality management, economics, accounting, and business ethics. For example, concepts such as motivation, demand/supply, human resources and personnel management are interrelated themes to the fraud triangle framework. Due to the various opportunities presented by the concepts, the fraud triangle serves as an important component in explaining why fraud may occur.

\section{The Fraud Triangle}

Opportunity Ability to carry out misappropriation of cash or organizational assets.

Figure 1: The Fraud Triangle

\section{Rationalization}

Justification of

dishonest actions.

\section{FRAUD}

The components of the framework capture the essence of the susceptibility of the restaurant industry to potential opportunistic behaviors. Opportunity may occur, for example, when company management has uncontrolled access to company funds. In a restaurant company, this could be a group of corporate account reconciliations that are completed but not reviewed. If the control is not there, opportunity for fraud ensues. Pressure helps to explain why 
and when the fraud occurs and is very closely linked to motivation. These pressures are often associated with debt, operating performance and related business results (Cressey, 1973). For example, management bonus structure is often tied to restaurant operating performance. In difficult financial times, management may manipulate waste or inventory cost in order to bump up profits when controls in this area are lacking. Additionally, rationalization in the restaurant industry may occur when executive management involved in the fraud attempts to shift the blame to others. An example of this may be the justification of a failed major business decision or marketing initiative by shifting blame to third parties, the board or other executive teams.

The relevance for analyzing these risk factors is to identify environmental and internal factors that may contribute to related opportunities and potential misconduct. These environmental factors refer to the effects of the recession, inflation, seasonal fluctuations, and increased competition. The internal factors may apply to the specific business factors such as cash handling, financial reporting practices, structure, and labor practices. The study will assess various macro-economic factors shown to impact the restaurant industry. These factors together with certain specific characteristics of the industry such as size, operations and culture will function as control variables in estimating the effects of the Sarbanes-Oxley Act on fraudulent behavior. The study will therefore assess the impact of the SOX Act on increased risk of fraud, controlling for size, debt, organizational structure, macro-economic factors, stock compensation, return on assets, international sales and employee turnover.

Finally, this study will analyze the disclosures of publicly traded restaurant companies to determine whether or not a deficiency will occur, based on the previously mentioned variables. This will be accomplished through a probit analysis utilizing the incidence of a reported internal control deficiency as the dependent variable, a measure of increased fraud risk. The study 
assumes a binary distribution of increased fraud risk measured through reported internal control deficiencies, i.e., the study will estimate the probability that an entity will be at an increased risk of fraud based on variables that are linked to the fraud triangle. More specifically, the study will estimate the following relationship:

$$
g(\mu)=\beta 0+\beta 1 X
$$

where $\beta 0+\beta 1 \mathrm{X}$ is the structural component and $\mathrm{g}()$ is the link and $\mu$ is the mean of a conditional response distribution at a given point in the covariate space. Because the distribution of the response variable, i.e., reported deficiency, is non-normal, the connection or link between the structural components to the response becomes the crucial element at this step.

The fundamental objective of the study is therefore to understand the relationship of certain variables on the impact of reported deficiencies according to the Sarbanes-Oxley Act and increased risk of fraud. Despite the Sarbanes-Oxley Act, misconduct and fraud risk remains a part of business behavior. According to the SEC and the Association of Certified Fraud Examiners, misconduct has increased by 5\% in the last few years (ACFE, 2013). Discovering factors that nurture business misconduct is timely during trying times such as those unleashed by the perceived steering role of financial practices in the recent Great Recession. Understanding the factors that may shape misconduct in financial reporting may provide restaurant companies with appropriate guidance towards understanding the specific opportunistic behavior conditions that relate to specific variables defined for restaurant companies. Thus, more targeted controls could be applied which would mitigate effects of revenue loss, reputational loss, disruption of business operations and investor confidence erosion. 


\section{$\underline{\text { Research Questions }}$}

The study will be prompted by the subsequent research questions:

Q1: Does the Sarbanes-Oxley Act have a significant impact on increased risk of fraud in the restaurant industry?

Q2: Controlling for company size, does the Sarbanes-Oxley Act have a significant impact on increased risk of fraud in the restaurant industry?

Q3: Controlling for employee turnover, does the Sarbanes-Oxley Act have a significant impact on increased risk of fraud in the restaurant industry?

Q4: Controlling for risk factors and macro-economic factors, does the Sarbanes-Oxley Act have a significant impact on increased risk of fraud in the restaurant industry?

Q5: Controlling for the Great Recession, does the Sarbanes-Oxley Act have a significant impact on increased risk of fraud in the restaurant industry?

\section{Significance of the Study}

The study contributes to the current body of literature regarding fraud and the effectiveness of the Sarbanes-Oxley Act on detecting fraud risk, when considering other relevant factors that make the restaurant industry vulnerable to fraudulent acts and unethical behavior. The importance of this study is evident, when considering that the cost of conforming to the SOX disclosure requirements is tremendous. Compliance with section 404 is perhaps one of the most contentious areas of the SOX Act, largely due to the opinions that the costs of compliance far exceed the benefits. For example, a study in 2005 estimated that Fortune 100 companies exhausted approximately $\$ 5.9$ million to fulfill the reporting requirements for their first year of compliance with section 404 of the Act (De Franco, 2005; Gupta \& Nayar, 2006; Hammersley et 
al., 2008). Given these high costs of compliance, it is necessary to evaluate the benefit and rewards of the disclosures to help provide an assessment of the effectiveness of a law that was put into effect with the intent to improve control and deter fraud.

For the first time, this study could offer publicly traded restaurant companies with guidance towards a more thorough understanding of the specific conditions that might contribute to fraudulent behavior and increased risk of fraud. Additionally, the identified conditions could help managers to improve internal control in areas identified as high risk. By utilizing an approach that will estimate the probability of a reported internal control deficiency based upon industry characteristics and macro-economic factors, restaurant companies may be able to deter fraudulent acts. Finally, this study contributes to the effectiveness of the fraud triangle framework in explaining the opportunistic behavior characteristics that may lead to reported deficiencies.

\section{Limitations of the Study}

It is important to recognize that the Sarbanes-Oxley Act was put in place to regulate publicly traded companies only. Therefore, for purposes of this study, privately traded companies are excluded. This is a limitation of the study because the results may indicate a problem that is more or less pervasive since the sample is representative of a small number of companies in the United States. Additionally, because this study is only analyzing restaurant companies, the results cannot be generalized to other publicly traded hospitality companies or to privately held restaurant companies. Finally, it should be noted that reported internal control deficiencies are indicative of increased fraud risk, but not necessarily conclusive that fraud has occurred. Therefore, just because a company has reported a deficiency, it doesn’t indicate fraud, 
necessarily. The study precludes the ability to conclude that fraud is always a result of an internal control deficiency. 


\section{CHAPTER 2: LITERATURE REVIEW}

This chapter presents the theoretical framework of the suggested research and affords a detailed review of the constructs that will be used in the research model. First, a discussion of the fraud triangle will be described, which details the framework that serves as an explanation for why opportunistic behavior may occur in the restaurant industry. Then, characteristics of the restaurant industry will be presented and linked to the fraud triangle, and an analysis regarding the prevalence of fraud for the industry based on both external and internal variables will be described through past research in this area. Finally, the impact of the Sarbanes-Oxley will be explained in terms of its effectiveness in deterring fraud.

\section{Fraud Triangle}

Despite focused efforts to extinguish fraud, asset misappropriation and fraudulent financial reporting, it seems that fraud in its numerous practices is a problem that is growing in severity and occurrence (Levisohn, 2009). An explanation for why fraud occurs is embedded in the framework known as the "fraud triangle". The fraud triangle is the model that explains the factors that may cause an individual or a company to commit occupational fraud. The framework was first proposed by Dr. Donald Cressey (1950) and consists of three constructs: pressure/motivation, opportunity and rationalization. The three constructs offer an explanation as to why management commits fraud, and the dynamic relationship that underlies the acts of occupational fraud. Together, when these three constructs exist, misconduct and fraudulent behavior may occur in the workplace.

The theoretical framework of the fraud triangle is based on the notion that the formulae is actually a triangle with equally weighted constructs (pressure/motivation, opportunity and 
rationalization) (Cressey, 1973; Dellaportas, 2013). The framework stipulates that all three of these constructs must be in existence in order for fraud to occur, and the tie that brings these three constructs together is rooted within the studies of psychology and sociology (Zahra, Priem \& Rasheed, 2007). Cressey (1971) essentially argues that the conceptualizations of the fraud triangle components are based on individual's or management's morality and a desire to solve a perceived problem. In the context of company management, this means that management rationalize fraudulent behavior in an attempt to resolve subjective problems, both perceived and real. For example, in the case of the restaurant industry, the morality component is essential as an underlying factor to the fraud triangle - management must establish that they are capable of distinguishing between unethical and ethical behavior. Then, based on the fraud triangle framework, the choice is made to commit the fraudulent act based on the constructs of pressure/motive, opportunity and rationalization. This is a normative view where fragile morality is addressed through actions against the company (Morales et. al, 2014). In other words, the fraud triangle is a technical device that aims to assess the probability of occurrence of acts that are deemed to be unacceptable by society (Morales et. al, 2014).

The probability of fraud occurrence when considering the three constructs simultaneously has been illustrated through other researchers investigating allegations of fraudulent financial reporting by companies. For example, Loebbecke and Willingham (1988) studied several SEC white papers relating to auditing and accounting enforcement regulations in order to ascertain the presence of risk factors of fraud. From this research, they established a framework that supports the fraud triangle, suggesting that auditors should consider the three conditions in order to determine the likelihood of fraudulent financial reporting. The Loebbecke and Willingham ("L/W") model pointed to: 1 ) the conditions (opportunity) of the entity that would allow fraud to 
occur 2) the motivation (pressure) of management to perpetrate a fraud and 3) the attitude of management such that they might knowingly and deliberately commit fraud based on their ethical values (rationalization).

Additionally, Bell and Carcello (2000) found backing for the prevalence of the fraud triangle constructs for a group of approximately 77 financial fraud activities. The fraud triangle components were tested and the researchers found that the model correctly classified $74 \%$ of the fraud cases. They also specifically found that when pressure/motivation, opportunity and rationalization exist, the most common risk factors identified were a weak control environment, rapid growth, and aggressive management attitudes towards earnings projections. The identified risk factors are the results of the empirically tested model and are often analyzed according to industry and company characteristics. These risk factors will be explored in greater detail in the section entitled "industry characteristics and increased fraud risk".

Also, Rezaee (2005), in his examination of fraud circumstances for firms, found indication of the presence of all of the fraud triangle components in fraud companies through a five factor framework known as CRIME. CRIME stands for "cooks, recipes, incentives, monitoring and end results” (Rezaee, 2005), and the combination of these elements explains and justifies the instances of financial statement fraud by extending the fraud triangle (Rezaee, 2005). "Cooks" addresses who typically commits fraud, while "recipes" addresses how the fraud was committed (i.e., overstating revenues through weaknesses in internal controls). Recipes therefore, support the opportunity construct of the fraud triangle. "Incentives" are the third factor and they complement the fraud triangle construct of pressure/motivation by explaining the common incentives for firms and their "cooks" to execute fraud of financial statements. 
Finally, “monitoring” and "end results” are the fourth and fifth components of Rezaee’s (2005) proposed framework, and a lack of both of these components greatly contributes to increased fraud risk. Monitoring refers to a company having responsible corporate governance, including direct oversight from an audit committee or board of directors. Without these mechanisms, a company is more susceptible to a weak internal control environment and an increased risk of fraudulent financial reporting. Therefore, it may be stated that a lack of adequate monitoring increases the "opportunities" for fraud, which is another construct of the fraud triangle. "End results", a final component of CRIME, refers to the high financial and reputational consequences of committing financial statement fraud. When individuals or companies are not deterred by consequences, it can be said that the motivation and rationalization to commit the fraud are high. This last component addresses both the pressure/motivation and rationalization constructs of the fraud triangle.

In further support of the fraud triangle components working together simultaneously, Victor and Cullen (1988) have noted that ethical and unethical behaviors cannot simply be explained by pressures or rationalizations alone; the company has a role in contributing to the opportunistic behavior. This means that the company sets the tone and should provide context for a company's ethical climate. When this doesn't happen, increased fraud risk ensues. However, when a strong ethical climate is evident, opportunities conducive to employee fraud may be reduced (Hogan et. al, 2008). Additionally, research in psychology and organizational behavior has demonstrated that management makes egocentric interpretations of fairness and ethics in the absence of structured expectations (Kaplan, 2001). For example, due to the subjective nature of earnings management because of the wide variability of accounting techniques, multiple interpretations of ethical actions in cases involving earnings management 
exist. This means that in the absence of expectations for ethical behavior, rationalization to commit fraud may occur.

Hernandez and Groot (2007b) likewise found that the usage of motivational systems and prospects for fraudulent behavior are aligned with higher fraud risk when coupled with perceived need at the executive level. The focus of their study was on the attitude/rationalization component of the fraud triangle, and they were able to determine the nature and extent of influence of management attitude on fraud risk assessments when considering opportunities to engage in fraud. The study confirmed that the ethical tone in an organization is largely linked to senior management attitudes, and that intentions to engage in fraudulent activity are derived from moral reasoning levels, or rationalization. This affirms the fraud triangle framework and provides assessments from the perspective of external auditors evaluating companies’ fraud risk, which is a slightly different approach compared to the other researchers in this area. Previous studies looked at the presence or absence of risk factors and mapped them to the fraud triangle. This study utilized risk-framed scales to identify specific weights of each factor to illustrate the underlying impact of the fraud triangle.

As noted by the review above, many academic studies have affirmed Cressey’s work, and as a direct result, the American Institute of Certified Public Accountants (AICPA) distributed the Statement of Auditing Standards No. 99 (“SAS 99”), which maps fraud risk factors to each of the three constructs in the fraud triangle. All of the literature reviewed relating to the application of the fraud triangle and the impact of occupational fraud has been analyzed in the context of accounting and auditing literature, since those are the disciplines most likely to evaluate the impact of occupational fraud in terms of financial statement fraud. Therefore, it can be stated that the application of the fraud triangle has been modest. This study seeks to address the gap in 
empirical research in applying the fraud triangle to incidences of reported internal control deficiencies in publicly traded restaurant companies, an industry inherently susceptible to fraud (Allen, 2008). A summary of the application of the fraud triangle in prior research is summarized in Table 1.

Table 1. Applications of the Fraud Triangle Framework

\begin{tabular}{|c|c|c|c|c|}
\hline Authors & Pressure & Opportunity & Rationalization & Results \\
\hline Cressey (1971) & $\mathrm{X}$ & $\mathrm{X}$ & $\mathrm{X}$ & $\begin{array}{l}\text { Pressure/Motivation } \\
\text { Opportunity } \\
\text { Rationalization }\end{array}$ \\
\hline $\begin{array}{l}\text { Loebbecke and } \\
\text { Willingham } \\
\text { (1988) }\end{array}$ & $\mathrm{X}$ & $\mathrm{X}$ & $\mathrm{X}$ & $\begin{array}{l}\text { C- conditions of fraud } \\
\text { M- motivation of management } \\
\text { to perpetrate a fraud } \\
\text { A-Attitude of management such } \\
\text { that they might knowingly and } \\
\text { deliberately commit fraud }\end{array}$ \\
\hline $\begin{array}{l}\text { Victor and } \\
\text { Cullen (1988) }\end{array}$ & $\mathrm{X}$ & $\mathrm{X}$ & $\mathrm{X}$ & $\begin{array}{l}\text { Pressure/Motivation } \\
\text { Opportunity } \\
\text { Rationalization }\end{array}$ \\
\hline $\begin{array}{l}\text { Bell and } \\
\text { Carcello (2000) }\end{array}$ & $\mathrm{X}$ & $\mathrm{X}$ & $\mathrm{X}$ & $\begin{array}{l}\text { C- conditions of fraud } \\
\text { M- motivation of management } \\
\text { to perpetrate a fraud } \\
\text { A-Attitude of management such } \\
\text { that they might knowingly and } \\
\text { deliberately commit fraud }\end{array}$ \\
\hline Rezaee (2005) & $\mathrm{X}$ & $\mathrm{X}$ & $\mathrm{X}$ & $\begin{array}{l}\text { CRIME - crooks, recipes, } \\
\text { incentives, monitoring and end } \\
\text { results }\end{array}$ \\
\hline $\begin{array}{l}\text { Hernandez and } \\
\text { Groot (2007) }\end{array}$ & $\mathrm{X}$ & $\mathrm{X}$ & $\mathrm{X}$ & $\begin{array}{l}\text { Attitudes } \\
\text { Moral reasoning }\end{array}$ \\
\hline
\end{tabular}




\section{Fraud Triangle Construct - Pressure/Motivation}

As noted, the first construct of the fraud triangle is pressure - defined by Cressey (1953; 1971) as the motivation needed for the occurrence of fraud in the work place. Pressure is often the force behind an individual's or group of workers motivation to pledge or not pledge to certain deeds or actions, and is critically important to understanding common motivators to commit fraud (Albrecht, 2003; Wells, 1997). It is noted by Cressey (1953) that pressure is defined from a "non-shareable" problem, which represents the root cause that motivates offenders to behave in an unethical manner. The components that comprise the notion of motivation are unique, intricate and usually change over time according to individual and company circumstance. To evaluate these changes, Handy (1976) has suggested that motivation is the coming together of perceived need and the probability of desired results.

This means that management calculates an " $E$ " (energy, enthusiasm, effort) and internally calculates the probability of realizing the preferred outcome. For example, when employees begin employment with a company, some determination will be made in regards to the employees "E" set forth. Companies also provide an "E", either by salary and benefits or other resources available that will help to achieve corporate strategic priorities. The give-and-take provides the "psychological contract" between the company and the employee (Weisburd et al., 1995). The inferred yet intangible contract can be explained as the joint and unshared opportunities between the employee and the company based on the first contracts and the employee's motivation intentions. When both groups adhere to the intangible contract simply, (i.e., when it is grasped fully and certified by both parties), the motivation of the employee becomes clear. 
In order to understand pressures and motivators so that behaviors can be mitigated, the psychological contract for individuals must first be understood. By understanding the conditions by which a potential employee joins a company, organizations can better ensure that they are meeting their demand for services and hopefully sustain a consistent "E" put forth over time. If, however, a company fluctuates its “E”, or intensifies demands on an employee or groups of employees, "E” will change according to the employees calculation of motivation (Ramamoorti, 2008). Likewise, as employees are subject to various pressures, "E” may deviate and thus contribute to the "non-shareable" problem that is conducive to fraud (Albrecht et al., 2012). Additionally, senior management responsible for setting the tone at the top should consider how to sustain or adjust the intangible psychological contract in order to keep the employees, and themselves, as productive and ethical team members. This may mean an increase in manpower and salary, and/or increased responsibilities, coupled with communicated expectations of ethical behavior.

Handy's "E” analysis described above provides that before any decision is made to act, there is an unconscious or conscious calculation, which assesses the employees' needs, desired results, and "E" factor (energy, enthusiasm, effort) cost of achieving the desired results. The individual's needs and desired results, as well as the "E" factor, all point to pressures/motivators of misconduct when an "unshareable” problem exists (Cressey, 1971). Cressey's hypothesis stemmed from research in the field of criminology, and he categorized the non-shareable problems/pressures into six categories: debt problems, personal failure problems, uncontrollable business problems (recession/inflation), problems relating to "gaining status" (in reference to living above means), problems relating to employee and human resources relations, and problems stemming from a perceived high level of isolated problems. 
It is noted that a pressure/motivator for fraudulent behavior can be personal, professional or both, and motivators may be financial (high personal debt, medical bills), perceived financial (desire for material goods), or non-financial (addictions, high pressure for favorable results) (Wilkes, 2004; Wells, 1997). More specifically, recent literature has categorized common motivators or stressors increasing fraudulent behaviors as: 1) financial pressures; 2) vices; 3) pressures relating to work conditions and 4) other pressures, for example, a desire for material items or status (Dellaportas, 2013).

Examples of common personal pressures are the incapability of being able to pay bills or an addiction to drugs or gambling (ACFE, 2012). Professional pressures arise when one feels pressure for strong financial performance at work or the need to mask another employee's performance issues. Additionally, when financial stability is threatened by the economy or the industry, pressure to manipulate earnings may occur (Kasznik \& McNichols, 2002). Regardless of the type of motivator, it's important to recognize that the pressure may be real or perceived and as long as the pressure is viewed as an "unshareable need" the conditions for fraud exist. It does not make a difference whether or not the incentive is based in reality or makes sense to others (Degeorge et al., 1999).

Audit and accounting researchers have utilized Cressey’s definitions in literature, but have provided slightly different but related interpretations and definitions. For example, Lister (2007) stated that the incentive to commit fraudulent acts is like the "source of heat for a fire", and described three types of pressure that fit this definition: personal pressures to pay for a certain lifestyle, employment pressure due to compensation arrangements or financial interest from management, and external pressures, such as threats to the business's financial stability through market fluctuations, debt covenants and elevated analyst expectations. Also, Vona 
(2008) affirmed that reason to commit a fraudulent act is usually correlated with personal and corporate pressures on employees, citing "red flags" such as increased liabilities and meeting debt and earnings projections. Additionally, Albrecht et al. (2008, 2010) signified that pressure and motive can be either non-financial or financial, and provided illustrations of perceived financial pressures that can incentivize fraud such as corporate financial losses, declining sales, an inability to compete with competitors, living beyond means, personal greed and debt, inadequate credit and the inability to meet short-term credit goals, going concerns and the capability of reaching financial forecasts and unanticipated financing needs. Non-financial pressure examples include the desire to present results that are more desirable than what actually happened, work relations frustrations and possibly a group of disgruntled employees who wish to try and cause company downfall by challenging the system. Murdock (2008) extended this idea and claimed that pressure could be non-financial, financial, political or social. Social and political pressure may happen when employees feel that they must be viewed in a positive light because of the importance that they place on their existing reputation and status, while nonfinancial pressure can occur due to personal weaknesses for gambling or drugs. Finally, Chen \& Elder (2007) determined six basic categories for pressure and motivation including disobedience of debt obligations, problems originating from employee issues, the impact of the market on a company's financial performance, achievement of strategic priorities and relationships between employees.

Based on an understanding and synthesis of literature presented as well as a review of SAS 99, it seems that "pressure" may best be classified into four general types that may lead to fraud. These are: financial stability, external pressure, manager's personal financial situations, and meeting financial targets (Skousen, 2009). Financial stability refers to the pressure that 
managers face when financial stability and/or profitability are threatened by industry, economic, and company operating environments. For example, if a firm is suffering from below industry average growth, managers may resort to fraud tactics to improve the company outlook. External pressure refers largely to meeting external financing needs or obtaining financing needs in order to remain competitive. Supporting this pressure category, Efendi et al. (2007) found that intentional errors and misstatements are more probable for companies controlled by debt covenants, companies that issue new or debt equity capital, or companies that have a chief executive officer that also functions as the chairman of the board. Personal financial situations draws on previous researchers' findings that personal problems resulting from debt or living beyond one's means provide conditions for the prevalence of fraud. For example, numerous researchers have found indication that executive stock option compensation provides encouragements for behavior that is fraudulent or corrupt (Summers \& Sweeney, 1998; Lie, 2005; Burns \& Kedia, 2006). This is because stock options drive up the share price and provide additional incentives for insider trading, a significant problem noted by Glass Lewis \& Co (2006). Since personal financial problems are dependent upon company financial performance, this fraud pressure becomes stronger. Finally, meeting financial targets is evident as a pressure as manager's performance is often tied to bonus payouts and salary increases (Summers \& Sweeney, 1998).

The differing classifications and definitions of "pressure" provide evidence that the construct is not directly observable; therefore, researchers in this field have measured the construct of pressure through proxy variables (Skousen, 2009). For example, Chen and Elder (2007) utilized several proxies including forecast error by analysts, cash flow from operations that measures negatively, and executive and board shareholdings often considered in debt and 
credits ratios to measure pressures relating to corporate downturn and transgression of obligations. Lister (2007) and Skousen (2009) measured personal, employment and external pressure through proxies of rapid asset growth, increased need for cash and the presence of debt financing. However, Persons (1995) found that the most substantial variables indicative of fraud were leverage, asset composition and company size.

Expounding on Persons' (1995) findings and relating these to the categories of pressures per SAS 99, proxies developed for financial stability included gross profit margin, sales and asset growth (Beasley, 2000; Beneish, 1997), which are often utilized as measures of company size. Additionally, when considering measurements of external pressures relating to debt financing, the financial leverage ratio is the most common measurement of the amount of debt. When considering pressure relating to personal financial need, Dunn (2004) provided evidence relating executive stock ownership to their personal financial situations. If stock ownership is significant, personal finances are threatened. Therefore, a proxy for personal financial need is often defined in terms of ownership, or the percentage of shares owned by management out of the total shares outstanding. Finally, return on total assets ("ROA") is a measure of operating performance widely used to indicate how efficiently assets have been utilized. ROA is frequently used as an assessment of managers’ performance and in determining bonuses. Therefore, ROA, or asset composition, is an appropriate proxy measurement for the pressure of meeting financial targets.

Regardless of the interpretations of pressure provided in literature, it's interesting to note that the conclusions about non-shareable problems and the way that they are resolved seems to relate specifically to individuals, and assumes that such individuals become trust violators in an organization when confronted with the pressures described. However, non-shareable problems 
could also motivate groups of individuals, representative of a company's culture, to commit fraud. For example, Lister (2007) indicated that external pressures such as intense competition or not meeting analyst's expectations may induce fraud committed by groups of individuals. Likewise, the four main categories of pressure defined above could relate to both the individual and group of individuals in a company.

In further support of the four main categories of pressure, many studies have focused on other specific risk factors that may induce fraud by employees and executive management. Pressure to meet forecasts provided by analysts' as well as compensation and enticement structures rank high on a list as factors that incentivize managers to misstate earnings (Dechow et al., 1996). Additionally, the need for financing from external sources or reduced financial results are conditions that may increase manipulation of earnings by executives. For example, Rosner (2003) found that companies with significantly decreased cash flows had large overstatements of earnings in non-going-concern years that often were trailed by overstatement reversals in goingconcern years, as determined by accrual behavior and executive stock compensation levels. Such results provide an indication that failing companies are more susceptible to earnings mismanagement.

When examining some of these specific pressures through the lens of the restaurant industry, it is imperative to note that the industry as a whole underperformed during the Recession, making it susceptible to poor performance and increased pressure to meet analysts' expectations (Rosner, 2003). In a study of Swedish restaurant companies, it is noted that competition is very high, often resulting in price wars among different companies who reduce prices and then try to compensate through increased sales (Alalehto, 2000). This environment is therefore dependent on the discretionary income of consumers, and this increased pressure may 
lead to earnings mismanagement through overstatement. Additionally, restaurant companies are often ladled with heavy debt covenants as a result of construction and development loans as they build up locations (Sidel, 2007). Finally, publicly traded restaurant companies are heavily dependent on investors who often offer discounted stock options to employees in order to promote increases in share price. As information about acquisitions and divestitures are revealed, insider trading may become a pressure and motivator for fraud (Hogan et al., 2008).

Both pressures and opportunities are often determined by factors that occur at both the individual and company level (Carcello et al., 2006). However, without pressures that provide a motivation for fraud, opportunities to engage in fraud cease to become an issue. Therefore, according to the fraud triangle, it can be said that opportunity doesn't exist unless a pressure exists. The next section will discuss the second construct of the fraud triangle - "opportunity".

\section{Fraud Triangle Construct - Opportunity}

Opportunity is described as an atmosphere or temporary environment that enables fraud to be committed, usually with a small perceived probability of being caught or reprimanded (Cressey, 1973; Jensen, 1993). Openings for opportunity exist for misconduct when firms have weak internal controls, a lack of policies and/or procedures, unauthorized or unsupervised access to assets (lack of segregation of duties) or a deficiency of management oversight and review (Bratton, 2002; Young, 2005). SAS 99 further confirms that the opportunity for fraud increases when certain risk factors exist for a company. Some risk factors include the susceptibility of the industry to market changes as well as the nature of the industry, coupled with the specific operations of the company such as whether or not there are significant or complex related party 
transactions; how effective management is at monitoring activities within the organization; and the level of complexity that exists in the organization (Albrecht et al., 2003).

These three categories described above are measured by proxy variables that have been defined in literature. For example, when addressing the nature of the industry, all companies have elements of subjective judgments, and accounts based on estimates. Loebbecke et al. (1989) noted that most frauds involved accounts receivable and inventory, therefore, receivables and inventory turnover are two appropriate measurements for increased opportunities of fraud. Confirming this, Summers \& Sweeney (1998) noted that uncollectible accounts (i.e., bad debts) and obsolete inventory are most often targeted by management when engaging in financial statement fraud. Additionally, Albrecht (2002) noted that when a firm has a large amount of international operations, the opportunity for fraud increases. The percentage of foreign sales is an appropriate measure of this opportunity, calculated by total foreign sales divided by total sales.

Ineffective monitoring deals mostly with the ability of the directors of the Board for a company, audit committee or oversight group such as internal audit to effectively monitor the organization in order to prevent fraud from occurring. Beasley et al. (2000) noted that companies with reported incidences of fraud consistently had fewer outside board members when compared to companies without incidence of fraud. Additionally, companies having a large and diverse audit committee are associated with a lower incidence of fraud reporting. Therefore, monitoring can be measured by determining the nature and extent of the members of the board (outside or inside) or the number of board members on the audit committee.

Finally, unsound and intricate organizational structures may be demonstrated by increased turnover of executive management, board of directors or legal counsel members. This 
is often measured by calculating the number of executives who left the company in the years prior to the fraud incidence. Additionally, evidence has also linked the CEO position to fraud when the CEO is also the chairman of the board. In incidences like this, the CEO is the dominate decision maker for an organization which may provide an increased opportunity for fraud. Beasley (1996) noted that the longer the CEO holds the position of power, the greater the likelihood that he/she would be able to control the decisions of the board of directors.

The underlying reason for these three categories of increased opportunities for fraud is the state of the internal controls structure, and management's commitment to strong corporate governance (Abbott et al., 2004). This is because corporate governance and internal controls set expectations for ethical behavior by employees. Loebbecke et al. (1989) surveyed audit firms that have had knowledge of incidences of financial statement fraud and found that weak internal controls and dominated management decisions that override internal controls are the leading circumstances that increase the probability of fraud occurrence. Weak corporate governance structures are often presented through ineffective monitoring of management. For example, Dechow et al. (1996) found that companies that manipulate performance are more probable to have dependent boards with a small turnover rate, a structure in which the CEO is also the Chairman of the Board, and a CEO who is also the founder of the company. Similarly, Farber (2005) found that companies who committed fraud had fewer financial experts on the board, fewer independent members and a larger percentage of CEOs who hold the title of Chairman of the board. This further contributes to the existing academic research that a weak corporate governance structure provides the greatest opportunity for fraud and supports the categories supported by SAS 99. 
The previous discussion provided information about company level opportunities, but it should also be noted that a significant amount opportunities for fraud arise from individuals who have increasing access to records and valuables in order to perform their ordinary job functions (Swartz \& Watkins, 2003). Additionally, as companies engage in more complicated transactions, responsibilities increase, as does the opportunity to engage in misconduct (Deakin \& Konzelmann, 2004).

Public companies in the restaurant industry are susceptible to opportunities for fraud based on the opportunities described above. The nature of the industry is a cash business, making the business more susceptible to fraud, and opportunities arise from a lack of internal controls. The ability to commit fraud in the restaurant industry results from inside knowledge of processes and procedures, and the ability to circumvent controls through weaknesses (Whitfield, 2013). Additionally, corporate governance structures in the restaurant industry vary according to the sophistication of the organization and the attitudes of senior management. The attitude or rationalizations are shaped where there are pressures and opportunities to commit fraud. The next section will discuss the third construct in more detail.

\section{Fraud Triangle Construct - Rationalization}

Rationalization is the third construct of the fraud triangle, and is the most difficult to measure. It's imperative to mention that rationalization in the context of occupational fraud usually consists of first time offenders, and not habitual predators (ACFE, 2012).

Rationalization is essentially an attitude, belief or position of the mind or ethical personality that enables an employee or group of employees of a company to intentionally misappropriate assets and then defend their dishonest activities (Cressey, 1973). There are generally two behaviors 
that define rationalized thought for fraud: borrowing and entitlement. In the borrowing mentality, individuals and companies justify embezzlement by convincing themselves that they will pay the money back once they get through their hard time (Ramos, 2003). The entitlement mentality involves justification by claiming to be owed something - usually cash or other assets (Wolfe, 2004). The individual may claim that they are committing the fraudulent act for their family or just simply because they are dissatisfied with the company or their job (Albrecht et al., 2005). Other common rationalizations include an attitude or belief that a company treats its employees badly, so they deserve to have money embezzled. Regardless of the belief, rationalization involves reconciling deeds with commonly established beliefs of decent of behavior and trust (Wolfe, 2004).

As stated, measuring rationalization within the frameworks of borrowing and entitlement is difficult, but research in audit literature notes that a quantifiable means of capturing this could be through review of executive stock compensation measures. Often, an incidence of audit failure and litigation is tied to executive stock compensation measures, indicating that fraud is more likely for companies that have high amounts of compensation for executives. Additionally, Vermeer (2003) notes that management may often rationalize financial reporting methods through the creation and use of accrual entries. Therefore, excessive use of discretionary accruals may lead to poor audit opinions, providing a rationalized thought for business activities. However, because it’s difficult to ascertain root causes of accrual entries, this is not an appropriate measure of rationalization for determining increased risk of fraud. Management may or may not have a stake in reporting issues and most of the time the entries are made in response to uncontrollable business activities (Gray \& Carlisle, 2002). 
Defining parameters for financial reporting can also have an effect on reducing the rationalized behavior and the opportunity to commit fraud (Hogan et al., 2008). Nelson et al. (2002) determined that the specifics of current standards of accounting deterred the rationalization of managers' attempt to manage earnings. Additionally, Gillett and Uddin (2005) found that the approach of the CFO toward financial reporting was a chief effect on an objective to misrepresent information. For restaurant companies, this means that rationalizations and attitudes can be managed by assessing the internal control environment and understanding the pressures and opportunities that exist for employees.

Of the three constructs in the fraud triangle, company executives have the most control over the "opportunity" construct. By limiting opportunities for fraud, companies can reduce their risk somewhat. Building policies, processes and internal controls may reduce opportunities for fraud. Additionally, by implementing specific procedures, companies may deter fraudulent behavior and reduce employee incentive towards misconduct (Murphy \& Dacin, 2011). However, as described by the research problem, pressures, opportunities and rationalizations may occur despite the most stringent controls in an organization. Opportunities may result from circumstances beyond company control that provide the chance to commit fraud.

It's important to note that the elements of the fraud triangle have not been considered or applied comprehensively to the restaurant industry. As previously reviewed, some researchers have looked to the fraud triangle as a means to define certain pressures, opportunities and rationalizations generally to corporate businesses, but not to hospitality businesses separately (Baker, 1998). The value in the application of the fraud triangle to the restaurant industry provides an opportunity to extend theoretical contributions that originated from mainstream 
accounting to hospitality literature, which is severely lacking in the current literature (Zimmerman, 2003).

A summary of the results of the fraud triangle in prior research is summarized in Table 2. The next section will discuss industry characteristics and company variables that further contribute to pressures, opportunities and rationalizations in the restaurant industry.

Table 2. Summary of Fraud Triangle Constructs - Results/Conditions

\begin{tabular}{|l|c|c|c|l|}
\hline \multicolumn{1}{|c|}{ Authors } & Pressure & Opportunity & Rationalization & Results/Conditions Identified \\
\hline Wilkes (2004) & $\mathrm{X}$ & & $\mathrm{X}$ & $\begin{array}{l}\text { Financial Pressures } \\
\text { Other Vices } \\
\text { Work-Related Pressures } \\
\text { Various Pressures }\end{array}$ \\
\hline $\begin{array}{l}\text { Kasznik \& } \\
\text { McNichols, } \\
(2002)\end{array}$ & $\mathrm{X}$ & & $\mathrm{X}$ & $\begin{array}{l}\text { Economic Pressures } \\
\text { Industry Pressures }\end{array}$ \\
\hline $\begin{array}{l}\text { Dechow et al., } \\
(1996)\end{array}$ & $\mathrm{X}$ & & & $\begin{array}{l}\text { Analyst Forecast Pressure } \\
\text { Compensation/Incentive } \\
\text { Structure Pressures }\end{array}$ \\
\hline Rosner (2003) & $\mathrm{X}$ & $\mathrm{X}$ & & $\begin{array}{l}\text { External Financing Pressures } \\
\text { Poor Financial Results } \\
\text { Pressures }\end{array}$ \\
\hline $\begin{array}{l}\text { Efendi et al. } \\
(2007)\end{array}$ & $\mathrm{X}$ & $\mathrm{X}$ & $\begin{array}{l}\text { Pressure resulting from debt } \\
\text { covenants } \\
\text { Pressure related to debt and } \\
\text { equity capital financing } \\
\text { Pressure resulting from a } \\
\text { unitary structure }\end{array}$ \\
\hline
\end{tabular}




\begin{tabular}{|c|c|c|c|c|}
\hline Authors & Pressure & Opportunity & Rationalization & Results/Conditions Identified \\
\hline $\begin{array}{l}\text { Summers \& } \\
\text { Sweeney, } \\
\text { (1998) } \\
\text { Lie (2005) } \\
\text { Burns \& Kedia, } \\
\text { (2006) }\end{array}$ & $\mathrm{X}$ & $\mathrm{X}$ & $\mathrm{X}$ & $\begin{array}{l}\text { Pressure from Stock Option } \\
\text { Compensation } \\
\text { Increased Competition }\end{array}$ \\
\hline $\begin{array}{l}\text { Abbott et al., } \\
\text { (2004) }\end{array}$ & & $\mathrm{X}$ & & $\begin{array}{l}\text { Evidence of a weak corporate } \\
\text { governance structure } \\
\text { Management's commitment to } \\
\text { internal control }\end{array}$ \\
\hline $\begin{array}{l}\text { Dechow et al. } \\
\text { (1996); } \\
\text { Farber (2005) }\end{array}$ & $\mathrm{X}$ & $\mathrm{X}$ & & $\begin{array}{l}\text { Lack of independent boards } \\
\text { Unitary structure for the } \\
\text { Chairman and CEO } \\
\text { Lack of financial experts on the } \\
\text { board }\end{array}$ \\
\hline $\begin{array}{l}\text { Swartz \& } \\
\text { Watkins, (2003) }\end{array}$ & & $\mathrm{X}$ & & $\begin{array}{l}\text { Increasing employee access to } \\
\text { records and valuables }\end{array}$ \\
\hline $\begin{array}{l}\text { Bratton, (2002) } \\
\text { Young, (2005) }\end{array}$ & & $\mathrm{X}$ & & $\begin{array}{l}\text { Weak internal controls } \\
\text { Lack of specific policies and } \\
\text { procedures } \\
\text { Unsupervised asset access } \\
\text { (Poor segregations of duties) } \\
\text { Lack of management review } \\
\text { and oversight }\end{array}$ \\
\hline $\begin{array}{l}\text { Ramos (2003) } \\
\text { Wolfe (2004) }\end{array}$ & $\mathrm{X}$ & & $\mathrm{X}$ & $\begin{array}{l}\text { Existence of the borrowing } \\
\text { mentality } \\
\text { Existence of the entitlement } \\
\text { mentality }\end{array}$ \\
\hline $\begin{array}{l}\text { Albrecht et al., } \\
\text { (2005) }\end{array}$ & $\mathrm{X}$ & & $\mathrm{X}$ & Employee Job Dissatisfaction \\
\hline $\begin{array}{l}\text { Hogan et al., } \\
\text { (2008) } \\
\text { Gillett and } \\
\text { Uddin (2005) }\end{array}$ & $\mathrm{X}$ & & $\mathrm{X}$ & $\begin{array}{l}\text { CFO Attitude } \\
\text { Aggressive financial reporting } \\
\text { parameters }\end{array}$ \\
\hline
\end{tabular}




\section{Industry Characteristics and Increased Fraud Risk}

Based on the previous discussion, past literature reveals general measurable variables that may contribute to increased fraud risk. In the context of specific industries, it's noted that many characteristics of the restaurant industry reveal similar variables found within the fraud triangle as noted in the accounting and audit literature. For example, the nature of the restaurant industry is often described as a periodic, seasonal and cyclic trade (Choi, 2007; Chathoth \& Olsen, 2007; Parsa, et al., 2005), often susceptible to changes in political, social and economic conditions, including inflation, unemployment and rising interest rates. These conditions are related to the financial stability variables often found within the "pressure" construct of the fraud triangle. Because these conditions have an obvious impact on earnings and measures of success, this seasonal variability and volatility should be considered when analyzing pressures in the restaurant industry (Yap, 2008). Additionally, the stringent requirements of the Sarbanes-Oxley Act in 2002 created reporting and monitoring of internal controls for the first time, resulting in increased amounts of reported internal control deficiencies (Ge \& McVay, 2005).

Restaurants may respond negatively to the political, social and economic pressures as evidenced by poor performance in profitability or growth and measured by changes in gross profit margin or asset size. Some restaurant industry pressures that may impact profitable sales growth include a lack of understanding of the consumer's perception, including the relevance of existing brands, and delays in opening new restaurants. Likewise, an inability to consider cost pressures, including increasing fees for supplies, utilities and health care providers contracted by restaurants, as well as an incapability of obtaining economies of scale in procurement, could compress margins and negatively impact sales and operations profit margin. Supporting these pressures, Ge and McVay (2005) discovered that firms with deficiencies in internal control are 
more multifarious, smaller and less gainful than those firms that have not disclosed deficiencies. Based on these findings, it can be stated that publicly traded restaurant companies with diminished earnings (as measured by gross profit margin) over time are at an increased risk of fraud due to pressures resulting from financial instability inherent in the industry. Likewise, restaurant companies that are smaller (and therefore may not have strong internal controls) with increasingly complex transactions create additional opportunities for fraud to be committed (Levisohn, 2009).

When considering additional external pressures, it’s clear that the success of publicly traded restaurant companies is dependent upon their ability to obtain debt financing in order to grow, as well as the capability to pay down liabilities, manage debt, and obtain financing for future acquirements (Advani, 2006). It is also noted that the world credit markets and the financial industry has experienced unparalleled mayhem, often described as obligatory insolvency which has necessitated various levels of governmental intervention. These events can negatively impact the obtainability of credit already established, as well as the accessibility and the future cost of credit. Therefore, when debt financing exists, in order to address past and future obligations, and remain competitive, restaurant companies are at an increased risk of fraud especially when disruptions in financial and credit markets exist.

Studies have revealed that restaurant company victory and demise is eventually correlated to restaurant leadership abilities and intentions; therefore, it can be stated that executives and managers' intentions are of utmost concern in understanding risk of fraud (Parsa et. al, 2005). Additionally, ineffective management may be connected to disappointing financial conditions, insufficient cash use and inadequacy in operations. Additionally, when conditions that relate to a poor financial situation exist and are coupled with perceived opportunity and 
rationalization, the propensity for fraud increases greatly. For example, the pressure to manipulate earnings through stock ownership may occur when manager and executive salaries are tied to bonus potential. Insider trading and knowledge of proposed transactions may enable a manager to act in an unethical manner by selling or buying up additional shares of discounted stock (Summers \& Sweeney, 1998; Lie, 2005; Burns \& Kedia, 2006). A significant fluctuation in shares available may provide evidence of concern. Additionally, feelings of failure may also motivate executives and managers to commit fraud. Researchers Haswell and Holmes (1989) conveyed that insufficient management, ineptitude and greenness are constant themes in elucidating restaurant failures, coupled with a bad product, weak organizational culture and marketing choices (Camillo et al., 2008). The pressure of failure may be too great for one to handle, leaving no other perceived option but to commit a fraudulent act.

It is also noted that the restaurant industry is extremely competitive with respect to pricing, level of service, locality, workforce, type/quality of food, with a plethora of wellestablished competitors. Growing competition in the industry is noted from a convergence of store, deli and restaurant services, particularly in supermarkets which now offer "meals of convenience”. Echoing Lister (2007), competitiveness is a condition that makes meeting financial targets difficult and provides opportunity for fraudulent behavior. External pressure from analysts and investors may create an incentive to misappropriate assets, which in turn distorts common financial measures of success such as return on assets. Given that assets are balance sheet items carried year over year, a significant fluctuation over a relatively short amount of time could provide an indication of increased fraud risk (Ge \& McVay, 2005).

It has been noted that the nature of the industry is a key opportunity that may result in an increased fraud risk. Doyle et al. (2007b) demonstrated that industries made up of companies 
that are younger, undergoing capital restructuring, or growing rapidly are at an increased likelihood of reporting internal control deficiencies. Likewise, Ashbaugh et al. (2006) discovered that firms with increasingly complex operations coupled with changes in organizational structure have less resources to put into internal controls and are therefore at an increased risk for accounting errors. The restaurant industry is often comprised of companies that are younger and undergoing restructuring, while attempting to grow through both domestic and international franchisee partners. While a collective exercise in the restaurant industry is to generate sales and profit through international franchisee relationships, there is no guarantee that international operations will be gainful or that international growth will be continually successful. International growth is subject to risks such as international political and economic conditions, foreign currency fluctuations and divergent cultures and consumer inclinations (Kim \& Gu, 2003). As noted then, a large percentage of international sales could result in increased fraud opportunities.

In addition to these industry characteristics, is has been noted that the restaurant industry is one of high employee turnover (Allen, 2008), due to workforce diversity and the presence of many perceived low skilled workers. In addition, as companies within the industry respond to declining performance, publicly traded restaurant companies may be subject to activist investors who wish to see a change in the executive management team. If a shake up like this would occur, the organizational structure of the company may become unstable, resulting in much greater opportunities for fraud to occur at all levels. As noted by Beasley (1996), further fraud incidences may occur if the CEO is also the chairman of the board, as this creates an opportunity for one person to control the tone of the company. These opportunities in the industry may be 
measured by benchmarking the turnover rate for each company and determining whether or not the CEO is also the chairman of the board.

Finally, variables relating to rationalization are present in the restaurant industry when considering the motivations and attitudes of management. It is noted that in difficult times, such as the Recession, aggressive financial reporting tactics may be used (Ashbaugh et al., 2006). Ultimately, the management team is responsible for the establishment and maintenance of financial reporting controls and reporting. As stated, when pressure and opportunities exist, rationalization becomes the final needed component for an increased risk of fraud to occur. Aggressive financial reporting tactics may be observed through executive compensation levels that are higher than average, and possibly through evidence of a change in auditor before the five year mandatory turnover (Ge \& McVay, 2005).

It is noted from the discussion above that many internal and external variables provide measurements to the constructs of pressure, opportunity and rationalization, which, when all present, increase the risk of occupational fraud. This study will focus on the variables most pertinent to the restaurant industry based on the inherent characteristics of U.S. publicly traded restaurant companies. First and foremost, this study will assess the influence of the SOX Act on incidences of reported internal control deficiencies. Since the Act itself mandated companies to evaluate the efficacy of internal control structures, it stands to reason that the introduction of the Act provides opportunities for increased fraud risk by highlighting vulnerable processes within a company and compelling companies to acknowledge existing control deficiencies. Second, the study will assess the impact of company size on the probability of increased fraud risk for restaurant companies, postulating that smaller and less profitable companies provide conditions more conducive to increased fraud risk. 
Additionally, this study will look to assess the relationship between the amount of debt a company has occurred and the incidence of reported internal control deficiencies. Empirical research notes that high amounts of debt create external pressures, thereby increasing the risk of fraud. In addition to debt financing, most publicly traded restaurant companies raise capital through equity financing and company stock programs. Restaurant companies are no exception, and frequently provide opportunities for management to buy up stock at a discounted price (Allen, 2008). Therefore, and thirdly, the presence of substantial stock compensation may provide incentives and rationalization for management to commit fraud, especially in periods of rough financial times. Thus, this study seeks to understand the impact of substantial stock compensation on increased fraud risk.

Additionally, return on assets may provide indicators of a company's ability to meet financial targets. Therefore, this study also hypothesizes that poor return on assets could increase the risk of fraud, as the pressure provides executive management with the motivation to manipulate earnings. Also, as most restaurant companies are expanding internationally, the percentage of international sales may increase fraud risk due to lack of control over foreign operations or the ability to circumvent controls in attempts to promote the strategy as a successful operation. Additionally, this study suggests that the organizational structure of the company may provide opportunity for increased fraud risk through a unitary tone at the top. Finally, incidences of employee turnover in addition to macroeconomic factors and the Great Recession may all provide additional increased fraud risk for publicly traded restaurant companies. Each of the variables described above provides a model that pertains to the central research problem and were selected based on a review of the literature. Figure 2 below summarizes the proposed model according to the variables presented. 


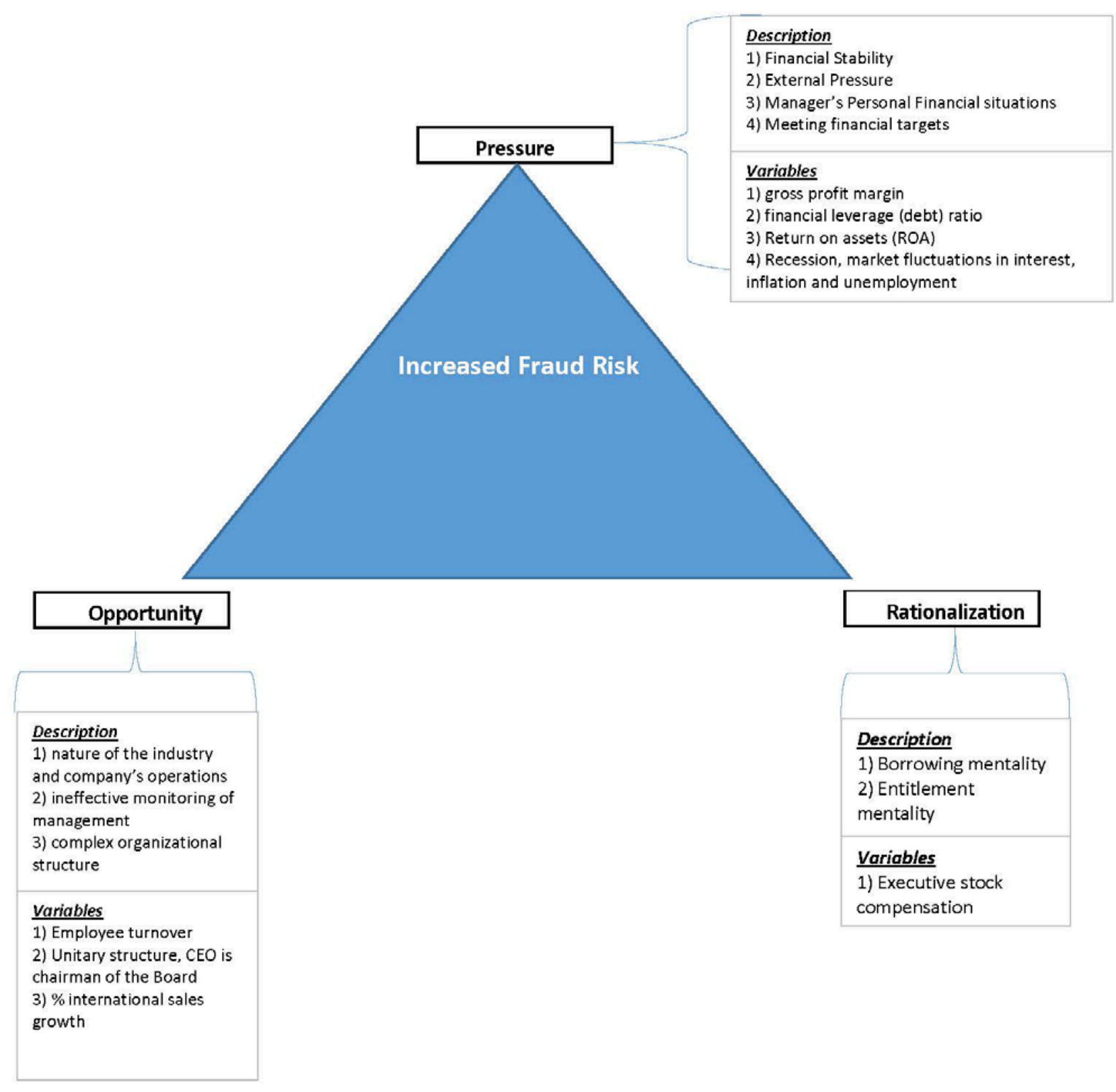

Figure 2: Proposed Model of the Fraud Triangle Framework in the Restaurant Industry

It's clear that the majority of research in this area has focused on investigating and understanding the characteristics of firms that have revealed deficiencies in internal control, the most common measure of increased fraud risk (Murphy \& Dacin, 2011). However, empirical research has not focused specifically on the characteristics of companies within the restaurant 
industry who have reported internal control deficiencies. The variables selected for the model have been tested in studies linked to instances of internal fraud, as well as studies linking predictors of fraud to financial results. As noted, this is an important area for research given the financial impact of the occurrence of fraud in the restaurant industry. Therefore, based on the literature reviewed and the previous discussion of the model, the following hypotheses are presented:

$\mathbf{H}_{\mathbf{1}}$ : The Sarbanes-Oxley Act of 2002 has had a significant impact on increased risk of fraud for restaurant companies.

$\mathbf{H}_{2}$ : Company size and amount of debt have a significant impact on increased risk of fraud, when internal control deficiencies are reported in accordance with the SarbanesOxley Act of 2002.

$\mathbf{H}_{3}$ : Evidence of substantial stock option compensation and poor return on assets has a significant impact on increased risk of fraud, when internal control deficiencies are reported in accordance with the Sarbanes-Oxley Act of 2002.

$\mathbf{H}_{\mathbf{4}}$ : Evidence of a large percentage of total international sales has a significant impact on increased risk of fraud, when internal control deficiencies are reported in accordance with the Sarbanes-Oxley Act of 2002.

$\mathbf{H}_{5}$ : Increased employee turnover has a significant impact on increased risk of fraud, when internal control deficiencies are reported in accordance with the Sarbanes-Oxley Act of 2002.

$\mathbf{H}_{6}$ : Organizational structure has a significant impact on increased risk of fraud, when internal control deficiencies are reported in accordance with the Sarbanes-Oxley Act of 2002. 
$\mathbf{H}_{7}$ : Macroeconomic factors such as inflation, unemployment, and rising interest rates have a significant impact on increased risk of fraud, when internal control deficiencies are reported in accordance with the Sarbanes-Oxley Act of 2002.

$\mathbf{H}_{\mathbf{8}}$ : The Great Recession has a significant impact on increased risk of fraud, when internal control deficiencies are reported in accordance with the Sarbanes-Oxley Act of 2002.

The next chapter will discuss the process and the methodology used to disconfirm and confirm the presented hypotheses. This study will utilize a probit model to determine the characteristics most conducive to increased fraud risk based on the probability of reporting internal control deficiencies for U.S. publicly traded restaurant companies, since inception of the SOX Act of 2002. The use of the probit model in this study will estimate the probability that an observable restaurant company with particular characteristics hypothesized above will be susceptible to increased risk of fraud through the reporting of an internal control deficiency. 


\section{CHAPTER 3: METHODOLOGY}

The following chapter describes the methods that will be utilized in the study to empirically assess the relationship between various characteristics or variables identified through the literature and the probability of increased risk of fraud based on incidences of reported internal control deficiencies. The chapter begins with a reminder of the purpose, research questions and hypotheses presented from the introduction and literature review. Then, the

research design is explained, along with an explanation and analysis of the measurements of the variables introduced in the proposed research design equation. Additionally, a table of the operational definitions of the variables supported by the literature is included. Following the design and measurements of variables, the description of the population and sample are presented. Finally, the data collection methods and a summary finalize the chapter.

\section{Research Questions and Hypotheses}

As previously stated, this study will analyze the disclosures of publicly traded restaurant companies to determine whether or not a company has a higher probability of increased fraud risk, based on variables such as the macroeconomic environment, the Sarbanes-Oxley Act, company size and amount of debt, employee turnover, organizational structure, international sales, return on assets and stock compensation. Specifically, the study will examine the impact of the Sarbanes-Oxley Act and the factors that contribute to increased risk of fraud in order to determine why fraud may occur despite the imposed regulation of the Sarbanes-Oxley Act. This will be accomplished through a probit analysis utilizing whether or not fraud is at an increased risk of occurring as the dependent binary variable, considering reports of deficiencies in internal 
control. As defined in the literature review, reports of internal controls deficiencies for public companies resulted from implementation of the 2002 Sarbanes-Oxley Act.

The probit is the most appropriate procedure to address the research questions because it is most commonly utilized to model binary outcome or dichotomous variables in terms of probability units (Long, 1997). Specifically, in the probit model, the typical normal distribution of the units of probability is exhibited as a linear combination of the predictor variables (Long, 1997). This method can be compared to an ordinary least squares regression, which when considered with binary dependent variables, is called a linear likelihood model capable of describing conditional probabilities. However, under the OLS method of regression, the residuals from the linear model disturb the homoscedasticity and assumptions of error normality, culminating in unacceptable standard errors and tests of hypotheses (Long, 1997; Hosmer \& Lemeshow, 2000).

In this study, a binary distribution of potential behavior is assumed, i.e., the study will estimate the probability that a company will have an increased risk of fraud or not based on the incidence of a reported internal control deficiency and other variables. More specifically, the study will estimate the following relationship:

$$
\mathrm{g}(\mu)=\beta 0+\beta 1 \mathrm{X}
$$

where $\beta 0+\beta 1 \mathrm{X}$ is the structural component and $\mathrm{g}()$ is the link and $\mu$ is the mean of a conditional response distribution at a given point in the covariate space. As noted above, because the distribution of the response variable, i.e., increased fraud risk, is non-normal under other techniques, the connection or link between the structural components to the response becomes the crucial element at this step. 
Certainly, the impact of the Sarbanes Oxley Act is the main consideration, controlling for other covariates, in discerning the link to increased risk of fraud, as demonstrated in the literature review. Therefore, the following research questions and hypotheses are presented:

Table 3: Research Questions and Hypotheses

\begin{tabular}{|c|c|c|}
\hline \# & Research Question & Hypothesis \\
\hline 1 & $\begin{array}{l}\text { Does the Sarbanes-Oxley Act have a } \\
\text { significant impact on detecting } \\
\text { increased risk of fraud in the restaurant } \\
\text { industry? }\end{array}$ & $\begin{array}{l}\text { The Sarbanes-Oxley Act of } 2002 \text { has had a } \\
\text { significant impact on increased risk of fraud for } \\
\text { restaurant companies. } \\
\mathbf{H}_{\mathbf{0}}=\text { There is no relationship between increased risk } \\
\text { of fraud and the Sarbanes-Oxley Act. } \\
\mathbf{H}_{\mathbf{1}}=\text { There is a significant relationship between } \\
\text { increased risk of fraud and the Sarbanes-Oxley Act. }\end{array}$ \\
\hline 2 & $\begin{array}{l}\text { Controlling for company size, does the } \\
\text { Sarbanes-Oxley Act have a significant } \\
\text { impact on increased risk of fraud in the } \\
\text { restaurant industry? }\end{array}$ & $\begin{array}{l}\text { Company size and amount of debt have a } \\
\text { significant impact on increased risk of fraud, when } \\
\text { internal control deficiencies are reported in } \\
\text { accordance with the Sarbanes-Oxley Act of } 2002 \text {. } \\
\mathbf{H}_{\mathbf{0}}=\text { There is no relationship between increased risk } \\
\text { of fraud and company size. } \\
\mathbf{H}_{\mathbf{0}}=\text { There is no relationship between increased risk } \\
\text { of fraud and amount of debt. } \\
\mathbf{H}_{1}=\text { There is a significant relationship between } \\
\text { increased risk of fraud and company size. } \\
\operatorname{Pr}\left(Y=1 \mid \mathrm{X}_{1}\right)=\Phi\left(\mathrm{X}_{1} \beta\right) \\
\mathbf{H}_{\mathbf{1}}=\text { There is a significant relationship between } \\
\text { increased risk of fraud and amount of debt. } \\
\operatorname{Pr}\left(Y=1 \mid \mathrm{X}_{2}\right)=\Phi\left(\mathrm{X}_{2} \beta\right)\end{array}$ \\
\hline
\end{tabular}




\begin{tabular}{|c|c|c|}
\hline \# & Research Question & Hypothesis \\
\hline 3 & $\begin{array}{l}\text { Controlling for employee turnover, } \\
\text { does the Sarbanes-Oxley Act have a } \\
\text { significant impact on increased risk of } \\
\text { fraud in the restaurant industry? }\end{array}$ & $\begin{array}{l}\text { Increased employee turnover has a significant } \\
\text { impact on increased risk of fraud, when internal } \\
\text { control deficiencies are reported in accordance with } \\
\text { the Sarbanes-Oxley Act of } 2002 \text {. } \\
\mathbf{H}_{\mathbf{0}}=\text { There is no relationship between increased risk } \\
\text { of fraud and employee turnover. } \\
\mathbf{H}_{\mathbf{1}}=\text { There is a significant relationship between } \\
\text { increased risk of fraud and employee turnover. } \\
\operatorname{Pr}\left(Y=1 \mid \mathrm{X}_{3}\right)=\Phi\left(\mathrm{X}_{3} \beta\right)\end{array}$ \\
\hline 4 & $\begin{array}{l}\text { Controlling for risk factors and macro- } \\
\text { economic factors, does the Sarbanes- } \\
\text { Oxley Act have a significant impact on } \\
\text { increased risk of fraud in the restaurant } \\
\text { industry? }\end{array}$ & $\begin{array}{l}\text { Macroeconomic factors of inflation, unemployment, } \\
\text { and interest rates have a significant impact on } \\
\text { increased risk of fraud, when internal control } \\
\text { deficiencies are reported in accordance with the } \\
\text { Sarbanes-Oxley Act of } 2002 \text {. } \\
\mathbf{H}_{0}=\text { There is no relationship between increased risk } \\
\text { of fraud and the macroeconomic factors. } \\
\mathbf{H}_{1}=\text { There is a significant relationship between } \\
\text { increased risk of fraud and macroeconomic factors. } \\
\operatorname{Pr}\left(\mathrm{Y}=1 \mid \mathrm{X}_{4}\right)=\Phi\left(\mathrm{X}_{4} \beta\right) \\
\operatorname{Pr}\left(\mathrm{Y}=1 \mid \mathrm{X}_{5}\right)=\Phi\left(\mathrm{X}_{5} \beta\right) \\
\operatorname{Pr}\left(\mathrm{Y}=1 \mid \mathrm{X}_{6}\right)=\Phi\left(\mathrm{X}_{6} \beta\right)\end{array}$ \\
\hline 5 & $\begin{array}{l}\text { Controlling for the Great Recession, } \\
\text { does the Sarbanes-Oxley Act have a } \\
\text { significant impact on increased risk of } \\
\text { fraud in the restaurant industry? }\end{array}$ & $\begin{array}{l}\text { The Great Recession has a significant impact on } \\
\text { increased risk of fraud, when internal control } \\
\text { deficiencies are reported in accordance with the } \\
\text { Sarbanes-Oxley Act of } 2002 \text {. } \\
\mathbf{H}_{\mathbf{0}}=\text { There is no relationship between increased risk } \\
\text { of fraud and the Great Recession. } \\
\mathbf{H}_{\mathbf{1}}=\text { There is a significant relationship between } \\
\text { increased risk of fraud and the Great Recession. } \\
\operatorname{Pr}\left(Y=1 \mid \mathrm{X}_{7}\right)=\Phi\left(\mathrm{X}_{7} \beta\right)\end{array}$ \\
\hline
\end{tabular}




\begin{tabular}{|c|c|c|}
\hline$\#$ & Research Question & Hypothesis \\
\hline 6 & $\begin{array}{l}\text { Controlling for organizational } \\
\text { structure, does the Sarbanes-Oxley Act } \\
\text { have a significant impact on increased } \\
\text { risk of fraud in the restaurant industry? }\end{array}$ & $\begin{array}{l}\text { Organizational structure has a significant impact on } \\
\text { increased risk of fraud, when internal control } \\
\text { deficiencies are reported in accordance with the } \\
\text { Sarbanes-Oxley Act of } 2002 \text {. } \\
\mathbf{H}_{\mathbf{0}}=\text { There is no relationship between increased risk } \\
\text { of fraud and organizational structure. } \\
\mathbf{H}_{\mathbf{1}}=\text { There is a significant relationship between } \\
\text { increased risk of fraud and organizational structure. } \\
\operatorname{Pr}\left(\mathrm{Y}=1 \mid \mathrm{X}_{8}\right)=\Phi\left(\mathrm{X}_{8} \beta\right)\end{array}$ \\
\hline 7 & $\begin{array}{l}\text { Controlling for international sales, } \\
\text { does the Sarbanes-Oxley Act have a } \\
\text { significant impact on increased risk of } \\
\text { fraud in the restaurant industry? }\end{array}$ & $\begin{array}{l}\text { Evidence of a large percentage of total international } \\
\text { sales has a significant impact on increased risk of } \\
\text { fraud, when internal control deficiencies are } \\
\text { reported in accordance with the Sarbanes-Oxley Act } \\
\text { of } 2002 \text {. } \\
\mathbf{H}_{\mathbf{0}}=\text { There is no relationship between increased risk } \\
\text { of fraud and international sales. } \\
\mathbf{H}_{1}=\text { There is a significant relationship between } \\
\text { increased risk of fraud and international sales. } \\
\text { Pr }\left(Y=1 \mid \mathrm{X}_{9}\right)=\Phi\left(\mathrm{X}_{9} \beta\right)\end{array}$ \\
\hline
\end{tabular}




\begin{tabular}{|c|c|c|}
\hline \# & Research Question & Hypothesis \\
\hline 8 & $\begin{array}{l}\text { Controlling for stock compensation } \\
\text { and return on assets, does the } \\
\text { Sarbanes-Oxley Act have a significant } \\
\text { impact on increased risk of fraud in the } \\
\text { restaurant industry? }\end{array}$ & $\begin{array}{l}\text { Evidence of substantial stock option compensation } \\
\text { and poor return on assets has a significant impact on } \\
\text { increased risk of fraud, when internal control } \\
\text { deficiencies are reported in accordance with the } \\
\text { Sarbanes-Oxley Act of } 2002 \text {. } \\
\mathbf{H}_{\mathbf{0}}=\text { There is no relationship between increased risk } \\
\text { of fraud and stock option compensation. } \\
\mathbf{H}_{\mathbf{0}}=\text { There is no relationship between increased risk } \\
\text { of fraud and return on assets. } \\
\mathbf{H}_{\mathbf{1}}=\text { There is a significant relationship between } \\
\text { increased risk of fraud and stock option } \\
\text { compensation. } \\
\text { Pr }\left(Y=1 \mid \mathrm{X}_{10}\right)=\Phi\left(\mathrm{X}_{10} \beta\right) \\
\mathbf{H}_{\mathbf{1}}=\text { There is a significant relationship between } \\
\text { increased risk of fraud and return on assets. } \\
\operatorname{Pr}\left(\mathrm{Y}=1 \mid \mathrm{X}_{11}\right)=\Phi\left(\mathrm{X}_{11} \beta\right)\end{array}$ \\
\hline
\end{tabular}

\section{$\underline{\text { Research Design }}$}

It is noted that $20 \%$ of companies distort economic authenticity through reported earnings (Wang, 2009), which may indicate increased risk of fraud. To comprehend the propensity for fraud, past research has determined that quantifiable methods with scientific formulas, like the Beneish model (established by Messod D. Beneish, 1999), may offer reliable measures to differentiate earnings management from manipulation (Yu, 2008). The model developed by Beneish is one such quantifiable model that utilized economic ratios and variables to ascertain whether or not a company has influenced its earnings and is at risk for fraud. Considering eight 
variables, Beneish described earnings manipulators as companies that are: (1) growing swiftly, (2) suffering from weakening basic performance measures, and (3) implementing aggressive accounting standards of practice. The first descriptors mentioned are considered to be incentive/pressure factors as noted in the fraud triangle — as these may result in increased risk based on inherent effects on stock price (Ashbaugh et. al, 2006). For his purpose of detecting these exploiters, Beneish utilized a probit model, and in sample tests, the model appropriately determined 76\% of recognized conspirators (Beneish, 1999).

This study complements Beneish’s methodological format for publicly traded restaurant companies and proposes a similar probit model to test the impact of the financial and nonfinancial variables on the incidence of reporting internal control deficiencies for publicly traded restaurant companies. As noted above, "Probit" refers to "probability unit" and is an additional term that refers to the Z-score of a normal distribution. The probit model assumes that the probability of manipulation, or increased fraud risk, remains small at first, but then surges quickly, leveling off as the variables dip into a territory of "red-flags". This generates a sigmoidal or S-shaped line that is be represented by the aggregate normal (Yu, 2008). The probit model actually transforms the sigmoid response curve to a straight line that can then be analyzed through a least squares or maximum likelihood test. The test of the model then uses the cumulative normal and determines the coefficients of the proposed variables that maximize the likelihood of creating the practical sample (Vincent, 2001). Thus, for this study, the probit model estimates likelihood by regressing the binary variable to the independent variables to determine characteristics which highlight increased fraud risk.

The first step in assessing the use of the probit model is to check the assumptions of the model. First, we assume that a distribution of unobservables exists, $f(\varepsilon i)$, and that such 
distribution is normal (Long, 1997). Additionally, as found in the classic linear model, the assumption of $E(\varepsilon i)=0$ is generalizable, as long as the independent variables retain a constant term $\mathbf{x i}$ ( as noted in this research design). Also, in probit, population variance values are not defined. All we can ever know is that the likelihood of fraud occurring is based on both $\beta$ and $\sigma$, and never on each by itself. For this reason, in a probit analysis, $\sigma=1$, and estimated coefficients are estimates of $\beta / \sigma$. Thus, in a probit model, if an observation has $y i=1$, it must be true that $\varepsilon i>-\beta \mathrm{x} i$ for that observation.

It's important to note that when assessing a company’s likelihood of being affected by fraud, a consideration should be recognized because such likelihood is not observable directly: it is only possible to observe increased fraud risk from internal control deficiencies that have been detected and subsequently reported. This problem has two insinuations. First, the result of being observed depends on the conclusions of two separate but latent developments: detection of the deficiency and report of the deficiency. Second, if the discovery process is not flawless (i.e., the likelihood of detection is not $100 \%$ ), then the likelihood of detected deficiencies (what is observed) will not be the same as the likelihood of increased fraud risk (what we want to predict). A standard probit model cannot address this partial observability issue.

Following Wang (2009), it is proposed that a bivariate probit model be used to resolve the instance of partial observability of increased fraud risk. Originally proposed by Poirer (1980) and also utilized by Feinstein (1990), the bivariate probit model, looks to the observed likelihood of detected deficiencies as the product of the latent likelihood of fraud risk commission and the latent likelihood of fraud risk detection. This model not only helps to resolve the fractional observability of fraud, but also provides the ability to estimate the separate effects of the restaurant industry on fraud risk detection and reported fraud risk (Li, 2013). 
Specifically, for this study, the partial observability problem is solved by separating companies that were found to have a reported internal control deficiency during some time during the years and companies that did not. To solve the problem, the group without deficiencies is split into groups, separated by a set of company characteristics, A, usually applied to the likelihood of fraud as defined through literature, and a different group of company characteristics, B, to fit the probability of detection. By capturing this, a subset of the B group is determined to have analogous characteristics A but different characteristics B compared to the A group. This group is likely to consist of companies that have committed fraud but have not been detected, and the remaining companies in the second group are companies that have not determined fraud. Then, the maximum likelihood method developed by Poirer (1980) is used to estimate the model with the appropriate sample of companies.

This study then proposes that the variables are created from the company's financials and external factors according to the model in order to produce an $\mathrm{M}$ score to define the gradation in which the increased fraud risk may occur. The M score will be based on a combination of the eleven different variables and weighted together according to the below formula:

$$
\operatorname{Prob} \mathrm{F}(\mathrm{Y})=\Phi(\mathbf{X} \beta 1+\ldots . \mathrm{X} \beta 11+\varepsilon)
$$

The first step in applying the equation above is to convert the dichotomous $\mathrm{Y}$ into a continuous variable, $\mathrm{Y}^{1}$, so that a regular linear function regression can be performed. Therefore, a link function, $\mathrm{F}(\mathrm{Y})$, is needed to take dichotomous $\mathrm{Y}$ in order to give a continuous real valued $\mathrm{Y}^{1}$. This provides a cumulative normal distribution $\Phi$, so that any given M-score provides a probability unit. The next step involves taking the odds ratio of y, which provides that if some occurrence with likelihood "p" happens, then the odds of it occurring are $O(p)=p /(1-p)$. 
Defining the odds ratio of $Y$ then changes the equation from the $(0,1)$ dichotomy to a continuous Y. It is noted that the ratio of odds is non-negative (O'Halloran, 2009). As the last step, a log of the odds ratio is taken. This is done in order to transform the function to a standard normal distribution. It's important to note that for the research problem at hand, the use of a probit model is necessary because of the assumption that there are latent variables that occur as part of the function. In a linear regression, $\mathrm{Y}$ would be observed directly. However, as noted, probits only show observations of 0 or 1 , in this case, whether or not there is an increased risk of fraud.

The last step involves estimating the values of the $\beta$ coefficients. A probit model allows for the calculated likelihood of each Y through any given set of $\beta$ coefficients, and the likelihood estimation determines the $\beta$ 's to maximize the likelihood of the given sample. The estimation step involves taking the logs of the sample likelihoods and solve for the probability. The value of the probability that maximizes the probability function is the population mean, and by searching for the values of $\beta$ by coding "probit" in a program such as stata will provide the needed coefficients to analyze in the equation.

After analyzing the values of the $\beta$ coefficients, it is necessary to test for random and fixed effects in the model and to estimate the marginal effects. Fixed effects removes the effect of the time-invariant characteristics so the net effect of the predictors on the dependent variable can be measured (Baum, 2006). The rationale behind the random effects model is that, unlike the fixed effects model, the variation across entities is assumed to be random and uncorrelated with the independent or predictor variables included in the model. Thus, with random effects, it is assumed that a company's error term is not correlated with the predictors. In order to determine whether effects are fixed or random, a test known as the Hausman test is to be performed as one of the final sensitivity tests applicable to the probit model. 
The specific steps of the probit model are summarized in the list below.

1) Create a link function by transforming the dichotomous $Y$ into a continuous variable, Y1

2) Take the odds ratio of $Y$ in order to move the line to a normal curve

3) Take the logs of the odds ratio of Y (concentrations) to create a normal distribution of Z scores

4) Estimate $\beta$ coefficients through Stata's maximum likelihood estimate

5) Graph the probits versus the log of the concentrations and fit a line of regression.

6) Determine the $95 \%$ Confidence Intervals

7) Perform sensitivity and marginal effects testing

Knowledge of the fundamentals of probit modeling as described above, in conjunction with understanding Beneish’s assumptions can assist analysts and executive managers in obtaining value for the restaurant industry, where the ability to forecast increased fraud risk ahead of the curve means the difference between profit and hefty fines or reputational losses. In understanding financial representations, it is clear that manipulators push the limits of the rules while “earnings managers” operate within the boundaries of accepted accounting principles. Additionally, it is noted that much of finance and accounting research includes binary variables (i.e., the buy/sell decision is binary), so it is shocking that probit is not more extensively utilized. There are only a few examples of the use of the model in this area of research. For example, the Beneish method was utilized by students to predict manipulation of Enron's financials one year prior to Enron's bankruptcy. Gray and Carlisle (2002) also highlighted this method and amplified it with a method of purchasing stocks with low-volume accruals and low-scaled net assets. 
Additionally, when considering the use of this method in the restaurant industry, only a handful of studies explored the impact of certain variables on dichotomous measures. The methodology was mostly considered for restaurant industry employment studies, e.g., the impact of the rise in minimum wage on restaurant companies' overall employment numbers (Card \& Krueger, 2001) and for estimates of supply chain disruptions on operating performance (Kuma, 2012). It appears that the extent of these studies is limited to certain areas and used intermittently for the purpose of discovering relationships.

The use of probit modeling for the restaurant industry has also been used to identify highrisk fraud candidates on a smaller scale in the restaurant sector, namely, for franchisee units. For example, Nigrini (2003) developed a procedure to identify audit violators through a risk based scoring process. The intent of his study was to use predictive modeling to identify fraud in sales reports for franchisees of an international quick service restaurant chain. Each restaurant was scored using a set of variables specific to expense reporting, and the scores were then averaged to give one general risk assessment for each restaurant. The same scoring approach was also used to detect check kiting, questionable expenses for vendors and potentially fraudulent travel agent expenses. The proposed study differs slightly from Nigrini's study in that the proposed study utilizes the fraud triangle as the basis for identifying the predictors instead of a numbering sequence known as Benford's law that is used pretty exclusively for accounting data. The next section will explain how and why each proposed variable will be measured.

\section{Measurement of Variables in the Equation}

Based on the description of the research design as noted above, the following panel model is proposed to test hypotheses 1-8: 


$$
\mathrm{P}(\text { Reported Deficiency }=1 \mid \mathrm{X})=\operatorname{Probit}\left(\beta_{0}+\sum_{\mathrm{n}=1}^{11} \beta_{\mathrm{n}} \mathbf{x}_{\mathrm{n}}+e_{\mathrm{t}}\right)
$$

Where $\mathrm{P}($ Reported Deficiency $=1 \mid \mathrm{X})=$ the probability of a reported deficiency in the annual report given $\mathrm{X}$; $\mathrm{X}=$ a vector of all independent variables; Probit is used to symbolize the probit function form; and Reported Deficiency = 1 when a restaurant company has reported an internal control deficiency according to SOX requirements listed in the annual report for a given year.

- $\quad \mathrm{x}_{1}=$ Company Size $=$ Individual companies’ gross profit margin - the industry median profit margin, with the gross profit margin calculated as (total sales - cost of goods sold) divided by total sales

- $\quad \mathrm{x}_{2}=$ Debt Leverage $=$ Individual companies’ financial leverage ratio - the industry median leverage ratio for each year studied, with financial leverage ratio calculated as average total debt divided by average total equity.

- $\quad \mathrm{x}_{3}=$ Employee Turnover $=$ Individual companies' turnover - the industry median turnover for each year studied, with turnover calculated as the average separations during the year divided by the total number of employees

- $\quad \mathrm{x}_{4}=$ Inflation Rate $=$ current market rates for each year studied

- $\quad \mathrm{x}_{5}=$ Unemployment Rate $=$ current market rates for each year studied

- $\quad \mathrm{x}_{6}=$ Interest Rate $=$ current market rates for each year studied

- $\mathrm{X}_{7}=$ Recession Year $=1$ when the year of study is either 2007, 2008, or 2009

- $\mathrm{x}_{8}=$ Organizational Structure $=1$ when the individual company has a CEO who is also the Chairman of the Board, for each year studied. 
- $\mathrm{X}_{9}=$ International Sales Growth $=$ Individual companies' international sales growth rate the industry median international sales growth rate for each year studied, with international sales rate calculated as average international sales divided by total sales.

- $\mathrm{x}_{10}=$ Executive Stock Compensation $=$ Individual companies' performance based stock compensation - the industry median stock compensation for each year studied, with stock compensation benchmarked to performance sensitivity measures.

- $\mathrm{x}_{11}=$ Return on Assets $=$ Individual companies' return on assets - the industry median return on assets for each year studied, with return on assets calculated as average net income divided by total assets.

The empirical model captures the year specific effects and provides the restaurant specific effects that influences the probability of increased risk of fraud, but have not been integrated in any examined variables. As described in the research design section, the error terms imply a non-normal distribution with a mean of 0 and a definitive variance.

Similar to Beneish’s groupings, as noted, the variables will be structured so that an incidence of a reported internal control deficiency means a higher likelihood of increased fraud risk. The partial observability issue will be addressed as described in the preceding "Research Design” section. As noted in the literature review, pressure to justify earnings is often explained by the market, and opportunity is available through financial statement reporting choices as measured by variables. The presented study incorporates incentives/pressure, opportunities and rationalization variables which is significant for executive managers and analysts, and matches the increasingly quantitative method of the SEC's accounting and finance quality model, providing evidence of a practical need for an industry specific model. 
The Xs and related $\beta$ coefficients in the presented equation include company size, amount of debt, employee turnover, current macroeconomic factors, the Recession, organizational structure, stock compensation, international sales growth, stock compensation, and return on assets. Each of these variables have been tested in past studies and are linked to common red flags of fraud, however it is noted that none of these variables have ever been applied in a comprehensive fashion to the restaurant industry. Therefore, this model represents a major contribution to existing hospitality literature because it bridges mainstream audit and accounting theories to the restaurant industry. While most research papers have looked to establish predictive measures for success for restaurant companies, there have been no studies that have looked at characteristics of increased risk of fraud.

This study has chosen not to investigate the incidence of auditor change, because rationale for changing auditors is often subjective based on many other factors, or is up for review every five years. In order to visibly comprehend how the variables defined in the literature are operationalized in the statistical procedure referenced in the Research Design section, the definitions are provided in Table 4, and each of the variable measurements will be discussed below.

Table 4: Operational Definitions

\begin{tabular}{|c|l|l|l|l|l|}
\hline$\#$ & \multicolumn{1}{|c|}{ Term } & Definition/Explanation & Formula/Denotion & Resource & Data Source \\
\hline $\mathbf{1}$ & Sarbanes- & Regulatory change that & Dummy variable & Wang & Secondary - \\
& Oxley Act of & affects the probability of & 0 - no internal \\
& 2002 & increased fraud risk & control deficiency \\
& & & $\begin{array}{l}\text { reported } \\
1-\text { internal control } \\
\text { deficiency reported }\end{array}$ & & \\
& & & & & \\
& & & & & \\
\end{tabular}




\begin{tabular}{|c|c|c|c|c|c|}
\hline \# & Term & Definition/Explanation & Formula/Denotion & Resource & Data Source \\
\hline 2 & Company Size & $\begin{array}{l}\text { How big or small a } \\
\text { company is measured } \\
\text { by profit margin }\end{array}$ & $\begin{array}{l}\text { Gross profit margin } \\
=\text { sales }- \\
\text { COGS/sales }\end{array}$ & $\begin{array}{l}\text { Beasley, } \\
\text { (2000) } \\
\text { Beneish, } \\
(1997)\end{array}$ & $\begin{array}{l}\text { Secondary - } \\
\text { SEC filings }\end{array}$ \\
\hline 3 & $\begin{array}{l}\text { Amount of } \\
\text { Debt }\end{array}$ & $\begin{array}{l}\text { Total amount of average } \\
\text { debt financing for a } \\
\text { company }\end{array}$ & $\begin{array}{l}\text { Financial Leverage } \\
\text { Ratio = average } \\
\text { total debt/average } \\
\text { total equity }\end{array}$ & $\begin{array}{l}\text { Persons } \\
\text { (1995) }\end{array}$ & $\begin{array}{l}\text { Secondary - } \\
\text { SEC filings }\end{array}$ \\
\hline 4 & $\begin{array}{l}\text { Employee } \\
\text { Turnover }\end{array}$ & $\begin{array}{l}\text { Average percentage of } \\
\text { employees that separate } \\
\text { from a company within } \\
\text { a year }\end{array}$ & $\begin{array}{l}\text { Annual Turnover } \\
\text { Rate = Average } \\
\text { separations during } \\
\text { the year/total } \\
\text { number of } \\
\text { employees }\end{array}$ & $\begin{array}{l}\text { Allen } \\
\text { (2008) }\end{array}$ & $\begin{array}{l}\text { Secondary - } \\
\text { SEC filings }\end{array}$ \\
\hline $\begin{array}{l}5 \\
6\end{array}$ & $\begin{array}{l}\text { Inflation rate } \\
\text { Unemployment } \\
\text { rate } \\
\text { Interest rate }\end{array}$ & $\begin{array}{l}\text { Current macroeconomic } \\
\text { factors }\end{array}$ & $\begin{array}{l}\text { Current Rates for } \\
\text { each year studied }\end{array}$ & $\begin{array}{l}\text { Ashbaugh } \\
\text { et al. } \\
\text { (2006) }\end{array}$ & $\begin{array}{l}\text { Secondary - } \\
\text { SEC filings }\end{array}$ \\
\hline 8 & $\begin{array}{l}\text { Recession } \\
\text { Years }\end{array}$ & $2007-2009$ & $\begin{array}{l}\text { Dummy variable } \\
0 \text { - all years except } \\
2007-2009 \\
1 \text { - years 2007- } \\
2009\end{array}$ & $\begin{array}{l}\text { Allen } \\
\text { (2008) }\end{array}$ & $\begin{array}{l}\text { Secondary - } \\
\text { SEC filings }\end{array}$ \\
\hline 9 & $\begin{array}{l}\text { Organizational } \\
\text { Structure }\end{array}$ & $\begin{array}{l}\text { Whether or not the } \\
\text { company has a unitary } \\
\text { structure }\end{array}$ & $\begin{array}{l}\text { Dummy variable } \\
0-\text { CEO is not } \\
\text { Chairman of the } \\
\text { Board } \\
1 \text { - CEO is } \\
\text { Chairman of the } \\
\text { Board }\end{array}$ & $\begin{array}{l}\text { Albrecht } \\
\text { et al. } \\
\text { (2003) }\end{array}$ & $\begin{array}{l}\text { Secondary - } \\
\text { SEC filings }\end{array}$ \\
\hline 10 & $\begin{array}{l}\text { International } \\
\text { Sales Growth }\end{array}$ & $\begin{array}{l}\text { Percentage of total sales } \\
\text { that are a result of } \\
\text { international operations }\end{array}$ & $\begin{array}{l}\text { Average } \\
\text { International } \\
\text { Growth = Average } \\
\text { International } \\
\text { Sales/Total Sales }\end{array}$ & $\begin{array}{l}\text { Kim and } \\
\text { Gu } \\
\text { (2003) }\end{array}$ & $\begin{array}{l}\text { Secondary - } \\
\text { SEC filings }\end{array}$ \\
\hline
\end{tabular}




\begin{tabular}{|c|l|l|l|l|l|}
\hline$\#$ & \multicolumn{1}{|c|}{ Term } & Definition/Explanation & Formula/Denotion & Resource & Data Source \\
\hline $\mathbf{1 1}$ & $\begin{array}{l}\text { Stock } \\
\text { Compensation }\end{array}$ & $\begin{array}{l}\text { Substantial executive } \\
\text { compensation }\end{array}$ & $\begin{array}{l}\text { Substantial } \\
\text { compensation }= \\
\text { benchmarked PS } \\
\text { (ExecComp } \\
\text { Database) }\end{array}$ & $\begin{array}{l}\text { Doyle et } \\
\text { al. } \\
(2007 b) \\
\text { Li (2003) }\end{array}$ & $\begin{array}{l}\text { Secondary - } \\
\text { SEC filings } \\
\text { and } \\
\text { ExecComp } \\
\text { Database }\end{array}$ \\
\hline $\mathbf{1 2}$ & $\begin{array}{l}\text { Return on } \\
\text { Assets }\end{array}$ & $\begin{array}{l}\text { A measure of how } \\
\text { profitable a company is } \\
\text { relative to its total assets }\end{array}$ & $\begin{array}{l}\text { Average ROA }= \\
\text { average net } \\
\text { income/total assets }\end{array}$ & $\begin{array}{l}\text { Ge \& } \\
\text { McVay } \\
\text { (2005) }\end{array}$ & $\begin{array}{l}\text { Secondary - } \\
\text { SEC filings }\end{array}$ \\
\hline
\end{tabular}

First, as noted in the literature, the Sarbanes-Oxley Act required publicly traded companies and executives to make assessments about the effectiveness of companies' internal control systems by disclosing incidences of internal control deficiencies. Therefore, the effectiveness of the Sarbanes-Oxley Act in determining increased risk of fraud may be measured by the incidence of a reported internal control deficiency (Doyle, 2007b). This is measured as a dichotomous variable, 0 if a deficiency is not reported, and 1 is a deficiency is reported. This variable is at the heart of the study, with the goal of essentially determining the effectiveness of the Sarbanes-Oxley Act in impacting the increased risk of fraud in publicly traded restaurant companies.

Company size, as noted by Whittington (1980) and Ge \& McVay (2005) is often measured by gross profit margin, among many other measurements. In the framework of the fraud triangle and the pressure construct, the most relevant measure of size in this area is gross profit margin, since it is the most sensitive to displays of diminished earnings when compared to industry averages and year over year comparisons (Beneish, 1997; Beasley, 2000). Thus, it can be stated that publicly traded restaurant companies with diminished earnings over time are at an increased risk of fraud due to pressures resulting from evidence of financial instability. 
In the context of this study, gross profit margin at the company level will be benchmarked against the industry median in order to determine poor profit margin (indicating diminished earnings and therefore an increased risk of fraud) compared to good profit margin. As in many service oriented businesses, benchmarking is a usual practice designed to compare individual company performance results to applicable industry benchmarks (Pyo, 2002). Median is selected as the benchmark to surpass because of the behavioral inclination of restaurant companies to achieve performance measures that are superior to at least half of its competition. Amount of debt is most commonly measured in terms of financial leverage, which is considered to be a major risk for fraud in both accounting and finance literature. Companies with greater leverage usually bear a larger cost of capital and thus incur more risk (Ely, 1995). As noted, the financial leverage ratio is the most common indicator of debt, and was selected because it provides a means of comparing debt amounts across companies and the industry. The importance of this ratio is noted when considering that leverage also as an impact on the financial success of companies. Approximately $30 \%$ of new restaurant companies go bankrupt within the first year of operations due to bankruptcy and mismanagement of debt (Hua et. al, 2012). Similar to the size variable, the financial leverage ratio may be compared to industry medians for companies with similar market capitalizations, a common measure of grouping public traded companies.

Employee turnover may be related to poor performance and increased risk of fraud in situations where companies mandate workforce reduction or closing of restaurants in order to reduce costs. The most common measure of turnover is to calculate the turnover rate on an annual basis, through review of the number of separations occurring each year. This number can then be compared to industry medians, with those companies who have a higher turnover rate 
than the median may be associated with an increased risk of fraud. The median turnover rate for restaurant companies is approximately $47 \%$ and will be used as the basis for determining companies at an increased fraud risk (NRA, 2014).

International sales growth as a major part of business operations for publicly traded restaurant companies is associated with an increased risk of fraud due to uncertainty related to international ventures. The measurement for international sales is the total percentage of international sales benchmarked to the industry median. As international sales continue to grow, the industry median reflects an increase in the rate in recent years to approximately $15 \%$. Companies with a larger number of international sales are subject to high growth (greater than industry medians) and may therefore be associated with increased risk of fraud (Kim \& Gu, 2003).

As noted in the literature review, stock-based executive compensation is another variable that may provide rationalization for managers to commit fraud. Past research by Li (2003) measured this rationalization through sensitivity performance percentages (PS) calculated for companies' top five executives. Per Li (2003), PS is equal to price per share of stocks plus the sensitivity of stock options. PS of stocks is defined as "the amount of shares possessed by an executive as a fraction of total shares outstanding, and PS of stock options is defined as the number of shares in options granted to an executive multiplied by the Black-Scholes hedge ratio divided by total shares outstanding” (Li, 2003). Li (2003) founded the calculation of PS following Core and Guay (2002), Palia (2001), and Yermack (1995). Based on this work, this study will utilize PS as a measure of stock-based executive compensation, utilizing unhindered stocks and options that have vested in place of all the options and stocks owned by an executive. This gives a complete measure of PS for short-term stock-based incentives, which is more 
precise than using all levels of stock and options ( $\mathrm{Li}, 2003)$. The reason for this is because fraud risk is a comparatively short-term occurrence and in order to profit from it, executives must be able to sell shares or exercise options in a defined period (Doyle, 2007b). The amounts of PS will be obtained from the ExecComp database, which tracks these amounts for publicly traded companies. Amounts that are higher than the industry median may be associated with increased risk of fraud (Li, 2003).

Return on assets is the most commonly used measure for restaurant operations to measure performance, and estimates a companies' efficient use of assets to produce profit (e.g. He et al., 2010; Schmidgall, 2006). One prevalent proxy for return on assets is Tobin's Q, however, this measure is not implemented in the current study due to the possible problem with endogeneity. Evidence shows that investment changes may reduce company performance yet grow Tobin’s Q, and Tobin’s Q is sensitive to changes as asset efficiency gets better (Dybvig \& Warachka, 2010; Hua et al. 2012). The rate of profit, or net income divided by total assets, still reigns as the fundamental ratio to forecast performance as compared to Tobin’s Q (Oliver et al., 1993) and, therefore, is the unit of measurement in this study. Additionally, as noted for the other variables, median is selected as the benchmark to surpass because of the behavioral propensity of companies to desire an ROA superior to at least half of its competition (Hua et al., 2012).

The variables of organizational structure and the Recession will be measured through the use of dummy variables $(0,1)$ while the macroeconomic factors such as the rates of interest unemployment, and inflation will apply the current rates for each year studied. In the case of organizational structure, Beasley (1996) and Li (2003) linked the CEO’s role to increased risk of fraud when the CEO is also the Chairman of the Board. Therefore, this variable is coded as a 0 when the CEO is not also Chairman of the Board and a 1 when the CEO is also the Chairman of 
the Board. Additionally, the Recession will be coded as a 1 for the years of 2007, 2008, and 2009, since these coincide with this major economic event in the United States. Controlling for the Recessionary time period is necessary as the restaurant industry experienced the most sensitivity to changes in economic conditions during this time period (Allen, 2008). The other variables are used to control for other macroeconomic factors that may impact increased risk of fraud because of the opportunities and pressures that may develop from changes in the rates of interest, inflation and unemployment.

Based on the model presented, expectations regarding the outcome of the study are based on review of past studies in this area. Within the restaurant industry, most of these expectations are driven by results of studies on financial performance of restaurants (Camillo et al., 2008). Since it follows that poor financial performance is often associated with an increased risk of fraud, expectations regarding such financial measures follow suit. First, it is estimated that company size, as measured by gross profit margin, may result in increased fraud risk for those companies that fall below the median gross profit margin of the industry as a whole because of the pressure that results from diminished earnings. Size is therefore expected to indicate a statistically significant influence on increased risk of fraud. Additionally, high amounts of debt for companies may also signal increased risk of fraud. Those companies with a leverage ratio higher than the median leverage ratio of the industry may indicate a statistically significant effect on increased risk of fraud. Employee turnover, while an important indicator of work force reduction, is also a main characteristic of the restaurant industry. This factor alone may not create a significant impact on increased risk of fraud. Therefore, it is estimated that the relationship between companies that have a turnover rate higher than $47 \%$ may not have a statistically significant influence on increased risk of fraud. 
Also, the relationship between international sales growth and increased fraud risk may not be statistically significant. Most companies include a platform of growth in business plans, and simply the incidence of expanding may not provide enough of a platform to indicate significant fraud risk. While past studies have determined increased sales growth as possible fraud indicators because of the uncertainty associated with political and financial pressures, the expectation is that the impact won't be significant. Another variable proposed in the model is executive stock based compensation. Performance sensitivity of the stock options available to executives is anticipated to have a significant effect on increased risk of fraud because of the inherent rationalization to create shareholder value through stock price. Executives from companies whose compensation is tied significantly to stock compensation (greater than half of the industry median) are expected to relate significantly to increased fraud risk.

It is further anticipated that companies with fluctuating return on assets are at an increased risk of fraud because of the strong ties to potential misappropriation of assets. Fluctuating ROAs as measured year over year by net income/total assets are expected to be indicative of increased fraud risk for companies with ratios greater than the median average fluctuation, year over year. This relationship is expected to be statistically significant. Finally, the dummy variables presented for organizational structure, the Recession, and the current rates for the macroeconomic factors are expected to have a substantial impact on increased risk of fraud because of the inherent pressures that each of these conditions stem from. Controlling for each of these variables is expected to present a statistically significant relationship providing for increased risk of fraud, when considering the Sarbanes-Oxley Act. In summary, it is expected that the probit model will reveal a significant impact on increased risk of fraud when controlling 
for size, amount of debt, stock compensation, return on assets, organizational structure, the Recession and other macroeconomic factors.

\section{Population and Sample of Study}

The study will adopt an exploratory research design using the case of publicly traded United States restaurant companies in order to provide a better understanding of the characteristics that may contribute to increased fraud risk for publicly traded companies. The population for this study will include all United States publicly traded restaurant companies that fall under the Securities and Exchange Commission coding of "Food and Beverage". Since Section 302 of the Sarbanes-Oxley Act became operational for all reports covering all available and normal reporting time periods that end after August 29, 2002, the sample time frame for this study will be from August 2002 to April 2014, with data pulled from the annual reports. The sample for this study will be obtained from the following sources: (1) EDGAR, the SEC's database of all electronic filings, through which a dataset of publicly traded restaurant companies 10-K filings will be obtained, which will then identify companies that have received a noted and reported internal control deficiency; and (2) Compliance Week, which includes a repository of disclosures pertaining to internal control deficiencies from all SEC filings belonging to the restaurant industry, in order to cross check the sample. The sampling unit will be the total population of publicly traded U.S. restaurant companies. The study will also use the median as the primary measure of company characteristics and performance, as stipulated by the variables in the model, compared to the industry. Academically, the median is not biased by extreme values; therefore, it offers a superior central measure compared to the mean of companies in the restaurant industry (Enz et al., 2001). Additionally, the study will not look at ways to segment 
the data because the qualifying factor of the median will suffice for segmentation compared the industry performance. The use of the median instead of the mean, for example, prevents undue skewness of the data and allows for meaningful comparisons to the industry (Baggio \& Klobas, 2001). Furthermore, the data relates to public company information that contains original details that have not been summarized, totaled or averaged. This provides a means of combatting Simpsons Paradox, a common pitfall resulting from the use of secondary data (Baggio \& Klobas, 2001). Simpsons Paradox states that since secondary data is often pre-processed, that relationships observed from data at the aggregate level are not necessarily the same as relationships observed at the level from which the data was aggregated (Simon, 1997).

This study derives a procedural thought development from the field of computer science, known as reverse engineering (Forte, 1992; Breuer, \& Lano, 1991; \& Chikofsky \& Cross, 1990). By explanation, reverse engineering involves the examination of a company system in order to best ascertain the system's mechanisms and relationships, and to create depictions of the system in another arrangement or at a developed level of perception (Chikofsky \& Cross, 1990). In this study, the subject system is internal control systems for publicly traded restaurant companies. The evaluation of the effectiveness and efficiency of an internal control system can be assessed through the understanding of company reported internal control activities' deficiencies, which when present in the aggregate, as demonstrated through the literature, may provide for an understanding of increased risk of fraud.

Since the research questions related to this study are first concerned with understanding the effect of the Sarbanes-Oxley Act through incidences of increased fraud risk, the data is coded for a 0 or a 1 to account for the existence of a reported internal control deficiency during the time period from August 2002-April 2014. Additionally, the assessment of the restaurant industry 
and company characteristics provided in the literature review produced key variables as potential indicators of increased fraud risk. Each of the other variables will be coded and the empirical relationship between the identified variable and the increased risk of fraud will be assessed. The variables are used to control for any confounding effects, thus focusing on the impact of the Sarbanes-Oxley Act on showcasing increased fraud risk for the companies. Therefore, it is noted that the study aims to provide a model of industry and company characteristics that may indicate increased risk of fraud, under provisions set forth by the Sarbanes Oxley Act.

\section{Data Collection}

The data collected from the population and sample described above will be obtained from secondary sources, and yields 54 publicly traded companies in the SEC's Standard Industry Code for "Food and Beverage" of 5812. Of these 54 publicly traded companies, 40 have been publicly traded during the years 2004-2014 and will comprise the total sample size. Since this study is looking to offer empirical results on determinants of increased fraud risk, this can be considered an event study, which has been used historically to quantify the effect of companies’ characteristics and activities on their market value. Prior literature contains excellent summaries of the use of the event studies method through the complementary finance theory (e.g., Srinivasan \& Bharadwaj 2004), which proclaims that a stock price reveals all the public evidence about a company, so only unexpected events or actions can modify the price of the stock (Fama et al. 1969), which may have an impact on increased fraud risk through common financial variables, as noted in the described literature review. Thus, if new information (i.e., macroeconomic factors or other performance indicators) affects investors such that they anticipate that the company will secure higher (lower) impending cash flows, the company's 
stock price increases (decreases) in response (Kim \& Gu, 2003). The data will show this phenomenon over time for the U.S. publicly traded restaurant companies in this study through the selection of independent variable measurements as previously described.

\section{Chapter Summary}

Chapter 3 describes the methods that will be utilized to answer the proposed research questions and hypotheses relating to understanding determinants of increased fraud risk for U.S. publicly traded restaurant companies, focusing primarily on the Sarbanes-Oxley Act and its role in effectively providing information relating to the probability of increased fraud risk through the incidence of reported internal control deficiencies. The research design presented is a probit model, selected primarily because the dependent variable is dichotomous - code as a 0 or 1 to illustrate increased fraud risk or not. The data will be collected from annual filing reports of publicly traded restaurant companies (secondary data source), providing information on variables that relate to the fraud triangle theoretical framework and the restaurant industry characteristics deemed most conducive to increased fraud risk. The data will be assessed for meaningful comparisons against restaurant industry medians - as medians are theoretically not subject to extreme distortions like arithmetic means. Chapter four will provide the results of the regression of the selected independent variables on the dichotomous dependent variable in order to provide insight regarding probability of increased fraud risk when considering certain factors. 


\section{CHAPTER 4: RESULTS}

\section{Introduction}

The following chapter provides the results to the proposed hypotheses revealed in Chapter 3 in order to determine the probability of increased fraud risk when considering the Sarbanes-Oxley Act and various factors. The chapter will first provide a description of the data. Then, the chapter proceeds to overview the descriptive statistics. Next, treatment of the data and methods of analyses for testing the hypotheses are provided with the related results. Finally, the chapter concludes with a brief summary of the results.

\section{$\underline{\text { Data Description }}$}

This study seeks to estimate the probability of increased risk of fraud as a result of deficiencies reported for publicly reported restaurant companies and controlling for specific industry and company characteristics or factors. The data is comprised of yearly time series data from 2004-2013, or a period of 10 years for 40 companies, across 12 variables, providing a complete data set of 4,800 data points. The dataset is therefore considered to be panel, also known as longitudinal or cross-sectional time series, and thus accounts for the individual heterogeneity of 40 publicly traded United States restaurant companies. As a panel data set, the data is strongly balanced, which means that each panel contains the same time points (Stata, 2012).

The variables utilized in this study are derived from the fraud triangle and include company size, amount of debt, employee turnover, organizational structure, the Recession, inflation rate, interest rate, executive stock compensation, return on assets, and international sales growth. The main premise of the fraud triangle is that pressure/incentive, opportunity and 
rationalization contribute to increased risk of fraud by management. In fact, the fraud triangle suggests that these three factors are present in every situation of fraud. Each of the variables presented in the model relates to these factors of the fraud triangle and have been defined, measured and justified through the literature review. The description of each variable is summarized in Table 5. Per review of Table 5, it is noted that the majority of the variables are continuous in nature and are ratios. Company size is also continuous, but this variable is in millions of dollars instead of a percent. For purposes of analysis, this variable will be transformed to its logged function in order to ensure that the data meets the assumptions of the statistical tests of the probit model. Company size varies due to different company market capitalizations, and taking the logarithmic values will reduce wide-ranging quantities to smaller scopes, enabling better understanding of the data patterns (Oswald, 1997).

The other independent variables, Recession and Organizational Structure, are categorical dummy variables and are coded as 0 or 1 . As defined in literature following the National Bureau of Economic Research, Recession years of 2007-2009 are coded as 1, with the rest of the years coded as 0 . Organizational structure is coded as 0 if the CEO is not also the Chairman of the Board, and 1 if the CEO is Chairman of the Board. Finally, the inflation rate, interest rate, and unemployment rate are continuous variables and are provided at the current rates for each year in the time series. 
Table 5: Description of Variables

\begin{tabular}{|c|c|c|c|}
\hline Variable & Symbol & Range & $\begin{array}{r}\text { Value } \\
\end{array}$ \\
\hline \multirow[t]{2}{*}{ Deficiency } & $\mathrm{DE}$ & $0-1$ & 0 = no deficiency noted; \\
\hline & & & 1 = deficiency noted \\
\hline Company Size & $\mathrm{SZ}$ & 0 - $\$ 344$ billion & Continuous \\
\hline Amount of Debt & DEBT & $0-100 \%$ & Continuous \\
\hline Employee Turnover & ET & $0-100 \%$ & Continuous \\
\hline Inflation rate & IR & $0-100 \%$ & Continuous \\
\hline Unemployment rate & UR & $0-100 \%$ & Continuous \\
\hline Interest rate & IRT & $0-100 \%$ & Continuous \\
\hline \multirow[t]{2}{*}{ Recession years } & $\mathrm{R}$ & $0-1$ & $0=$ not a Recession year; \\
\hline & & & $1=$ Recession year \\
\hline \multirow[t]{2}{*}{ Org. Structure } & ORG & $0-1$ & $0=\mathrm{CEO}$ is not Chairman of the Board \\
\hline & & & $1=\mathrm{CEO}$ is Chairman of the Board \\
\hline Intl. Sales Growth & INT & $0-100 \%$ & Continuous \\
\hline Stock Comp. & STOCK & $0-100 \%$ & Continuous \\
\hline Return on Assets & ROA & $0-100 \%$ & Continuous \\
\hline
\end{tabular}

\section{Descriptive Statistics Overview}

Based on the discussion outlined in chapter three, the frequency of the data is examined for outliers and trends among and across variables and time. Table 6 details the overall frequency of noted deficiencies for all identified companies (entities). It appears that overall, publicly traded restaurant companies in the dataset had more instances of zero reported deficiencies as compared to reported deficiencies, at $56.25 \%$ and $43.75 \%$, respectively. According to the Public Company Accounting Oversight Board (2014), these reported percentages are appropriate for the restaurant industry as a whole because many deficiencies are resolved in subsequent years and filings, indicating that it may be more prevalent to not have any deficiencies reported in a single year. Further, these percentages provide support for the problem of deficiencies occurring in the first place (close to $45 \%$ in a 10 year period), which has been 
demonstrated through the described problem statement in Chapter 1. Overall, the incident of a reported deficiency for any company in any given year is expected to be close to $50 \%$, based on review of past audit files (PCAOB, 2014).

Additionally, the cross-sectional data provides information regarding the descriptive statistics for overall reporting, including "between” and "within” statistics for each company in Table 6. Because the data is cross-sectional time series, the incidence of a reported deficiency may be assessed "between” each company over time, (e.g., Darden and Brinker International) and also “within” each company over time (e.g., Darden’s evolution of a reported deficiency or no reported deficiency over time). In terms of deficiencies, the percentages of deficiencies reported as compared to no deficiencies reported within each company is the same as the overall frequencies reported for each category. This is because the data set does not distinguish between how many deficiencies were reported each year, rather, the data simply reports whether there was a deficiency noted at all. Therefore, these statistics aren't meaningful to the overall research and are thus removed from analysis. Additionally, there has been both an incidence of a reported deficiency and an incidence of no reported deficiencies reported 100\% of the time between each company.

Table 6: Total Frequency of Deficiencies

\begin{tabular}{|c|c|c|c|c|}
\hline Variable & \multicolumn{2}{|c|}{ Overall } & \multicolumn{2}{c|}{ Between } \\
\hline Deficiency Noted & Freq. & Percent & Freq. & Percent \\
\hline 0 & 225 & 56.25 & 40 & 100 \\
\hline 1 & 175 & 43.75 & 40 & 100 \\
\hline Total & 400 & 100 & 80 & 200 \\
\hline & & & & \\
\hline & $(\mathbf{n}=\mathbf{4 0})$ \\
\hline
\end{tabular}


Table 7 and Figure 3 provide more details regarding whether or not a deficiency was reported for the total number of companies (forty) by year. Based on these reported statistics, it appears that the first year of required Sarbanes-Oxley compliance (2004) yielded the highest amount of companies with a reported deficiency (approximately 75\%). Additionally, it is interesting to note that in Recession years (2007-2009) there were variations in the total number of deficiencies reported. For example, 2007 had more instances of zero reported deficiencies, while 2008 reported increases in reported deficiencies and 2009 reported a decrease in deficiencies relative to the previous year. This might be explained by the effects of the Recession for publicly traded companies. For instance, although the Recession began in 2007, it didn’t technically begin until late 2007 (according to the National Bureau of Economic Research). Therefore, it is reasonable to expect that 2007 would have less incidences of a reported deficiency, according to the proposed hypothesis. Additionally, the increase in incidences of reported deficiencies in 2008 indicates that the companies are feeling the effects of the Recession through an incident of a reported deficiency, as noted in literature. However, the decrease in incidences of reported deficiencies in 2009 infers that the power of the Recession may have declined for publicly traded restaurant companies. This could have implications on the model and the proposed hypothesis relating to this variable. For example, the decline of the reported incidences of deficiencies in 2009 may indicate no significance on the incidence of a reported deficiency overall, which may lead to a rejection of the null hypothesis. Likewise, the rise in an incident of a reported deficiency in 2008 may offset the reduction in 2009, which may support the hypothesis overall.

Further relevant and interesting information includes the year in which the least amount of companies that reported a deficiency, which was in 2010 (the first year after the Recession). 
Likewise, it appears that 2011 had a tremendous spike in the incidence of a reported deficiency. Per review of the PCAOB " 4010 ” report, it is noted that the Board was concerned about the increase in the rate of reported deficiencies between 2010 and 2011. The report summarized inspection findings at a high level and did not identify particular companies or audits, however, it did identify a $22 \%$ increase in deficiencies and a root cause that related to overall control environment concerns (PCAOB, 2010). The spike of a reported deficiency in 2004 and 2011 may further be explained through company financial variables as defined in this study. Figure 3 also reveals a unique pattern among the companies. It appears that the population of restaurant companies are split according to whether or not a deficiency was reported year over year, as well as an observed cyclical pattern of a reported deficiency over time.

Table 7: Frequency of Deficiency, by Year

\begin{tabular}{|c|c|c|c|c|}
\hline & \multicolumn{3}{|c|}{ Deficiency Noted } & \\
\hline Year & $\mathbf{0}$ & $\mathbf{1}$ & Total \\
\hline 2004 & 10 & 30 & 40 \\
\hline 2005 & 25 & 15 & 40 \\
\hline 2006 & 26 & 14 & 40 \\
\hline 2007 & 28 & 12 & 40 \\
\hline 2008 & 17 & 23 & 40 \\
\hline 2009 & 23 & 17 & 40 \\
\hline 2010 & 29 & 11 & 40 \\
\hline 2011 & 15 & 25 & 40 \\
\hline 2012 & 25 & & 15 & 40 \\
\hline$\underline{2013}$ & $\underline{27}$ & & $\underline{13}$ & $\underline{40}$ \\
\hline Total & $\mathbf{2 2 5}$ & & $\mathbf{1 7 5}$ & $\mathbf{4 0 0}$ \\
\hline
\end{tabular}




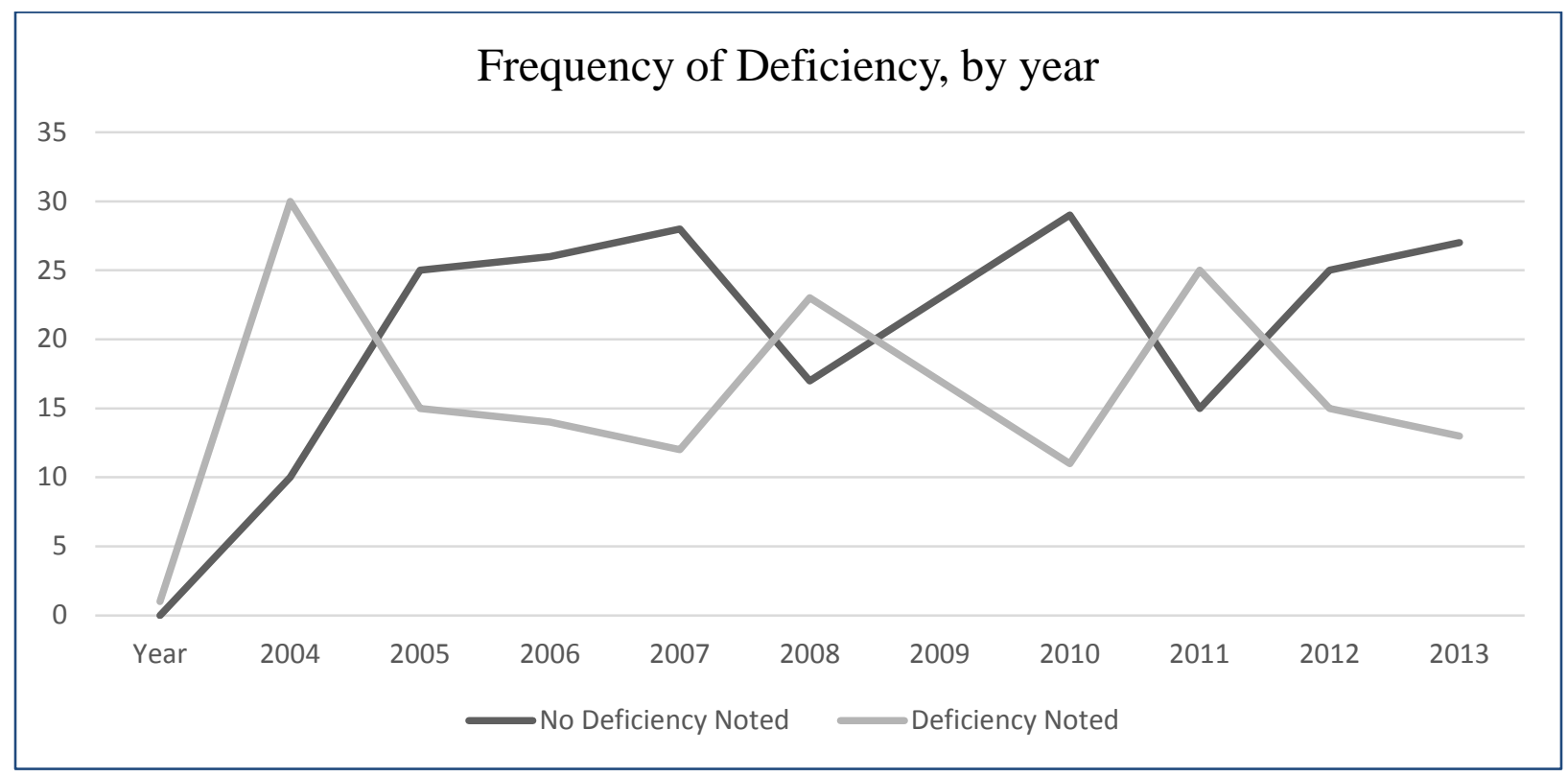

Figure 3: Frequency of Deficiency

In addition to descriptive frequency statistics for the binary dependent variable, additional interesting measures include the means, medians and standard deviations of the continuous independent variables (company size, debt, employee turnover, international sales growth, interest rate, inflation rate, unemployment rate, international sales growth, stock compensation and return on assets), including overall, between and within statistics. Table 8 reports these values, noting that mean numbers are percentages in decimal format. Reported standard errors are also included, which indicates how close the sample mean is from the true population mean (Aldrich \& Nelson, 1984). The median is also reported and is the central tendency value that is of most interest to this study, as the median is most often utilized to benchmark performance of companies compared to others within the same industry (Enz et. al, 2001). This will become useful in order to segregate companies to extrapolate conclusions relating to companies that meet certain criterion (Pyo, 2002). 
The median values reported are useful determinants of benchmarked performance against the industry as a whole. For example, based on the summary table, companies with a gross margin lower than 18.675 million dollars may demonstrate diminished earnings and therefore be at an increased risk of fraud since their margins are less than the industry average. This is the same benchmarking process with return on assets (median 5\%). Other financial measures such as debt, as measured by the financial leverage ratio (median 36\%), and international sales growth rate (median 9\%) may demonstrate increased risk of fraud when the amounts are higher than the industry medians. Additionally, benchmarked employee turnover indicates that companies with rates higher than $47 \%$, according to the dataset, may be at an increased risk of fraud. Finally, executive stock compensation performance sensitivity indicates that companies with amounts greater than $53 \%$ are also at an increased risk of fraud. The remaining continuous variables, (unemployment rate, interest rate and inflation rate) are macroeconomic factors that may provide additional insight regarding increased risk of fraud when considered in the proposed model. For example, it is noted that these variables are always mentioned in "Management's Discussion and Analysis” of key risk factors to the organization. Most notably, changes in these factors are usually linked to poor performance due to the impact on the business generally (Chathoth \& Olsen, 2007). As the data set reveals, several companies had declining performance during recession years as a result of a decline of overall industry performance during this time. Coupled with this decline in performance, it will further be interesting to learn whether or not these factors also have an impact on increased risk of fraud through reported incidences of deficiencies.

It's also interesting to note the standard deviations reported between each company. A large standard deviation means that the data includes a wide range of values, which makes sense 
given that the company information is comprised of several sub-sets of the industry, including fast food, fast casual, casual dining and fine dining establishments. Upon review of the data, this is particularly noticeable for company size, which includes a range of values from $\$ 0$-344 billion. The standard deviation is 39 , suggesting that a wide distribution of values that may be subject to distortion within the model. This may provide additional insight regarding the results of the probit model and may suggest that separating the companies by restaurant segment could provide more meaningful interpretation regarding the increased likelihood of fraud risk.

Additionally, "within” company data reveals relatively small standard deviations for the companies for all variables except for company size. The reported standard deviation is 25 , noting that size varies even within the same company, for all 40 companies. This further illustrates the wide distribution of values within this variable, across ten years. Debt also has a slightly larger standard deviation within a company, which could signify changes in capital structure over time due to growth or sales of properties. These changes within company structure may provide for an impact on reported deficiencies, which may be revealed through the probit model. 
Table 8: Summary Statistics of the Continuous Independent Variables

\begin{tabular}{|c|c|c|c|c|c|c|c|c|}
\hline Variable & & Mean & Median & Std. Dev. & Min & Max & & Observations \\
\hline \multirow[t]{3}{*}{ Company Size (in millions) } & Overall & 30.96491 & 18.675 & 46.63558 & 0.2 & 344 & $\mathrm{~N}=$ & 400 \\
\hline & Between & & & 39.40221 & 0.67007 & 213.7 & $\mathrm{n}=$ & 40 \\
\hline & Within & & & 25.63908 & -92.73509 & 231.2539 & $\mathrm{~T}=$ & 10 \\
\hline \multirow[t]{3}{*}{ Debt } & Overall & 0.5320771 & 0.36 & 2.457982 & 0.0000958 & .99 & $\mathrm{~N}=$ & 400 \\
\hline & Between & & & 0.7640328 & 0.0742273 & 5.04987 & $\mathrm{n}=$ & 40 \\
\hline & Within & & & 2.339037 & -4.514988 & 44.75221 & $\mathrm{~T}=$ & 10 \\
\hline \multirow[t]{3}{*}{ Employee Turnover } & Overall & 0.45905 & 0.47 & 0.064432 & 0.31 & 0.69 & $\mathrm{~N}=$ & 400 \\
\hline & Between & & & 0.0460429 & 0.39 & 0.581 & $\mathrm{n}=$ & 40 \\
\hline & Within & & & 0.0455999 & 0.29805 & 0.58805 & $\mathrm{~T}=$ & 10 \\
\hline \multirow[t]{3}{*}{ International Sales Growth } & Overall & 0.096843 & 0.09 & 0.0708079 & 0.0006416 & 0.5 & $\mathrm{~N}=$ & 400 \\
\hline & Between & & & 0.0306305 & 0.0373496 & 0.1524057 & $\mathrm{n}=$ & 40 \\
\hline & Within & & & 0.0640055 & -0.0431907 & 0.5003888 & $\mathrm{~T}=$ & 10 \\
\hline \multirow[t]{3}{*}{ Stock Compensation } & Overall & 0.6028794 & 0.536045 & 0.4079493 & 0.0761148 & 3.0028 & $\mathrm{~N}=$ & 400 \\
\hline & Between & & & 0.1125224 & 0.3942543 & 0.9147424 & $\mathrm{n}=$ & 40 \\
\hline & Within & & & 0.3924881 & -0.1486567 & 2.774833 & $\mathrm{~T}=$ & 10 \\
\hline \multirow[t]{3}{*}{ Return on Assets } & Overall & 0.0593969 & 0.05 & 0.0463734 & 0.0007153 & 0.4047619 & $\mathrm{~N}=$ & 400 \\
\hline & between & & & 0.0205396 & 0.0297659 & 0.1291816 & $\mathrm{n}=$ & 40 \\
\hline & within & & & 0.041691 & -0.0343451 & 0.3608891 & $\mathrm{~T}=$ & 10 \\
\hline \multirow[t]{3}{*}{ Interest Rate } & overall & 0.0198 & 0.0185 & 0.0055711 & 0.013 & 0.031 & $\mathrm{~N}=$ & 400 \\
\hline & between & & & 0 & 0.0198 & 0.0198 & $\mathrm{n}=$ & 40 \\
\hline & within & & & 0.0055711 & 0.013 & 0.031 & $\mathrm{~T}=$ & 10 \\
\hline \multirow[t]{3}{*}{ Inflation Rate } & overall & 0.0238 & 0.026 & 0.0112194 & 0.001 & 0.041 & $\mathrm{~N}=$ & 400 \\
\hline & between & & & 0 & 0.0238 & 0.0238 & $\mathrm{n}=$ & 40 \\
\hline & within & & & 0.0112194 & 0.001 & 0.041 & $\mathrm{~T}=$ & 10 \\
\hline \multirow[t]{3}{*}{ Unemployment Rate } & overall & 0.06892 & 0.06575 & 0.018904 & 0.0461 & 0.0963 & $\mathrm{~N}=$ & 400 \\
\hline & between & & & 0 & 0.06892 & 0.06892 & $\mathrm{n}=$ & 40 \\
\hline & within & & & 0.018904 & 0.0461 & 0.0963 & $\mathrm{~T}=$ & 10 \\
\hline
\end{tabular}


Additional descriptive statistics of interest include the summary statistics of the two categorical independent variables, the Recession and Organizational Structure. Table 9 summarizes this information. The Recession data is straightforward in that only $30 \%$ of the years studied were coded as recessionary, while Organizational Structure reveals that most companies in the restaurant sector do not have a CEO that is also the Chairman of the Board.

Table 9: Summary Statistics of the Categorical Independent Variables

\begin{tabular}{|c|c|c|c|c|}
\hline Variable & \multicolumn{2}{|c|}{ Overall } & \multicolumn{2}{c|}{ Between } \\
\hline Recession & Freq. & Percent & Freq. & Percent \\
\hline 0 & 280 & 70 & 40 & 100 \\
\hline 1 & 120 & 30 & 40 & 100 \\
\hline Total & 400 & 100 & 80 & 200 \\
\hline & \multicolumn{2}{|c|}{$\mathbf{( n = 4 0 )}$} & \\
\hline & \multicolumn{4}{|l|}{} \\
\hline
\end{tabular}

\begin{tabular}{|c|c|c|c|c|}
\hline Variable & \multicolumn{2}{|c|}{ Overall } & \multicolumn{2}{c|}{ Between } \\
\hline Organizational Structure & Freq. & Percent & Freq. & Percent \\
\hline 0 & 278 & 69.5 & 36 & 90 \\
\hline 1 & 122 & 30.5 & 17 & 42.5 \\
\hline Total & 400 & 100 & 53 & 132.5 \\
\hline & \multicolumn{2}{|c|}{$(\mathbf{n}=\mathbf{4 0 )}$} & \\
\hline
\end{tabular}

Observing the independent categorical variables together with the dependent variable also provides trends and frequencies of occurrence that may be useful. Table 10 demonstrates that for both variables that there are more cases of zero deficiencies noted when the company is not in a Recessionary time period and when the CEO is not also the Chairman of the Board. Additionally, there are more cases noted of a reported deficiency when in a Recessionary time period then when the CEO is also the Chairman of the Board. This may be indicative of the 
significance of the variables in the model. Finally, it should be noted that there are the least amount of cases when a deficiency is reported and the CEO is also the Chairman of the Board.

Table 10: Summary Statistics of the Independent Categorical Variables and the Categorical Dependent Variable

\begin{tabular}{|c|c|c|r|}
\hline Variable & & \\
\hline Deficiency Noted & \multicolumn{2}{|c|}{ Recession } & Total \\
\hline & $\mathbf{0}$ & $\mathbf{1}$ & 225 \\
\hline $\mathbf{0}$ & 157 & 68 & 175 \\
\hline $\mathbf{1}$ & 123 & 52 & 400 \\
\hline
\end{tabular}

\begin{tabular}{|c|c|c|r|}
\hline Variable & \multicolumn{2}{|c|}{ Org. Structure } & Total \\
\hline Deficiency Noted & $\mathbf{0}$ & $\mathbf{1}$ & 225 \\
\hline $\mathbf{0}$ & 152 & 73 & 175 \\
\hline $\mathbf{1}$ & 126 & 49 & 400 \\
\hline Total & 278 & 122 & \\
\hline
\end{tabular}

\section{Assumptions and Methods of Analyses}

As noted, this study assumes that the dependent random variable $\mathrm{Y}$ is binary, taking on but two values, 0 and 1 . The outcomes on $\mathrm{Y}$ are assumed to be mutually exclusive and exhaustive. For purposes of this study, the question of interest hinges on the value of the parameter $\mathrm{P}$, the probability that $\mathrm{Y}$ equals one (or $\mathrm{P}=\mathrm{P}(\mathrm{Y}=1)$ ). $\mathrm{Y}$ is assumed to depend on $\mathrm{K}$ observable variables $X_{k}, k=1 \ldots . ., K$. That is, it is assumed that the exogenous variables, account for the variation in $\mathrm{P}$. This relationship is indicated by writing $\mathrm{P}=\mathrm{P}\left(\mathrm{Y}=1 \mid \mathrm{X}_{1}, \ldots, \mathrm{X}_{\mathrm{k}}\right)$, or simply $\mathrm{P}=\mathrm{P}(\mathrm{Y} \mid \mathrm{X})$, where $\mathrm{X}$ denotes the set of $\mathrm{K}$ independent variables. This assumption is analogous to the standard regression model in which the exogenous variables account for the variation in the mean, or expectation, of $\mathrm{Y}$. 
Since the data is considered to be a micro-panel (few years and a large number of cases), cross-sectional dependence is not of concern and does not need to be tested. However, tests of overall bivariate normality should still be considered. The Doornik-Hansen (DH) test for bivariate normality (Doornik \& Hansen 2008) is based on the skewness and kurtosis of data that is transformed to insure independence (Beck et al., 2002). The DH test is preferred over the Shapiro-Wilk test because of the power and less stringent requirements (Doornik \& Hansen 2008). The null hypothesis is that the variables K are normally distributed. However, it's important to note that this does not speak to the errors of the probit model test which are nonnormal by nature, as discussed in Chapter 3 (D’Agostino, 1970). Table 11 reveals the results of this test to be greater than the p-value of .05, therefore, the null hypothesis cannot be rejected and it can be said that the variables are normally distributed.

Table 11: Test for Bivariate Normality

\begin{tabular}{|c|c|c|c|}
\hline Variable & Chi2 & df & Prob $>$ Chi2 \\
\hline Deficiency Noted Model & 1.39 & 7 & 0.6352 \\
\hline
\end{tabular}

\section{Unit Root}

The next step involves testing the continuous data points for the existence of a unit root. Specifically, the unit root test determines if the variables are stationary I(0), or if they are nonstationary I(1). Data points are often non-stationary, or have means, variances and co-variances that change over time (Kwiatkowski et al., 1991). Non-stationary behaviors can be trends, cycles, random walks or a combination of the three. Non-stationary data results may be spurious in that they may indicate a relationship between variables that does not really exist (Levin \& Lin, 
1992). Therefore, in order to receive consistent and reliable results, the data needs to be tested for stationarity, or for the presence of a unit root. In general, the null hypothesis for time series panel data is that the data is non-stationary, or contains a unit root. In order to test the data for the presence of a unit root, the variables are first tested in level form.

For each of the continuous variables, the Levin-Lin-Chu (LLC) unit root test is applied since it is most appropriate for longitudinal/panel data (Hoechle, 2007). After testing each of the variables in level form without a trend, the LLC indicated that all of the continuous variables except Debt and the Interest Rate are stationary (they do not contain a unit root). The null hypothesis for each of these is rejected. However, for Debt and Interest Rate, the null hypothesis could not be rejected. Therefore, the next step is to test the data in level form with a trend in order to observe all time-specific (or "macro") variation that may exist in the cross-sectional time series data. Use of this linear time trend constrains the time effect coefficients to lie on a straight line, making the data trend stationary (Diebold \& Kilian, 1997). Each of the continuous variables have been plotted to illustrate the trend stationary data, see Figures $4-12$. 


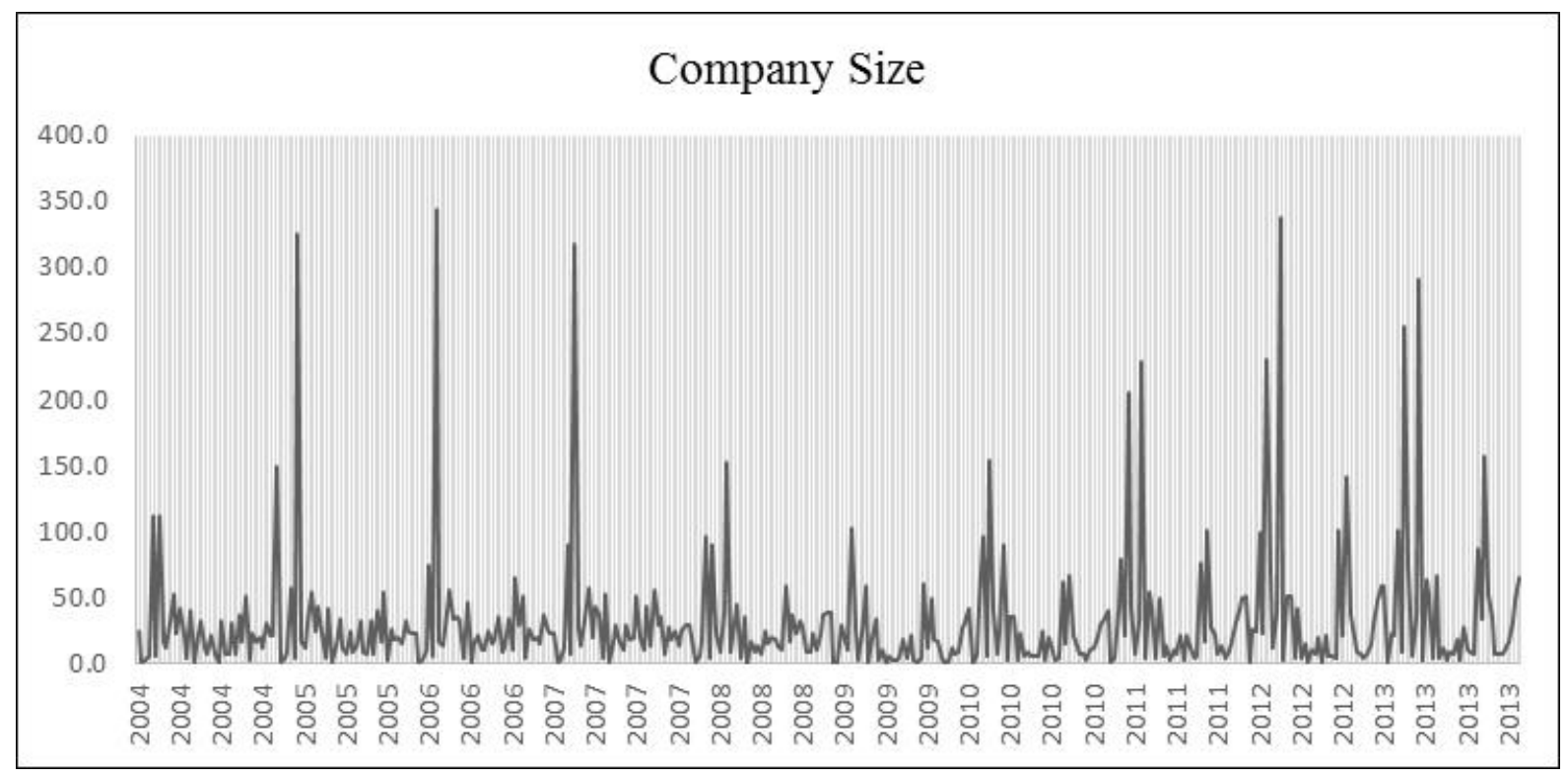

Figure 4: Company Size Trend

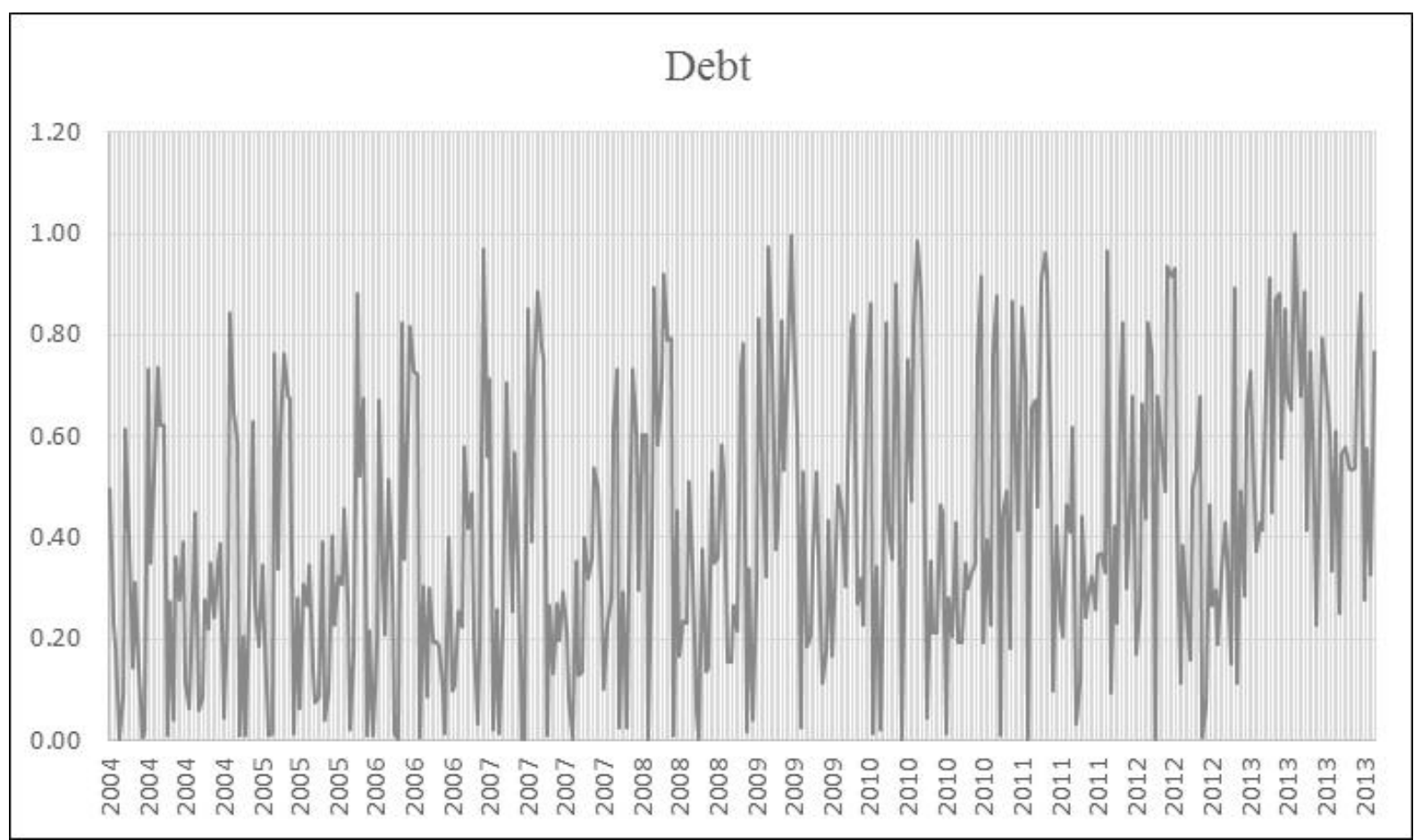

Figure 5: Debt Trend 


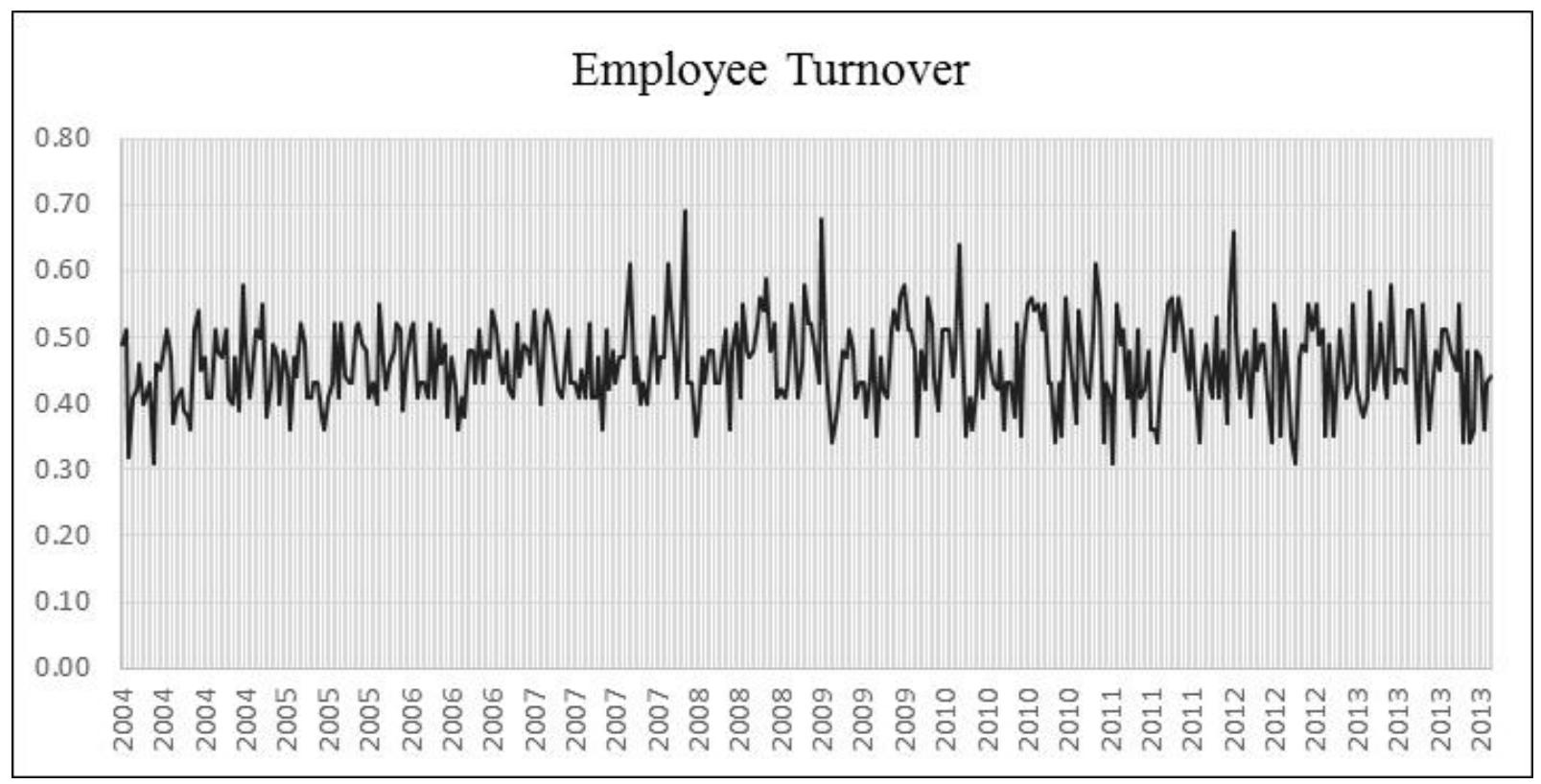

Figure 6: Employee Turnover Trend

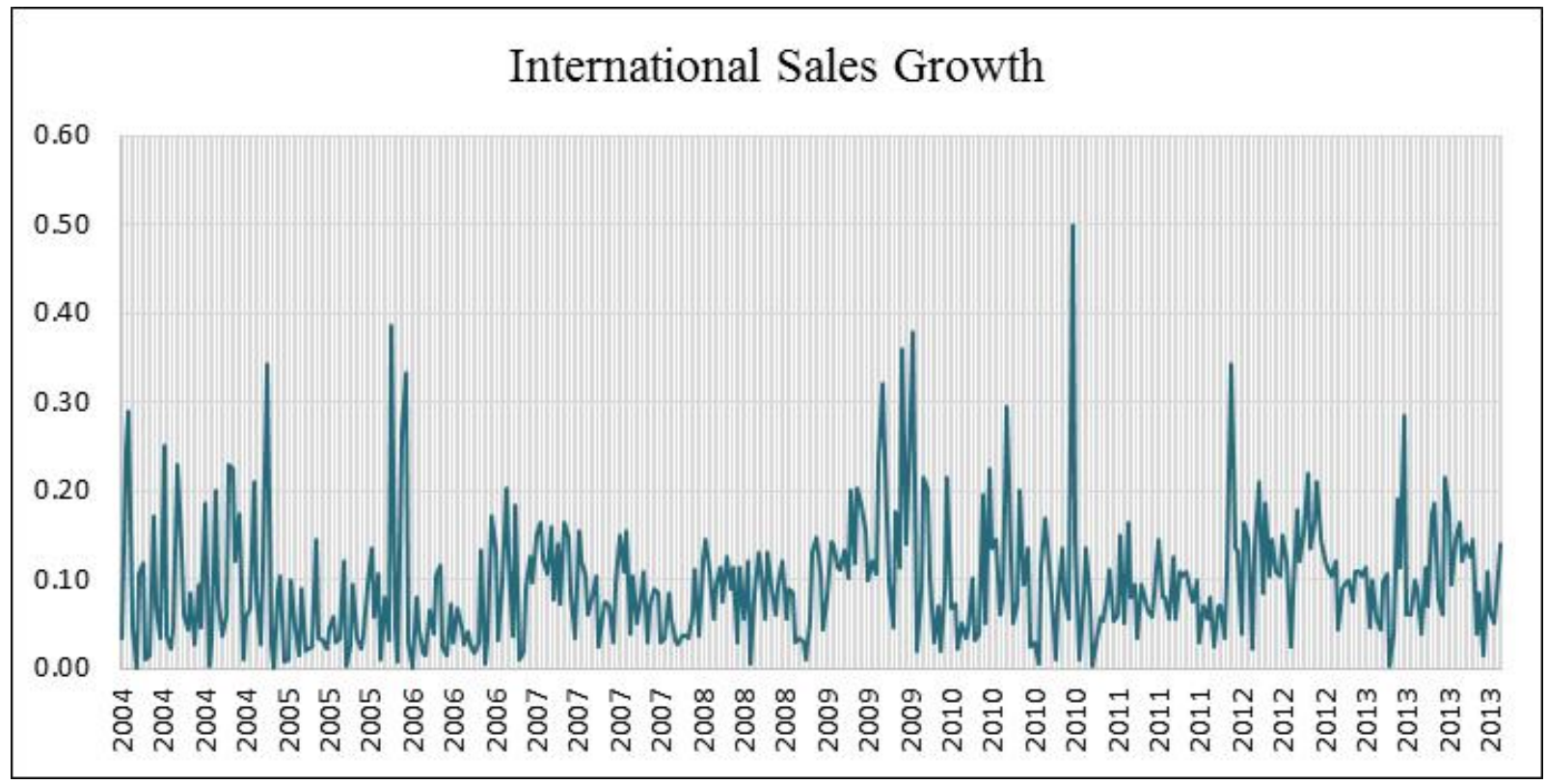

Figure 7: International Sales Growth Trend 


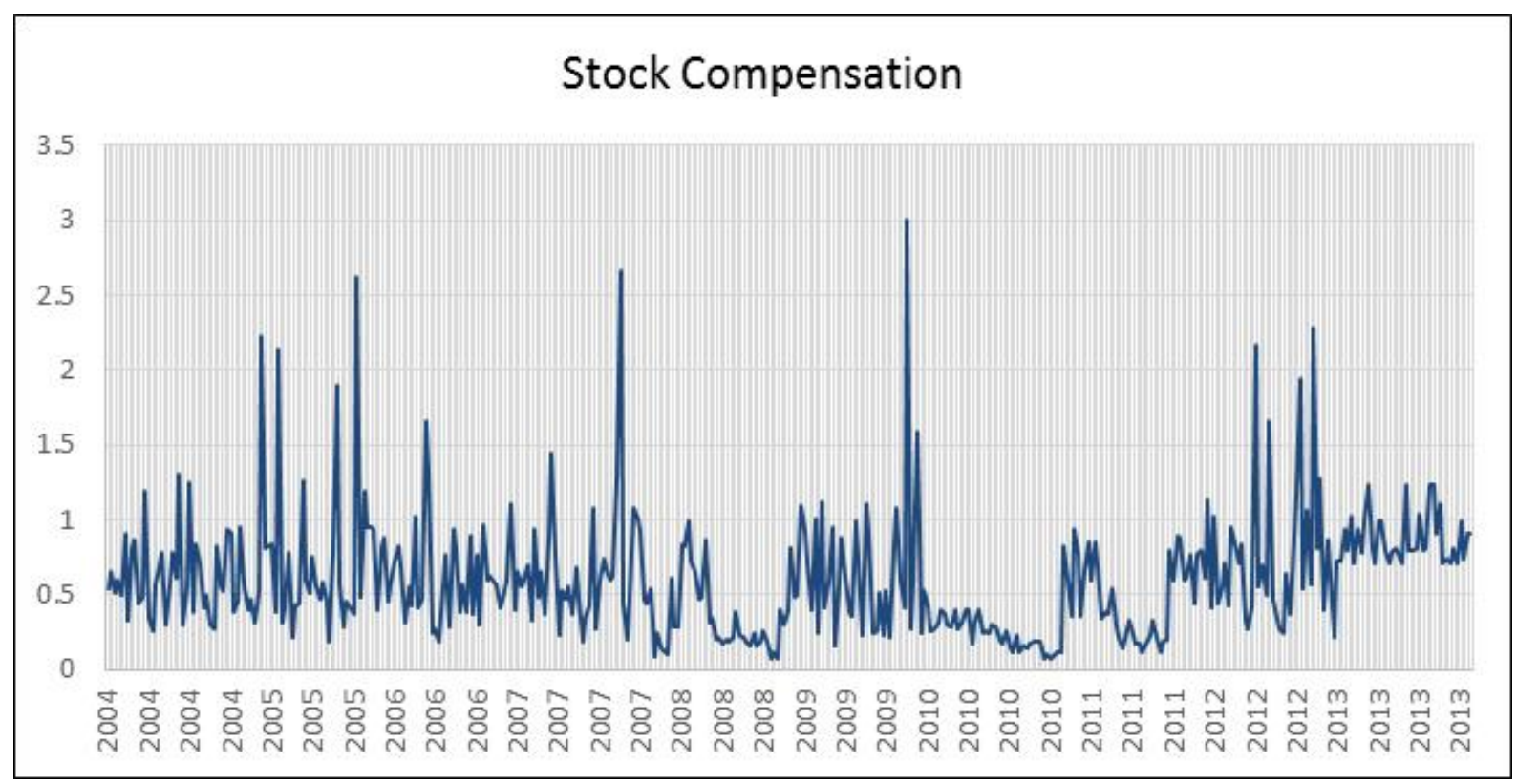

Figure 8: Stock Compensation Trend

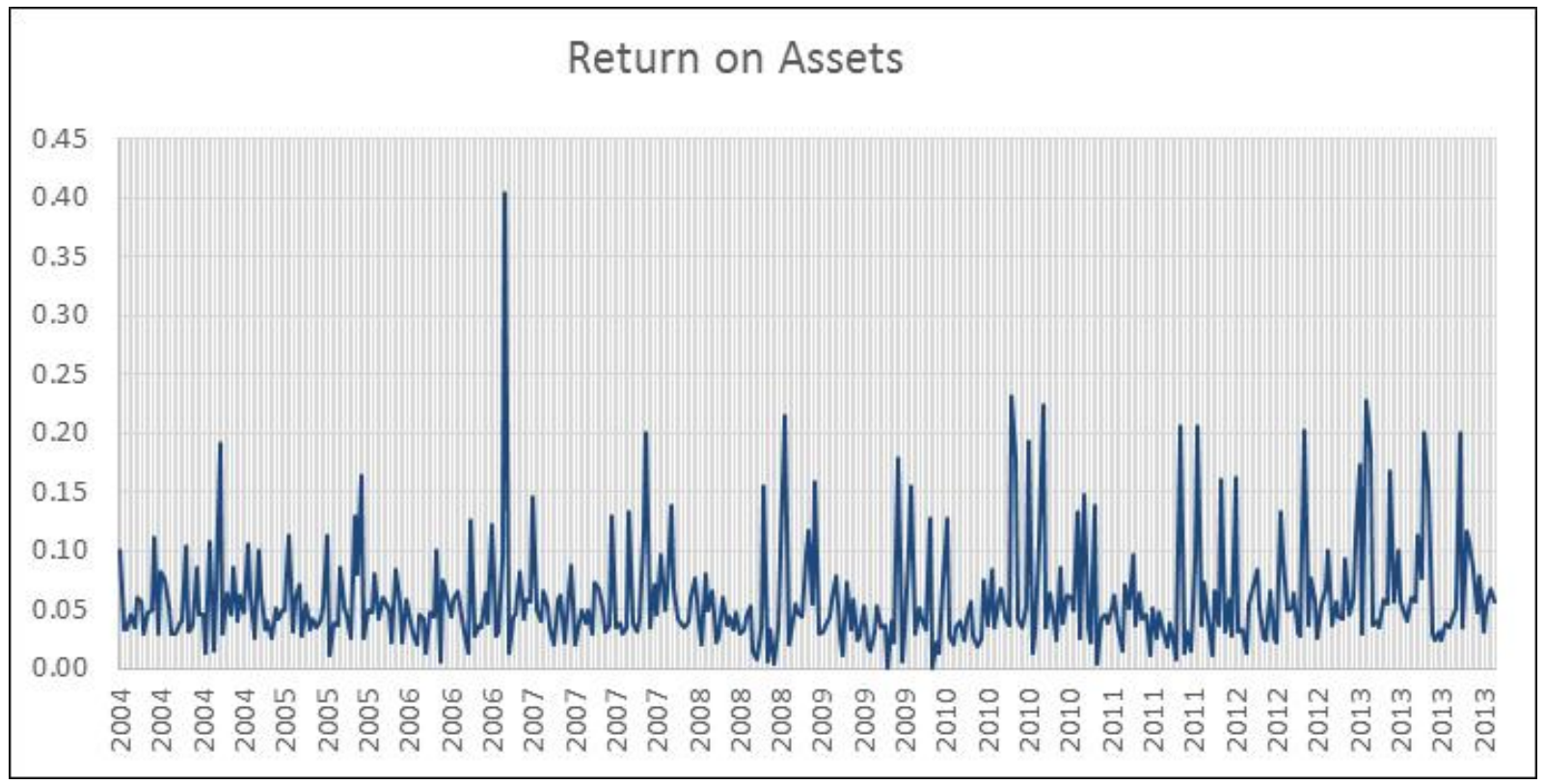

Figure 9: Return on Assets Trend 


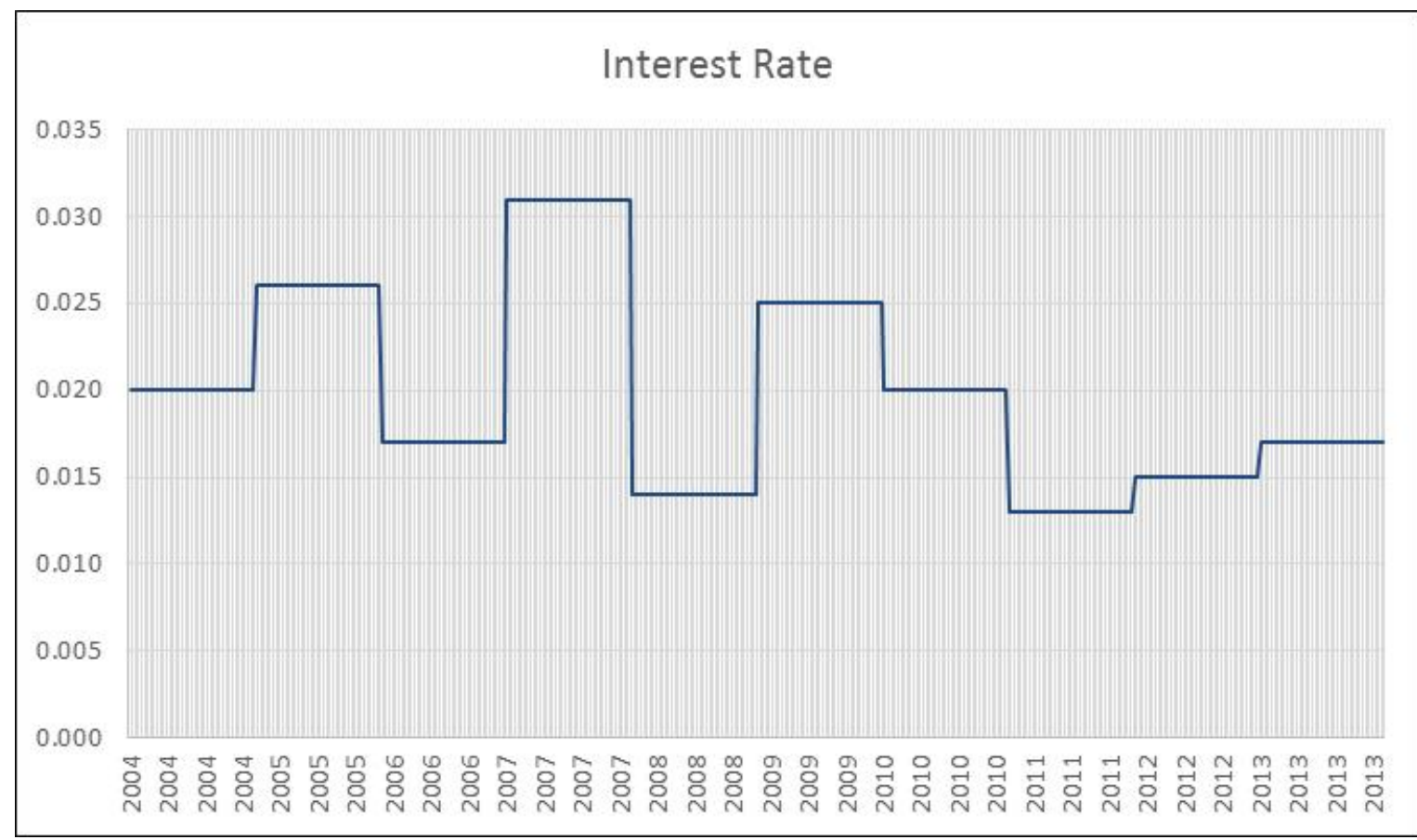

Figure 10: Interest Rate Trend

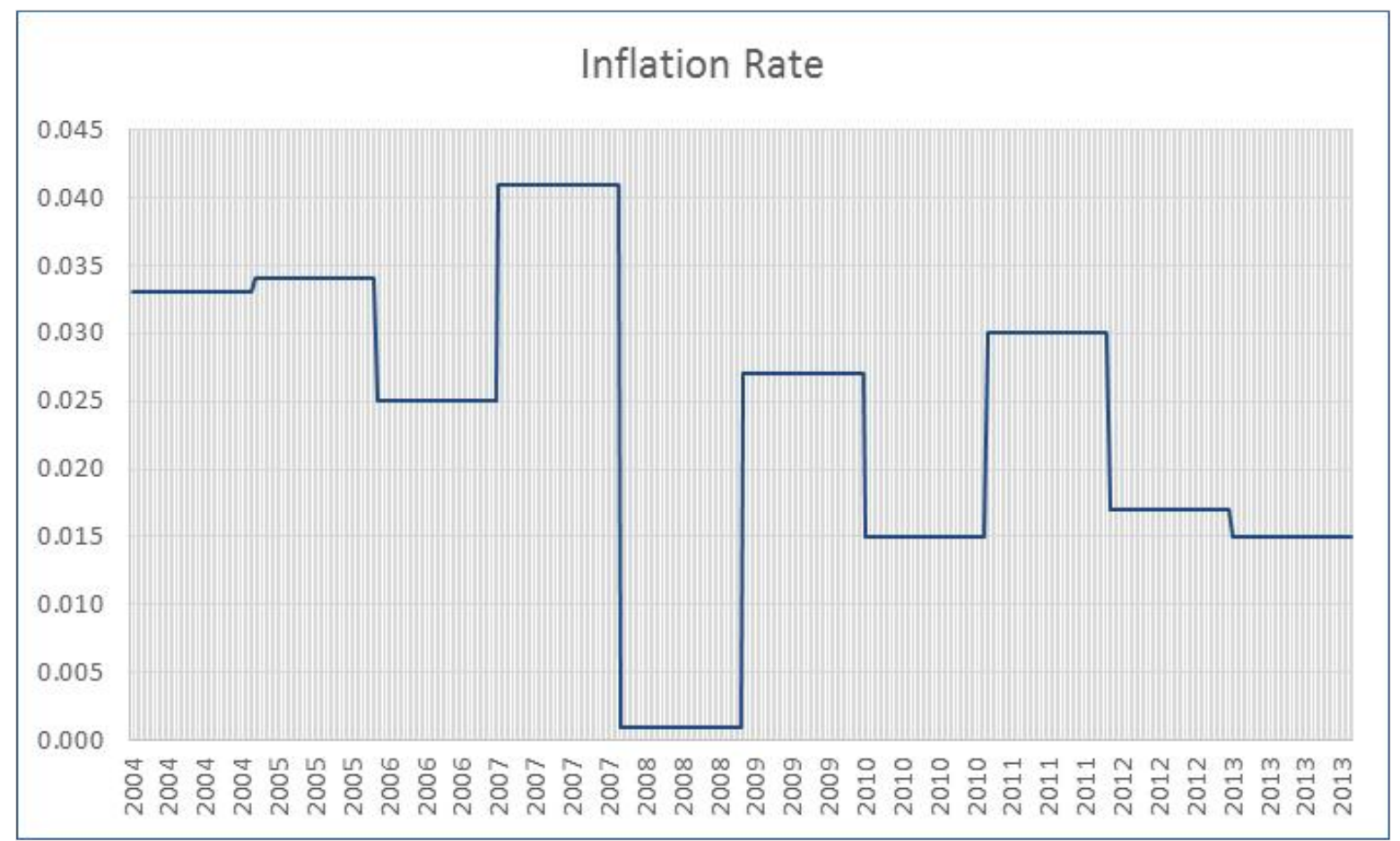

Figure 11: Inflation Rate Trend 


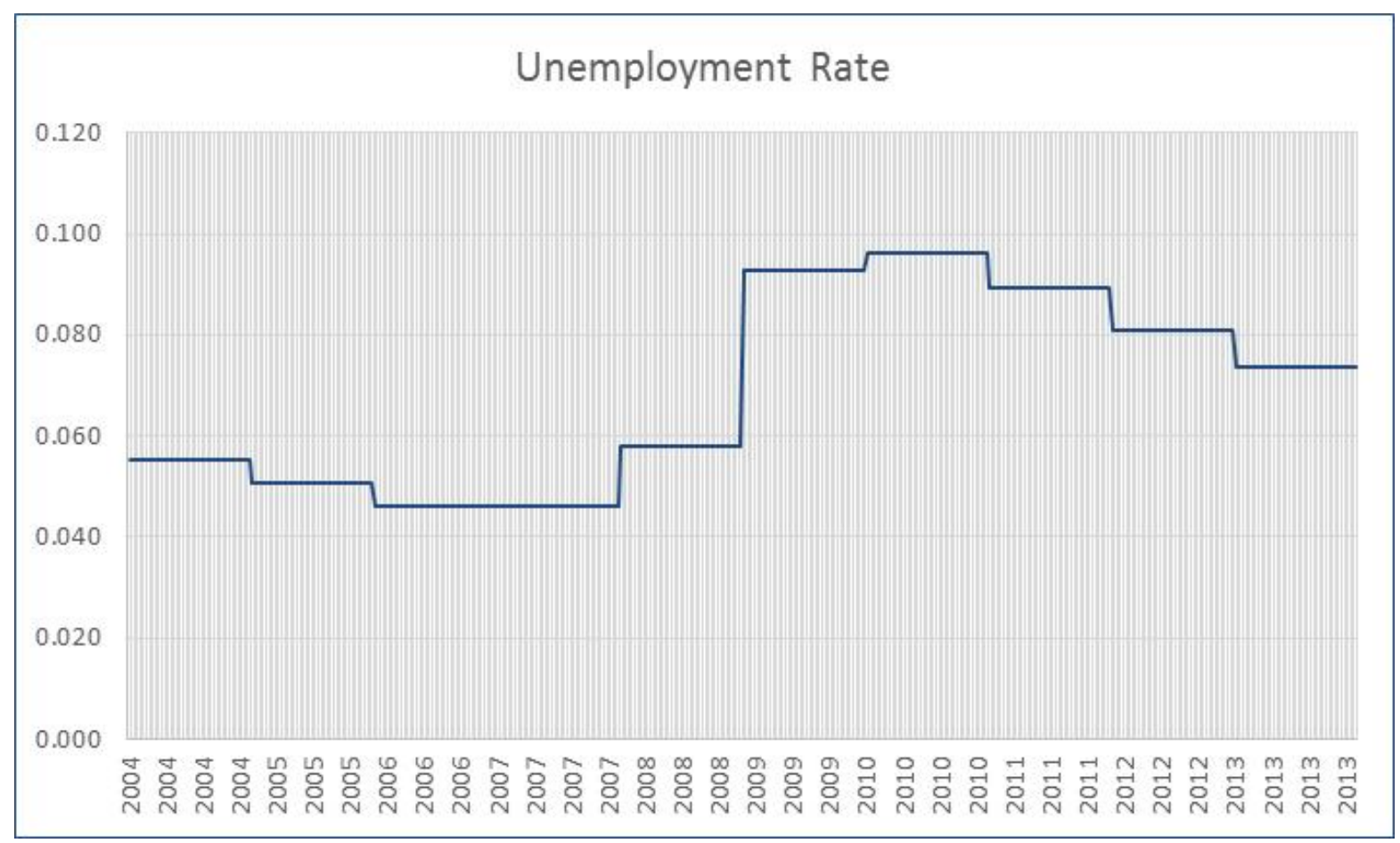

Figure 12: Unemployment Rate Trend

Once the time trend is utilized, as suggested above, all of the variables are significant at the $\mathrm{p}<.05$ level in level form with a trend. Therefore, the null hypothesis is rejected. There is no unit root for each of the continuous variables. Table 12 provides the initial unit root results for each of these variables, at level form and first difference, both with and without a trend. 
Table 12: Unit Root Tests

\begin{tabular}{|c|c|c|c|c|}
\hline & Level Form & Level Form & 1st Difference & 1st Difference \\
\hline Variable & (w/out trend) & (w/trend) & (w/out trend) & (w/trend) \\
\hline Company Size (natural log) & $-3.4382 *$ & $-8.5398 *$ & $-9.523^{*}$ & $-11.5837^{*}$ \\
\hline Debt & 0.5266 & $-5.8697 *$ & $-5.8608 *$ & $-33.5004 *$ \\
\hline Employee Turnover & $-6.3941 *$ & $-6.7435 *$ & $-7.4333 *$ & $-9.6461 *$ \\
\hline International Sales Growth & $-9.7748 *$ & $-9.7623 *$ & $-14.0903^{*}$ & $-17.7921^{*}$ \\
\hline Stock Compensation & $-8.0029 *$ & $-1.9118 *$ & $-3.8155^{*}$ & $-15.0584 *$ \\
\hline Return on Assets & $-8.055 *$ & $-7.6489 *$ & $-11.2796^{*}$ & $-14.1695^{*}$ \\
\hline Interest Rate & 0.4677 & $-3.1801 *$ & $-11.0854^{*}$ & -11.9427 \\
\hline Inflation Rate & $-3.95 *$ & $-1.9529 *$ & $-4.1595 *$ & $2.5032 *$ \\
\hline Unemployment Rate & $-11.1458 *$ & $-10.2776 *$ & $-8.4777 *$ & $-10.2776 *$ \\
\hline
\end{tabular}

*significant at the $\mathrm{p}<.05$ level

Based on the results of the unit root tests, it can be said that the variables are integrated of order zero, I(0) and order one, I(1). Since the variables are of mixed order, then the Pesaran autoregressive-distributed lag, or ARDL approach, is appropriate in order to treat the data and to determine the presence of long-run relationships between economic time series (Pesaran \& Shin, 1997).

First, it is important to understand the basis of ARDL models and how they are appropriate for estimating relationships between variables. In its basic form, an ARDL model is presented:

$$
\mathrm{y}_{\mathrm{t}}=\beta_{0}+\beta_{1} \mathrm{y}_{\mathrm{t}-1}+\ldots \ldots .+\beta_{\mathrm{k}} \mathrm{y}_{\mathrm{t}-\mathrm{p}}+\alpha_{0} \mathrm{x}_{\mathrm{t}}+\alpha_{1} \mathrm{x}_{\mathrm{t}-1}+\alpha_{2} \mathrm{x}_{\mathrm{t}-2}+\ldots \ldots \ldots+\alpha_{\mathrm{q}} \mathrm{x}_{\mathrm{t}-\mathrm{q}}+\varepsilon_{\mathrm{t}}
$$

where $\varepsilon_{\mathrm{t}}$ is a random disturbance term.

The model is "autoregressive" in the sense that the dependent variable $\mathrm{y}_{\mathrm{t}}$ is explained (in part) by lagged values of itself. It also has a distributed lag component in the form of successive lags of the " $x$ " explanatory variable. The ARDL approach allows for avoidance of adverse effects such as multicollinearity by imposing a restriction on the pattern (distribution) of values 
that the $\alpha$ coefficients could assume (Koyck, 1954). This enables the model to be manipulated into a new one that is autoregressive, but has an error term that follows a moving average process.

In the case of the data set for this study, it is clear from the unit root tests in Table 12 that most of the variables are stationary in level form while two variables (debt and interest rate) are not. Therefore, the data provides for an application of ARDL methodology, according to Pesaran et al. (2001) and Pesaran \& Shin (1999). Under this methodology, the model can be utilized under these conditions: 1) mixture of I(0) and I(1) data; 2) determination of different lag lengths as the variables enter the model.

There are several steps that must be followed to apply this methodology. First, none of the variables may be I(2), as such data will invalidate the methodology (Toda \& Yamamoto, 1995). By applying the test of the first difference for the continuous variables, it is apparent that none of the series are $\mathrm{I}(2)$. All variables are significant at the first difference, indicating that the null hypothesis is rejected. The variables are stationary and integrated I(1), so no need to move to I(2). The first step is satisfied.

The second step is to formulate an unrestricted error correction model (ECM), which is a particular type of ARDL model. To complete this step, the following model is formulated:

$$
\Delta \mathrm{y}_{\mathrm{t}}=\beta_{0}+\Sigma \beta_{\mathrm{i}} \Delta \mathrm{y}_{\mathrm{t}-\mathrm{i}}+\Sigma \gamma_{\mathrm{j}} \Delta \mathrm{x}_{1 \mathrm{t}-\mathrm{j}}+\Sigma \delta_{\mathrm{k}} \Delta \mathrm{x}_{2 \mathrm{t}-\mathrm{k}}+\theta_{0} \mathrm{y}_{\mathrm{t}-1}+\theta_{1} \mathrm{x}_{1 \mathrm{t}-1}+\theta_{2} \mathrm{x}_{2 \mathrm{t}-1}+\mathrm{e}_{\mathrm{t}}
$$

This model is very similar to a traditional error correction model, however, the difference is that the error correction term, $\mathrm{z}_{\mathrm{t}-1}$, has been replaced with the terms $\mathrm{y}_{\mathrm{t}-1}, \mathrm{x}_{1 \mathrm{t}-1}$, and $\mathrm{x}_{2 \mathrm{t}-1}$. What this means is that the lagged levels coefficients are not restricted as in a regular ECM. This is also referred to as a "conditional ECM” (Pesaran, 2001). Under the new equation, the conditions 
for running final unit root tests is satisfied. Finally, the appropriate number of lags must be selected in order to implement the model and test for unit roots. Lag selection will be discussed in the next section.

\section{Lag Selection}

The LLC test can also provide information regarding the appropriate number of lags for a probit model. Lags are important in modeling relationships, particularly financial ones, because it is likely that past values may affect today's values. In order to ensure that the variables are as free from bias/memory as possible, different lags for various variables may be utilized.

In order to determine how many lags to use, several selection criterion can be considered. The two most common are the Akaike Information Criterion (AIC) and the Schwarz' Bayesian Information Criterion (SIC/BIC/SBIC). These rules choose lag length $\mathrm{j}$ to minimize: $\log (\operatorname{SSR}(j) / n)+(j+1) C(n) / n$, where $\operatorname{SSR}(j)$ is the sum or squared residuals for the probit with $\mathrm{j}$ lags and $\mathrm{n}$ is the number of observations; $\mathrm{C}(\mathrm{n})=2$ for $\mathrm{AIC}$ and $\mathrm{C}(\mathrm{n})=\log (\mathrm{n})$ for BIC. For purposes of the probit model and specifications from the Levin-Lin-Chu test, the AIC will be utilized in this study. The AIC can tell the extent of the proportional quality of the data for the model, and provides a means for model selection. By reviewing the corresponding AIC values, a determination can be made regarding the values that minimize the AIC, meaning that selection is optimal at minimal values because it provides the model that minimizes the information lost (Akaike, 1974).

The appropriate number of lags is determined through the Levin-Lin-Chu (LLC) unit root test for longitudinal/panel or cross-sectional time series data, and are integrated in the final unit 
root analysis (see Table 15). First, it is noted that an assessment of the maximum number of lags for the model is specified through the following formula, advocated by Schwert (1989):

$$
\mathrm{P}_{\max }=\text { int }\left[12 \mathrm{x}(\mathrm{T} / 100)^{1 / 4}\right]
$$

where $\mathrm{P}_{\max }$ provides the maximum number of lags, and $\mathrm{T}$ indicates the number of observations. Since $\mathrm{T}$ is 10 for this panel dataset, the maximum lag length was noted to be 6 .

Based on review of literature, this maximum number of lags is expected since many of these financial variables are dependent and related year over year. For example, financial ratios and variables are dependent on prior year numbers since the ratio is often developed as an average of beginning and ending year balances. Table 13 provides the maximum number of lags overall that minimizes the AIC criterion.

Table 13: Akaike's Information Criterion and Bayesian Information Criterion

\begin{tabular}{|c|c|c|c|c|c|c|}
\hline Model & Obs & Null & df & AIC & BIC & Lags \\
\hline Probit Deficiency Noted & 120 & -69.72522 & 11 & 161.4504 & 192.1128 & 6 \\
\hline
\end{tabular}

Next, the optimal lag length based on this criterion needs to be established for each variable, based on the appropriate number of lags that reduces the AIC to its minimum. Based on the LLC specifications for the variables proposed, the appropriate number of lags that minimizes the AIC varies according to the related variable and is specified through the LLC test. Table 14 provides the appropriate number of lags for each variable. 
Table 14: Optimal Lag Selection

\begin{tabular}{|l|c|}
\hline Variable & Lags-AIC minimized \\
\hline Company Size (natural log) & 2 \\
\hline Debt & 1 \\
\hline Employee Turnover & 2 \\
\hline International Sales Growth & 2 \\
\hline Stock Compensation & 1 \\
\hline Return on Assets & 2 \\
\hline Interest Rate & 1 \\
\hline Inflation Rate & 1 \\
\hline Unemployment Rate & 2 \\
\hline
\end{tabular}

From an industry analysis perspective, the number of optimal lags indicated for each variable makes intuitive sense based on the properties and definitions presented. Lagged variables confirm long-term trends, and provide evidence as to how long it takes for past effects on variables to dilute from current variable time effects (Pesaran \& Shim, 1997). For financial variables that are heavily dependent on balance sheet data, it is logical to see at least 1 lag in order to account for the carry-over effect. Therefore, it is expected that company size, international sales growth, employee turnover and return on assets will optimally need two lags to dilute past effects. Additionally, unemployment rate is a classic lagged operator, often providing evidence as to how the economy is performing overall. Since these trends take time to dilute and often confirm long term trends, two lags is also appropriate for this variable. However, while interest and inflation rates are also macroeconomic conditions, these variables change more frequently and are dependent on other economic changes (Allen, 2008). Therefore, the optimal lag selection for both interest and inflation remains at 1 . The final unit root tests that reveal the optimal lag selection combined with the appropriate form of the data are presented in 
Table 15. All of the variables are stationary in the first difference and lags are provided based on the AIC criterion and previous unit root tests under the ARDL approach.

Table 15: Final Unit Root Tests

\begin{tabular}{|l|c|c|c|c|c|}
\hline & & $\begin{array}{c}\text { Level Form } \\
\text { Level Form }\end{array}$ & $\begin{array}{c}\text { 1st } \\
\text { Difference }\end{array}$ & $\begin{array}{c}\text { 1st } \\
\text { Difference }\end{array}$ \\
\hline Variable & Lags & $\begin{array}{c}\text { (w/out } \\
\text { trend) }\end{array}$ & (w/trend) & $\begin{array}{c}\text { (w/out } \\
\text { trend) }\end{array}$ & (w/trend) \\
\hline Company Size (natural log) & 2 & $0.1598^{*}$ & $-2.8940^{*}$ & $-2.2626^{*}$ & $-14.8467^{*}$ \\
\hline Debt & 1 & 0.5266 & $-5.8697^{*}$ & $-5.8608^{*}$ & $-33.5004^{*}$ \\
\hline Employee Turnover & 2 & $-5.3013^{*}$ & $-8.3490^{*}$ & $-7.4168^{*}$ & $-47.3111^{*}$ \\
\hline International Sales Growth & 2 & $-9.5047^{*}$ & $-28.0088^{*}$ & $-20.3805^{*}$ & $-10.4299^{*}$ \\
\hline Stock Compensation & 1 & $-8.0029 *$ & $-1.9118^{*}$ & $-3.8155^{*}$ & $-15.0584^{*}$ \\
\hline Return on Assets & 2 & $-10.1175^{*}$ & $-10.8629 *$ & $-14.6257^{*}$ & $-17.6448^{*}$ \\
\hline Interest Rate & 1 & 0.4677 & $-3.1801^{*}$ & $-11.0854^{*}$ & $-11.9427^{*}$ \\
\hline Inflation Rate & 1 & $-3.95^{*}$ & $-1.9529^{*}$ & $-4.1595^{*}$ & $2.5032^{*}$ \\
\hline Unemployment Rate & 2 & $-8.9943^{*}$ & $-2.0011^{*}$ & $-7.4677^{*}$ & $-9.0714^{*}$ \\
\hline
\end{tabular}

*significant at the $\mathrm{p}<.05$ level

\section{Probit Model}

In order to properly analyze the panel data, it is also necessary to test for random or fixed effects in the model. Fixed effects explores the relationship between the dependent (deficiency noted) and predictor variables within an entity (in this case, companies). Each company has its own individual characteristics that may or may not influence predictor values. For example, business practices may influence employee turnover. When using a fixed effects analysis, it is assumed that something within the company may impact or influence the predictor or dependent variables, and this needs to be controlled (Baltagi, 2008). This is the rationale behind the assumption of the correlation between the entity’s error term and predictor variables. Fixed 
effects removes the effects of the time-invariant characteristics so the net effect of the predictors on the dependent variable can be assessed (Baum, 2006).

Another important assumption of the FE model is that the time-invariant characteristics are unique to the company and should not be correlated with other individual characteristics. Each company is different, so each company's error term and the constant term should not be correlated with the others. If the error terms are correlated, then the FE method is not suitable since inferences may not be correct. In this case, the relationship should be modeled according to the random-effects.

The rationale behind the random effects model is that, unlike the fixed effects model, the variation across entities is assumed to be random and uncorrelated with the independent or predictor variables included in the model. Additionally, random effects assumes that the company's error term is not correlated with the predictors. In this study, there is a reason to believe that the differences across or between entities may have some influence on the dependent variable. Additionally, it is noted that the within-cluster is minimal and the variables are slow to change over time. The Hausman test of specification is performed specifically to determine if effects are fixed or random. The null hypothesis is that the unique errors are not correlated with the regressors, meaning that the preferred model is random effects. Table 16 contains the results of the Hausman test, and indicates that the null hypothesis should be rejected. The appropriate model to use is one with random effects. 
Table 16: Hausman Specification Test

\begin{tabular}{|c|c|c|c|c|c|}
\hline & Coefficients & & & & \\
\hline Variable & (b) & (B) & (b-B) & $\operatorname{sqrt}\left(\operatorname{diag}\left(V_{-} \mathbf{b}-V_{-}(B)\right)\right.$ & Prob $>$ Chi2 \\
\hline Overall & Fixed & random & Difference & S.E. & $\begin{array}{c}.6496 \text { (Reject the } \\
\text { Null) }\end{array}$ \\
\hline Company Size & 0.0085653 & 0.00713 & 0.001435 & 0.0359166 & \\
\hline Debt & -0.0084979 & -0.0118 & 0.003277 & 0.002923 & \\
\hline Employee Turnover & -0.3906534 & -0.4451 & 0.054452 & 0.3568587 & \\
\hline Recession & 0.1601604 & 0.16854 & -0.008381 & 0.0094892 & \\
\hline Organizational Structure & -0.0265176 & -0.056 & 0.029474 & 0.0895469 & \\
\hline International Sales Growth & -0.2613468 & -0.5899 & 0.328595 & 0.1530319 & \\
\hline Stock Compensation & -0.0250029 & -0.0018 & -0.023244 & 0.014914 & \\
\hline Return on Assets & -0.5290084 & -0.4558 & -0.07318 & 0.2289579 & \\
\hline Interest Rate & -30.29344 & -30.37 & 0.076898 & 0.4280127 & \\
\hline Inflation Rate & 10.41124 & 10.3705 & 0.040762 & 0.0557477 & \\
\hline Unemployment Rate & -0.4692909 & -0.0191 & -0.450147 & 0.5296718 & \\
\hline
\end{tabular}

With the results of the Hausman test provided, the probit model can be appropriately analyzed without concern for estimator bias. The results of the probit model in level and first difference indicate that the only variables of significance are the Recession, interest rate and inflation rate. Therefore, based on review of the LLC AIC criterion, lagging the variables in order to dilute effects of memory is appropriate to minimize level of the AIC. Tables 17 and 18 indicate the results of the probit model in level form and first difference, and with the identified lags plus the appropriate form, respectively. 
Table 17: Level and First Difference Form Probit

\begin{tabular}{|l|c|c|c|c|}
\hline \multicolumn{1}{|c|}{ Variable } & Coefficient & Standard Error & Z-score & p-value \\
\hline Company Size (natural log) & .0195163 & 0.0579732 & -0.34 & 0.736 \\
\hline D.Debt & -.1567498 & .2816093 & -0.56 & 0.578 \\
\hline Employee Turnover & -1.230915 & 1.099447 & -1.12 & .263 \\
\hline Recession & .4610985 & .1829721 & 2.52 & $.012^{*}$ \\
\hline International Sales Growth & -1.504544 & 1.024778 & -1.47 & 0.142 \\
\hline Stock Compensation & .0102213 & .1669473 & .06 & .952 \\
\hline Return on Assets & -1.264054 & 1.499313 & -.84 & 0.399 \\
\hline D.Interest Rate & -82.27159 & 20.39948 & -4.03 & $0.000^{*}$ \\
\hline Inflation Rate & 27.66125 & 9.222203 & 3.00 & $0.003^{*}$ \\
\hline Unemployment Rate & .1417111 & 3.922169 & 0.04 & .971 \\
\hline Organizational Structure & -.1604483 & .161009 & -1.00 & .319 \\
\hline
\end{tabular}

*Significant at $\mathrm{p}<.05$ level

Table 18: Final Probit Model (form and identified lags included)

\begin{tabular}{|l|r|r|r|c|}
\hline \multicolumn{1}{|c|}{ Variable } & \multicolumn{1}{c|}{ Coefficient } & Standard Error & Z-score & p-value \\
\hline D.Company Size (natural log) & .0480868 & .0668365 & .72 & .472 \\
\hline D.Debt & -.3937673 & .3058717 & -1.29 & .198 \\
\hline D.Employee Turnover & -1.706809 & 1.18543 & -1.44 & .150 \\
\hline Recession & .7711787 & 2540667 & 3.04 & $.002^{*}$ \\
\hline D.International Sales Growth & .0287585 & 1.130567 & 0.03 & .980 \\
\hline D.Stock Compensation & -.0179812 & .1873975 & 0.10 & .924 \\
\hline D.Return on Assets & 1.211963 & 1.706828 & 0.71 & .478 \\
\hline D.Interest Rate & .768265 & 21.67142 & 3.55 & $.000^{*}$ \\
\hline D.Inflation Rate & -.190374 & 9.441415 & -2.11 & $.035^{*}$ \\
\hline D.Unemployment Rate & .25997 & 7.193341 & 3.61 & $.000^{*}$ \\
\hline Organizational Structure & -.1462004 & .1723243 & -.85 & .396 \\
\hline
\end{tabular}

*Significant at $\mathrm{p}<.05$ level

The overall final probit model is significant at $\mathrm{p}<.05$; with a chi-square value of .0501 .

The chi-square value is utilized in analysis instead of the F-statistic because of the previously determined selection of a random effects model (Baltagi, 2008). Additionally, the model provides the intra-class correlation, rho, which indicates the percent of variance that is due to 
differences across panels (companies). This value is .530191, which indicates that over half of the variance (53\%) is due to differences across (or between) panels (companies). This variance provides additional support for separating the data into sub-segments according to type of restaurant company (fast casual, fine dining, etc.) (Chathoth \& Olsen, 2007). However, before evaluating the different segments of companies within the restaurant industry, the next section will discuss the statistically significant variables found in the overall model and conclude regarding the likelihood of increased risk of fraud for the significant variables in the model.

\section{Likelihood of Increased Fraud Risk}

As noted in the overall model, the results reveal that the model as a whole is a significant fit to the data. Specifically, the Recession, interest rate, inflation rate and unemployment rate all appear to have a significant impact on the increased risk of fraud as evidenced by an incidence of a reported internal control deficiency. However, each of the more specific "company level" variables are not significant in the overall model. Each of these variables will be evaluated based on the coefficients presented in the model.

\section{Research Objective \#1: Company Size}

This research objective seeks to investigate the probability of increased risk of fraud when considering the company size of a population of publicly traded restaurant companies. The corresponding proposed hypotheses were noted as follows: 
Table 19: Research Objective 1 Hypothesis

\begin{tabular}{|c|l|c|c|}
\hline Variable & \multicolumn{1}{|c|}{ Hypothesis } & Equation & Results \\
\hline $\begin{array}{l}\text { Company } \\
\text { Size }\end{array}$ & $\begin{array}{l}\mathrm{H}_{0}=\text { There is no relationship between } \\
\text { increased risk of fraud and company size. }\end{array}$ & $\operatorname{Pr}\left(\mathrm{Y}=1 \mid \mathrm{X}_{1}\right) \neq \Phi\left(\mathrm{X}_{1} \beta\right)$ & $\begin{array}{c}\text { Cannot } \\
\text { Reject }\end{array}$ \\
\hline & $\begin{array}{l}\mathrm{H}_{1}=\text { There is a significant relationship } \\
\text { between increased risk of fraud and } \\
\text { company size. }\end{array}$ & $\operatorname{Pr}\left(\mathrm{Y}=1 \mid \mathrm{X}_{1}\right)=\Phi\left(\mathrm{X}_{1} \beta\right)$ & Reject \\
\hline
\end{tabular}

It is noted that company size is positively correlated to the incidence of a reported deficiency $(\mathrm{B}=.0480868, \mathrm{z}=.72, \mathrm{p}>.05)$, but is not statistically significant. Therefore, the null hypothesis cannot be rejected. It can be said that there is no relationship between increased risk of fraud and company size, and the probability of a relationship between a reported deficiency and company size is zero, for all combined companies in the restaurant industry dataset.

\section{Research Objective \#2: Debt}

The second research objective aims to determine the probability of increased risk of fraud when considering the amount of debt incurred by a population of publicly traded restaurant companies. The corresponding proposed hypotheses were noted as follows:

Table 20: Research Objective 2 Hypothesis

\begin{tabular}{|c|l|c|c|}
\hline Variable & \multicolumn{1}{|c|}{ Hypothesis } & Equation & Results \\
\hline Debt & $\begin{array}{l}\mathrm{H}_{0}=\text { There is no relationship between } \\
\text { increased risk of fraud and debt. }\end{array}$ & $\operatorname{Pr}\left(\mathrm{Y}=1 \mid \mathrm{X}_{2}\right) \neq \Phi\left(\mathrm{X}_{2} \beta\right)$ & $\begin{array}{c}\text { Cannot } \\
\text { Reject }\end{array}$ \\
\hline & $\begin{array}{l}\mathrm{H}_{1}=\text { There is a significant relationship } \\
\text { between increased risk of fraud and debt. }\end{array}$ & $\operatorname{Pr}\left(\mathrm{Y}=1 \mid \mathrm{X}_{2}\right)=\Phi\left(\mathrm{X}_{2} \beta\right)$ & Reject \\
\hline
\end{tabular}


Based on the final probit model, debt is negatively correlated to the incidence of a reported deficiency $(\mathrm{B}=-.3937673, \mathrm{z}=-1.29, \mathrm{p}>.05)$, and it is not statistically significant. Therefore, the null hypothesis cannot be rejected. Based on the results, it can be said that there is no relationship between increased risk of fraud and debt for the overall population of restaurant companies, and the probability of a relationship between a reported deficiency and debt is zero, for all combined companies in the restaurant industry dataset.

\section{Research Objective \#3: Employee Turnover}

The third research objective aims to determine the probability of increased risk of fraud when considering the annual employee turnover observed by a population of publicly traded restaurant companies. The corresponding proposed hypotheses were noted as follows:

Table 21: Research Objective 3 Hypothesis

\begin{tabular}{|l|l|c|c|}
\hline Variable & \multicolumn{1}{|c|}{ Hypothesis } & Equation & Results \\
\hline $\begin{array}{l}\text { Employee } \\
\text { Turnover }\end{array}$ & $\begin{array}{l}\mathrm{H}_{0}=\text { There is no relationship between } \\
\text { increased risk of fraud and employee } \\
\text { turnover. }\end{array}$ & $\operatorname{Pr}\left(\mathrm{Y}=1 \mid \mathrm{X}_{3}\right) \neq \Phi\left(\mathrm{X}_{3} \beta\right)$ & $\begin{array}{c}\text { Cannot } \\
\text { Reject }\end{array}$ \\
\hline & $\begin{array}{l}\mathrm{H}_{1}=\text { There is a significant relationship } \\
\text { between increased risk of fraud and } \\
\text { employee turnover. }\end{array}$ & $\operatorname{Pr}\left(\mathrm{Y}=1 \mid \mathrm{X}_{3}\right)=\Phi\left(\mathrm{X}_{3} \beta\right)$ & Reject \\
\hline
\end{tabular}

It is noted that employee turnover is negatively correlated to the incidence of a reported deficiency ( $\mathrm{B}=-1.706809, \mathrm{z}=-1.44, \mathrm{p}>.05$ ), and is not statistically significant. Therefore, the null hypothesis cannot be rejected. It can be said that there is no relationship between increased risk of fraud and employee turnover, and the probability of a relationship between a reported 
deficiency and employee turnover is zero, for all combined companies in the restaurant industry dataset.

\section{Research Objective \#4: Organizational Structure}

The fourth research objective seeks to investigate the probability of increased risk of fraud when considering whether or not the population of publicly traded restaurant companies has an organizational structure where the CEO is also the Chairman of the Board. The corresponding proposed hypotheses were noted as follows:

Table 22: Research Objective 4 Hypothesis

\begin{tabular}{|c|l|c|c|}
\hline Variable & \multicolumn{1}{|c|}{ Hypothesis } & Equation & Results \\
\hline $\begin{array}{c}\text { Organizational } \\
\text { Structure }\end{array}$ & $\begin{array}{l}\mathrm{H}_{0}=\text { There is no relationship between } \\
\text { increased risk of fraud and } \\
\text { organizational structure. }\end{array}$ & $\operatorname{Pr}\left(\mathrm{Y}=1 \mid \mathrm{X}_{4}\right) \neq$ & $\begin{array}{c}\text { Cannot } \\
\text { Reject }\end{array}$ \\
\hline & $\begin{array}{l}\mathrm{H}_{1}=\text { There is a significant } \\
\text { relationship between increased risk of } \\
\text { fraud and organizational structure. }\end{array}$ & $\operatorname{Pr}\left(\mathrm{Y}=1 \mid \mathrm{X}_{4} \beta\right)=$ & Reject \\
\hline
\end{tabular}

Based on the final probit model, organizational structure is negatively correlated to the incidence of a reported deficiency $(\mathrm{B}=-.1462004, \mathrm{z}=-.85, \mathrm{p}>.05$ ), and it is not statistically significant. Therefore, the null hypothesis cannot be rejected. Based on the results, it can be said that there is no relationship between increased risk of fraud and whether or not the CEO is also Chairman of the Board for the overall population of restaurant companies. Thus, the probability of a relationship between a reported deficiency and whether or not the CEO is also Chairman of the Board is zero, for all combined companies in the restaurant industry dataset. 


\section{Research Objective \#5: International Sales Growth}

The fifth research objective seeks to determine the probability of increased risk of fraud when considering the amount of international sales growth of publicly traded restaurant companies over time. The corresponding proposed hypotheses were noted as follows:

Table 23: Research Objective 5 Hypothesis

\begin{tabular}{|c|l|c|c|}
\hline Variable & \multicolumn{1}{|c|}{ Hypothesis } & Equation & Results \\
\hline $\begin{array}{l}\text { International } \\
\text { Sales Growth }\end{array}$ & $\begin{array}{l}\mathrm{H}_{0}=\text { There is no relationship between } \\
\text { increased risk of fraud and } \\
\text { international sales growth. }\end{array}$ & $\operatorname{Pr}\left(\mathrm{Y}=1 \mid \mathrm{X}_{5}\right) \neq$ & $\begin{array}{c}\text { Cannot } \\
\text { Reject }\end{array}$ \\
\hline & $\begin{array}{l}\mathrm{H}_{1}=\text { There is a significant } \\
\text { relationship between increased risk of } \\
\text { fraud and international sales growth. }\end{array}$ & $\operatorname{Pr}\left(\mathrm{Y}=1 \mid \mathrm{X}_{5}\right)=$ & Reject \\
\hline
\end{tabular}

It is noted that international sales growth is positively correlated to the incidence of a reported deficiency $(\mathrm{B}=.0287585, \mathrm{z}=.03, \mathrm{p}>.05)$, but is not statistically significant. Therefore, the null hypothesis cannot be rejected. It can be said that there is no relationship between increased risk of fraud and international sales growth, and therefore, the probability of a relationship between a reported deficiency and international sales growth is zero, for all combined companies in the restaurant industry dataset.

\section{Research Objective \#6: Stock Compensation}

The sixth research objective seeks to investigate the probability of increased risk of fraud when considering the stock option compensation for executives of publicly traded restaurant companies over time. The corresponding proposed hypotheses were noted as follows: 
Table 24: Research Objective 6 Hypothesis

\begin{tabular}{|c|l|c|c|}
\hline Variable & \multicolumn{1}{|c|}{ Hypothesis } & Equation & Results \\
\hline $\begin{array}{c}\text { Stock } \\
\text { Compensation }\end{array}$ & $\begin{array}{l}\mathrm{H}_{0}=\text { There is no relationship between } \\
\text { increased risk of fraud and stock } \\
\text { compensation. }\end{array}$ & $\operatorname{Pr}\left(\mathrm{Y}=1 \mid \mathrm{X}_{6}\right) \neq$ & $\begin{array}{c}\text { Cannot } \\
\text { Reject }\end{array}$ \\
\hline & $\begin{array}{l}\mathrm{H}_{1}=\text { There is a significant } \\
\text { relationship between increased risk of } \\
\text { fraud and stock compensation. }\end{array}$ & $\operatorname{Pr}\left(\mathrm{Y}=1 \mid \mathrm{X}_{6} \beta\right)=$ & Reject \\
\hline
\end{tabular}

Based on the final probit model, stock compensation is negatively correlated to the incidence of a reported deficiency $(\mathrm{B}=-.0179812, \mathrm{z}=.10, \mathrm{p}>.05)$, and it is not statistically significant. Therefore, the null hypothesis cannot be rejected. Based on the results, it can be said that there is no relationship between increased risk of fraud and executive stock compensation over time for the overall population of restaurant companies. Thus, the probability of a relationship between a reported deficiency and executive stock compensation is zero, for all combined companies in the restaurant industry dataset.

\section{Research Objective \#7: Return on Assets}

This research objective looks to investigate the probability of increased risk of fraud when considering return on assets over time for a population of publicly traded restaurant companies. The corresponding proposed hypotheses were noted as follows: 
Table 25: Research Objective 7 Hypothesis

\begin{tabular}{|c|l|c|c|}
\hline Variable & \multicolumn{1}{|c|}{ Hypothesis } & Equation & Results \\
\hline $\begin{array}{c}\text { Return } \\
\text { on } \\
\text { Assets }\end{array}$ & $\begin{array}{l}\mathrm{H}_{0}=\text { There is no relationship between } \\
\text { increased risk of fraud and return on } \\
\text { assets. }\end{array}$ & $\operatorname{Pr}\left(\mathrm{Y}=1 \mid \mathrm{X}_{7}\right) \neq \Phi\left(\mathrm{X}_{7} \beta\right)$ & $\begin{array}{c}\text { Cannot } \\
\text { Reject }\end{array}$ \\
\hline & $\begin{array}{l}\mathrm{H}_{1}=\text { There is a significant relationship } \\
\text { between increased risk of fraud and } \\
\text { return on assets. }\end{array}$ & $\operatorname{Pr}\left(\mathrm{Y}=1 \mid \mathrm{X}_{7}\right)=\Phi\left(\mathrm{X}_{7} \beta\right)$ & Reject \\
\hline
\end{tabular}

It is noted that return on assets is positively correlated to the incidence of a reported deficiency ( $\mathrm{B}=1.211963, \mathrm{z}=.71, \mathrm{p}>.05)$, but is not statistically significant. Therefore, the null hypothesis cannot be rejected. It can be said that there is no relationship between increased risk of fraud and return on assets over time, and therefore, the probability of a relationship between a reported deficiency and company size is zero, for all combined companies in the restaurant industry dataset.

\section{Research Objective \#8: Recession}

This research objective looks to investigate the probability of increased risk of fraud when considering the recessionary time period of 2007-2009 for a population of publicly traded restaurant companies. The corresponding proposed hypotheses were noted as follows:

Table 26: Research Objective 8 Hypothesis

\begin{tabular}{|c|l|c|c|}
\hline Variable & \multicolumn{1}{|c|}{ Hypothesis } & Equation & Results \\
\hline Recession & $\begin{array}{l}\mathrm{H}_{0}=\text { There is no relationship between } \\
\text { increased risk of fraud and the Great } \\
\text { Recession. }\end{array}$ & $\operatorname{Pr}\left(\mathrm{Y}=1 \mid \mathrm{X}_{8}\right) \neq \Phi\left(\mathrm{X}_{8} \beta\right)$ & Reject \\
\hline & $\begin{array}{l}\mathrm{H}_{1}=\text { There is a significant relationship } \\
\text { between increased risk of fraud and the } \\
\text { Great Recession. }\end{array}$ & $\operatorname{Pr}\left(\mathrm{Y}=1 \mid \mathrm{X}_{8}\right)=\Phi\left(\mathrm{X}_{8} \beta\right)$ & $\begin{array}{c}\text { Cannot } \\
\text { Reject }\end{array}$ \\
\hline
\end{tabular}


Based on the presented model, it is noted that the existence of the Recession is positively correlated to the incidence of a reported deficiency $(\mathrm{B}=.7711787, \mathrm{z}=3.04, \mathrm{p}<.05)$, and is statistically significant. Therefore, the null hypothesis is rejected. It can be said that there is a significant relationship between increased risk of fraud and the Great Recession time periods for publicly traded restaurant companies. The next step is to determine the marginal effects of this significant relationship between the variables (Ho, 2012). Since the coefficient is significant, this means that a Recessionary time period will raise the z-score of the probability of increased risk of fraud by .77. However, this does not translate into a constant effect on the original Y, as it depends on the starting point of Y. Thus, it can be stated that the marginal impact of changing a variable is not constant and needs to be calculated (D'Agostino, 1970). To calculate the marginal impact or effects, an applied formula that takes into account the coefficients of all of the variables in the model is necessary:

$\left(\operatorname{Pr}\left(\mathrm{Y}=1 \mid \mathrm{X}_{5 \mathrm{i}}=0\right)=\Phi\left(\beta_{1} \mathrm{X}_{1 \mathrm{i}}+\beta_{2} \mathrm{X}_{2 \mathrm{i}}+\beta_{3} \mathrm{X}_{3 \mathrm{i}}+\beta_{4} \mathrm{X}_{4 \mathrm{i}}+\beta_{5} \mathrm{X}_{5 \mathrm{i}}+\beta_{6} \mathrm{X}_{6 \mathrm{i}}+\beta_{7} \mathrm{X}_{7 \mathrm{i}}+\beta_{8} \mathrm{X}_{8 \mathrm{i}}+\beta_{9} \mathrm{X}_{9 \mathrm{i}}+\beta_{10} \mathrm{X}_{10 \mathrm{i}}+\beta_{11} \mathrm{X}_{11 \mathrm{i}}\right)\right.$

After applying the formula, the variables are set to their medians and the cumulative distribution factors are determined for the Recession variable and the sum of the other variables. Based on the results and formula application, it can be said that each additional case of a Recessionary time period for a company yields an increase of about $30 \%$ in the likelihood of increased risk of fraud through a reported control deficiency.

\section{Research Objective \#9: Macroeconomic Factors}

This research objective looks to investigate the probability of increased risk of fraud when considering significant macroeconomic factors such as the interest, inflation and 
unemployment rates over time for a population of publicly traded restaurant companies. The corresponding proposed hypotheses were noted as follows:

Table 27: Research Objective 9 Hypothesis

\begin{tabular}{|c|c|c|c|}
\hline Variable & Hypothesis & Equation & Results \\
\hline $\begin{array}{l}\text { Macroeconomic } \\
\text { Factors }\end{array}$ & $\begin{array}{l}\mathrm{H}_{0}=\text { There is no relationship between } \\
\text { increased risk of fraud and } \\
\text { macroeconomic factors. }\end{array}$ & $\begin{array}{l}\operatorname{Pr}\left(Y=1 \mid X_{9}, X_{10}, X_{11}\right) \\
\neq \Phi\left(X_{9} \beta, X_{10} \beta, X_{11} \beta\right)\end{array}$ & Reject \\
\hline & $\begin{array}{l}\mathrm{H}_{1}=\text { There is a significant relationship } \\
\text { between increased risk of fraud and } \\
\text { macroeconomic factors. }\end{array}$ & $\begin{array}{l}\operatorname{Pr}\left(Y=1 \mid X_{9} X_{10}, X_{11}\right) \\
=\Phi\left(X_{9} \beta, X_{10} \beta, X_{11} \beta\right)\end{array}$ & $\begin{array}{l}\text { Cannot } \\
\text { Reject }\end{array}$ \\
\hline
\end{tabular}

Based on the presented model, it is noted that both the interest and unemployment rates are positively correlated to the incidence of a reported deficiency $(\mathrm{B}=.768265, \mathrm{z}=3.55, \mathrm{p}<$ $.05),(\mathrm{B}=.25997, \mathrm{z}=.3 .61, \mathrm{p}<.05)$, respectively, and are statistically significant. The inflation rate is negatively correlated to the incidence of a reported deficiency, but is also still statistically significant $(\mathrm{B}=-.190374, \mathrm{z}=-2.11, \mathrm{p}<.05)$.

Based on the model, the null hypothesis is rejected for all three rates. It can be said that there is a significant relationship between increased risk of fraud and the macroeconomic factors of interest, inflation and unemployment rates. Using the marginal effects formula presented in equation 8 , it can be said that each additional change in interest rates yields an increase of about $29 \%$ in the likelihood of increased risk of fraud through a reported control deficiency. Likewise, it can be said that each additional change in inflation rates yields an increase of about $22.5 \%$ in the likelihood of increased risk of fraud through a reported control deficiency. Finally, using the 
marginal effects equation, it can be said that each additional change in unemployment rates yields an increase of about $6.4 \%$ in the likelihood of increased risk of fraud through a reported control deficiency.

\section{Results: Type of Restaurant Segment}

As noted, the results of the overall model provides an opportunity to further disaggregate the data in order to look at specific segments of companies in the restaurant industry. This is justified through the analysis of the variance in the overall model (53\%), as well as the wide distribution of standard deviations for company size, which indicates that several types of restaurants exist in the dataset with varying profit margins (Parsa et. al, 2005; Jennings, 2012). The National Restaurant Association segments restaurants based on the menu and service style, pricing, and preparation method (NRA, 2014). Among the most common categories are quick service, fast casual, casual dining or full service, and fine dining. This study employs this categorization for the 40 publicly traded companies in the dataset. Each company was reviewed for its standard competitive set in order to determine appropriate groupings into one of the four categories.

\section{Quick Service Restaurants Results}

The quick service restaurants, also known as fast food restaurants, are characterized as having fast, efficient, take out ready foods at affordable prices (Ryu et. al, 2008). When analyzing this segment from the presented data, the population includes 9 companies over a 10 year period across 12 variables, providing 1,080 total data points. Unit root tests are performed as described in the previous section. The final unit root tests that reveal the optimal lag selection combined with the form of the data is presented in Table 28. Also, based on the principles of 
ARDL models as described, the variables are presented in mixed order for inclusion in the probit model. For the quick service restaurant segment, the variables are all stationary in the first difference, with the exception of stock compensation, which is stationary in level form. Therefore, the null hypothesis for each of the variables is rejected; there is no unit root. Additionally, lags are incorporated and optimized at the minimized AIC level for each of the variables and presented in Table 28.

Table 28: QSR Final Unit Root Tests

\begin{tabular}{|l|c|c|c|c|c|}
\hline & & $\begin{array}{c}\text { Level } \\
\text { Level Form }\end{array}$ & $\begin{array}{c}\text { 1st } \\
\text { Form } \\
\text { Difference }\end{array}$ & $\begin{array}{c}\text { 1st } \\
\text { Difference }\end{array}$ \\
\hline Variable & Lags & $\begin{array}{c}\text { (w/out } \\
\text { trend) }\end{array}$ & (w/trend) & $\begin{array}{c}\text { (w/out } \\
\text { trend) }\end{array}$ & (w/trend) \\
\hline Company Size (natural log) & 1 & 1.7370 & -.2897 & $-2.8763^{*}$ & $-6.3273^{*}$ \\
\hline Debt & 2 & $-11.1798^{*}$ & $-14.9497^{*}$ & $-9.9182^{*}$ & $-1.8516^{*}$ \\
\hline Employee Turnover & 2 & $-3.2397^{*}$ & $-7.4415^{*}$ & $-7.7288^{*}$ & $-60.2228^{*}$ \\
\hline International Sales Growth & 2 & $-6.605^{*}$ & $-18.8330^{*}$ & $-20.8925^{*}$ & $-46.8251^{*}$ \\
\hline Stock Compensation & 1 & $-2.1242^{*}$ & 2.0901 & 1.5208 & $-7.402^{*}$ \\
\hline Return on Assets & 2 & -1.3857 & $-4.1847^{*}$ & $-3.0731^{*}$ & $-71.9056^{*}$ \\
\hline Interest Rate & 1 & .2218 & -1.5085 & $-5.2583^{*}$ & $-5.6649^{*}$ \\
\hline Inflation Rate & 1 & $-1.8736^{*}$ & -0.9264 & $-1.9730^{*}$ & 1.1874 \\
\hline Unemployment Rate & 1 & $-5.2869^{*}$ & $-4.8751^{*}$ & $-4.0213^{*}$ & $-4.6691^{*}$ \\
\hline
\end{tabular}

*significant at the $\mathrm{p}<.05$ level

Because the overall probit model indicated the use of random effects instead of fixed effects, this same methodology is applied to the probit model for quick service restaurants, in order to maintain consistency in reporting results and to control estimator bias. As noted in Table 29, the overall probit model for the quick service restaurants is significant at $\mathrm{p}<.05$; with a chi-square value of .0417. The chi-square value is utilized in analysis instead of the F-statistic because of the determined selection of a random effects model (Baltagi, 2008). Additionally, the 
model also provides the intra-class correlation, rho, indicating the percent of variance that is due to differences across panels (companies). This value is .0658975, which means that the variance between companies is only $6.5 \%$. This makes intuitive sense because the restaurants all belong to the same competitive set, or category. Table 29 provides the details regarding significance for each of the variables in the model.

Table 29: QSR Final Probit Model (form and identified lags included)

\begin{tabular}{|l|c|c|c|c|}
\hline Variable & Coefficient & Standard Error & Z-score & p-value \\
\hline DL.Company Size (natural log) & .2706034 & .3942566 & .69 & .492 \\
\hline DL2.Debt & 3.307191 & 1.49896 & 2.21 & $.027^{*}$ \\
\hline DL2.Employee Turnover & -6.336522 & 4.521925 & -1.4 & .161 \\
\hline Recession & .4174241 & .7317968 & .57 & .568 \\
\hline DL2.International Sales Growth & 2.238144 & 1.785982 & 1.25 & .210 \\
\hline DL.Stock Compensation & -.0516211 & .5343187 & -.10 & .923 \\
\hline DL2.Return on Assets & .8385168 & 2.439287 & .34 & .731 \\
\hline DL.Interest Rate & -89.02561 & 35.29353 & -2.52 & $.012^{*}$ \\
\hline DL.Inflation Rate & 22.49714 & 15.03998 & 1.50 & .135 \\
\hline DL.Unemployment Rate & -.7023625 & 26.58042 & -.03 & .979 \\
\hline Organizational Structure & .376746 & .39447 & .96 & .340 \\
\hline
\end{tabular}

*Significant at $\mathrm{p}<.05$ level

While the above results reveal that the model as a whole is a significant fit to the data, only debt and interest rate appear to have a significant impact on the increased risk of fraud as evidenced by an incidence of a reported internal control deficiency. Therefore, it can be said that there is a significant relationship between increased risk of fraud and interest rate. This is interesting to note because the original probit model for all restaurant companies determined that all of the macroeconomic factors are significant. For quick service restaurants, interest rate is the only variable of the macroeconomic conditions to still be significant. Using the marginal effects 
equation, it can be said that each additional change in interest rates yields an increase of about $17.5 \%$ in the likelihood of increased risk of fraud through a reported control deficiency for quick service restaurants. Additionally, there is a significant relationship between increased risk of fraud and debt. Debt is the only company-specific variable that indicates significance for quick service restaurants. This makes sense, as a large number of quick service units are dependent upon debt financing for growth (Chathoth \& Olsen, 2007). Using the marginal effects equation, it can be said that each additional unit change in debt leverage yields an increase of about $67 \%$ in the likelihood of increased risk of fraud through a reported control deficiency for quick service restaurants.

The results of the probit model for the quick service restaurants provide an opportunity to explore this segment in greater detail in future research. This will be further explained in Chapter 5. Next, the results for the fast casual restaurant segment will be provided for additional insight regarding the overall model.

\section{Fast Casual Restaurants Results}

Over the last decade, the fast casual restaurants have become one of the rapidest growing concepts of the restaurant industry (Ryu et. al, 2010). Although these restaurants are a smaller part of the overall market when compared to quick service and casual dining segments, they are exploding on the restaurant scene. This category of restaurants was established in the 1990s, and

is characterized by higher food quality and better atmosphere than quick service restaurants, but does not offer full table service. When analyzing this segment from the presented data, the population includes 11 companies over a 10 year period across 12 variables, providing 1,320 total data points. Unit root tests are performed as described in the previous section for the 
overall model. The final unit root tests that reveal the optimal lag selection combined with the form of the data is presented in Table 30. For the fast casual restaurant segment, the variables are all stationary in the first difference. Therefore, the null hypothesis for each of the continuous variables is rejected; there is no unit root. Additionally, lags are incorporated and optimized at the minimized AIC level for each of the variables and presented in Table 30.

Table 30: Fast Casual Final Unit Root Tests

\begin{tabular}{|l|c|c|c|c|c|}
\hline & & $\begin{array}{c}\text { Level } \\
\text { Form }\end{array}$ & $\begin{array}{c}\text { Level } \\
\text { Form }\end{array}$ & $\begin{array}{c}\text { 1st } \\
\text { Difference }\end{array}$ & $\begin{array}{c}\text { 1st } \\
\text { Difference }\end{array}$ \\
\hline Variable & Lags & $\begin{array}{c}\text { (w/out } \\
\text { trend) }\end{array}$ & $\begin{array}{c}\text { (w/trend) } \\
\text { (w/out } \\
\text { trend) }\end{array}$ & (w/trend) \\
\hline Company Size (natural log) & 1 & $-3.0858^{*}$ & $-6.1240^{*}$ & $-5.0750^{*}$ & $-5.4206^{*}$ \\
\hline Debt & 2 & -0.7491 & -1.4396 & $-1.8019^{*}$ & 6.1485 \\
\hline Employee Turnover & 1 & $-2.9685^{*}$ & $-2.4948^{*}$ & $-3.9215^{*}$ & $-4.4625^{*}$ \\
\hline International Sales Growth & 2 & $-3.1391^{*}$ & $-22.5958^{*}$ & $-15.4999^{*}$ & 11.7075 \\
\hline Stock Compensation & 1 & $-2.6110^{*}$ & $-2.9146^{*}$ & $-4.7168^{*}$ & $-6.6775^{*}$ \\
\hline Return on Assets & 1 & -0.8428 & -1.0111 & $-2.5388^{*}$ & $-5.9763^{*}$ \\
\hline Interest Rate & 1 & 0.2452 & $-1.6677^{*}$ & $-5.8132^{*}$ & $-6.2628^{*}$ \\
\hline Inflation Rate & 1 & $-2.0714^{*}$ & -1.0241 & $-2.1813^{*}$ & 1.3127 \\
\hline Unemployment Rate & 1 & $-5.8449^{*}$ & $-5.3896^{*}$ & $-4.4457^{*}$ & $-5.1619^{*}$ \\
\hline
\end{tabular}

*significant at the $\mathrm{p}<.05$ level

Because the overall probit model indicated the use of random effects instead of fixed effects, this same methodology is applied to the probit model for fast casual service restaurants, in order to maintain consistency in reporting results and to control estimator bias. As noted in Table 31, the overall probit model for the fast casual restaurants is significant at $\mathrm{p}<.1$; with a chi-square value of .0748. The chi-square value is utilized in analysis instead of the F-statistic because of the determined selection of a random effects model (Baltagi, 2008). Additionally, the model also provides the intra-class correlation, rho, indicating the percent of variance that is due 
to differences across panels (companies). This value is .0003148, which means that the variance between companies is only .03\%. This makes intuitive sense because the restaurants all belong to the same competitive set, or category. Table 31 provides the details regarding significance for each of the variables in the model.

Table 31: Fast Casual Final Probit Model (form and identified lags included)

\begin{tabular}{|l|c|c|r|c|}
\hline \multicolumn{1}{|c|}{ Variable } & Coefficient & Standard Error & Z-score & p-value \\
\hline DL.Company Size (natural log) & -.2135908 & .2428322 & -.88 & .379 \\
\hline DL2.Debt & -1.626176 & 1.484329 & -1.10 & .273 \\
\hline DL.Employee Turnover & -1.465534 & 3.395324 & -.43 & .666 \\
\hline Recession & .0358663 & .3486531 & .10 & .918 \\
\hline DL2.International Sales Growth & 5.457722 & 2.245515 & -.30 & $.015^{*}$ \\
\hline DL.Stock Compensation & .6784089 & .3769354 & 1.80 & $.072^{* *}$ \\
\hline DL.Return on Assets & -8.200609 & 4.256949 & -1.93 & $.054^{* *}$ \\
\hline DL.Interest Rate & 21.29187 & 25.9344 & .82 & .412 \\
\hline DL.Inflation Rate & -13.60071 & 14.02891 & -.97 & .332 \\
\hline DL.Unemployment Rate & 1.219329 & 12.90158 & .09 & .925 \\
\hline Organizational Structure & -.1250649 & .4119568 & -.30 & .761 \\
\hline
\end{tabular}

*Significant at $\mathrm{p}<.05$ level

** Significant at $\mathrm{p}<.1$ level

While the above results reveal that the model as a whole is a significant fit to the data at $\mathrm{p}<.1$, only international sales growth, stock compensation and return on assets have a significant impact on the increased risk of fraud as evidenced by an incidence of a reported internal control deficiency. This is interesting to note because the original probit model for all restaurant companies determined that all of the macroeconomic factors are significant, while the model does not seem to indicate that these factors are significant for fast casual concepts. This may be explained by the strong growth rate of these types of restaurants noted over recent time (Ryu et. al, 2010), meaning that this group of restaurants is not sensitive to changes in macroeconomic 
factors. However, as noted, the company specific variables still may provide insight into increased fraud risk. Using the marginal effects equation, it can be said that each additional change in international sales growth yields an increase of about 95\% in the likelihood of increased risk of fraud through a reported control deficiency for fast casual restaurants. Additionally, there is a significant relationship between increased risk of fraud and executive stock compensation. This makes sense, as a large number of fast casual restaurant units are dependent upon capital equity for growth (Ryu et. al, 2010). Using the marginal effects equation, it can be said that each additional unit change in stock compensation percentage yields an increase of about $15.5 \%$ in the likelihood of increased risk of fraud through a reported control deficiency for fast casual restaurants. Finally, the significant relationship between increased risk of fraud and return on assets can be analyzed accordingly. Using the marginal effects equation, it can be said that each additional unit change in return on assets yields an increase of about $11.1 \%$ in the likelihood of increased risk of fraud.

The results of the probit model for the fast casual restaurants provide an opportunity to explore this segment in greater detail in future research. This will be further explained in Chapter 5. Next, the results for the casual dining restaurant segment will be provided for additional insight regarding the overall model.

\section{Casual Dining Restaurants Results}

Casual dining restaurants often make up the largest segment of restaurant companies, in food service sales (NRA, 2014). Restaurants in this segment are characterized by full table service, specialized cuisine, higher food quality and better atmosphere; although décor, food and service is usually less remarkable than a fine dining establishment (Hwang et al., 2011). When 
analyzing this segment from the presented data, the population includes 10 companies over a 10 year period, providing 1,200 total data points. Unit root tests are performed as described in the previous section for the overall model. The final unit root tests that reveal the optimal lag selection combined with the form of the data is presented in Table 32. Also, based on the principles of ARDL models as described, the variables are presented in mixed order for inclusion in the probit model because of differences in integrated order. For the casual dining restaurant segment, the variables are all stationary in level form, with the exception of company size and interest rate, which are stationary in the first difference. Therefore, the null hypothesis for each of the variables is rejected; there is no unit root. Additionally, lags are incorporated and optimized at the minimized AIC level for each of the variables and presented in Table 32.

Table 32: Casual Dining Final Unit Root Tests

\begin{tabular}{|c|c|c|c|c|c|}
\hline & & $\begin{array}{l}\text { Level } \\
\text { Form }\end{array}$ & $\begin{array}{l}\text { Level } \\
\text { Form }\end{array}$ & $\begin{array}{c}\text { 1st } \\
\text { Difference }\end{array}$ & $\begin{array}{c}\text { 1st } \\
\text { Difference }\end{array}$ \\
\hline Variable & Lags & $\begin{array}{l}\text { (w/out } \\
\text { trend) }\end{array}$ & (w/trend) & $\begin{array}{l}\text { (w/out } \\
\text { trend) }\end{array}$ & (w/trend) \\
\hline Company Size (natural log) & 2 & -1.5283 & -1.0200 & $-2.6307 *$ & $-15.0845^{*}$ \\
\hline Debt & 2 & $-1.6634^{*}$ & $-3.7525 *$ & $-2.6843^{*}$ & $-9.2248^{*}$ \\
\hline Employee Turnover & 1 & $-2.8486 *$ & $-3.8229 *$ & $-3.3532 *$ & $-4.3157 *$ \\
\hline International Sales Growth & 2 & $-5.5253 *$ & 1.9944 & 4.7551 & $-7.3672 *$ \\
\hline Stock Compensation & 1 & $-6.4339 *$ & $-4.6491 *$ & $-5.8149 *$ & $-9.5876^{*}$ \\
\hline Return on Assets & 1 & $-4.8396 *$ & $-3.6892 *$ & $-5.5787 *$ & $-6.0750 *$ \\
\hline Interest Rate & 1 & 0.2338 & -1.5901 & $-5.5427 *$ & $-5.9713^{*}$ \\
\hline Inflation Rate & 1 & $-1.9750^{*}$ & -0.9765 & $-2.0798^{*}$ & 1.2516 \\
\hline Unemployment Rate & 1 & $-5.5729 *$ & $-5.1388 *$ & $-4.2388 *$ & $-4.9216 *$ \\
\hline
\end{tabular}

*significant at the $\mathrm{p}<.05$ level

Because the overall probit model indicated the use of random effects instead of fixed effects, this same methodology is applied to the probit model for casual dining restaurants, in 
order to maintain consistency in reporting results and to control estimator bias. As noted in Table 33, the overall probit model for the casual dining segment is significant at $\mathrm{p}<.05$; with a chi-square value of .0245. The chi-square value is utilized in analysis instead of the F-statistic because of the determined selection of a random effects model (Baltagi, 2008). Additionally, the model also provides the intra-class correlation, rho, indicating the percent of variance that is due to differences across panels (companies). This value is .009521, which means that the variance between companies is only .9\%. This makes intuitive sense because the restaurants all belong to the same competitive set, or category. Table 33 provides the details regarding significance for each of the variables in the model.

Table 33: Casual Dining Final Probit Model (form and identified lags included)

\begin{tabular}{|l|c|c|r|c|}
\hline \multicolumn{1}{|c|}{ Variable } & Coefficient & Standard Error & \multicolumn{1}{c|}{ Z-score } & \multicolumn{1}{c|}{ p-value } \\
\hline DL2.Company Size (natural log) & -.1015746 & .1701989 & -0.60 & 0.551 \\
\hline L2.Debt & -2.323406 & .7465542 & -3.11 & $0.002^{*}$ \\
\hline L.Employee Turnover & 5.347689 & 3.537109 & 1.51 & 0.131 \\
\hline Recession & .6133752 & .3503187 & 1.75 & $0.080^{* *}$ \\
\hline L2.International Sales Growth & 4.935901 & 3.879924 & 1.27 & 0.203 \\
\hline L.Stock Compensation & .7898839 & .3477333 & 2.27 & $0.023^{*}$ \\
\hline L.Return on Assets & 4.791631 & 3.96842 & 1.21 & 0.227 \\
\hline L.Interest Rate & -68.30555 & 28.16733 & -2.42 & $0.015^{*}$ \\
\hline L.Inflation Rate & 18.79369 & 13.76444 & 1.37 & 0.172 \\
\hline L.Unemployment Rate & .7623437 & 9.070301 & 0.08 & 0.933 \\
\hline Organizational Structure & -1.24621 & .3821696 & -3.26 & $0.001^{*}$ \\
\hline
\end{tabular}

*Significant at $\mathrm{p}<.05$ level

**Significant at $\mathrm{p}<.1$ level

While the above results reveal that the model as a whole is a significant fit to the data at $\mathrm{p}<.05$, a mix of the variables at both the macro and company level are significant, including the Recession, interest rate, debt, stock compensation and organizational structure. These variables 
all have a significant impact on the increased risk of fraud as evidenced by an incidence of a reported internal control deficiency. This is interesting to note because the original probit model for all restaurant companies determined that all of the macroeconomic factors are significant, while none of the company level variables were significant. This may suggest that the casual dining segment has been most affected by the macroeconomic conditions and related company factors due to their size in the industry.

For the macroeconomic conditions, using the marginal effects equation, it can be said that each additional change in a Recessionary time period yields an increase of about $36 \%$ in the likelihood of increased risk of fraud through a reported control deficiency for casual dining restaurants. Additionally, using the marginal effects equation, it can be said that each additional change in interest rates yields an increase of about $19 \%$ in the likelihood of increased risk of fraud through a reported control deficiency for casual dining restaurants.

For the company level variables, it can be said that a significant relationship exists between increased risk of fraud and debt, as a large number of casual dining restaurant units are dependent upon debt financing for growth (Chathoth \& Olsen, 2007). Using the marginal effects equation, it can be said that each additional unit change in debt leverage yields an increase of about 22\% in the likelihood of increased risk of fraud through a reported control deficiency for casual dining restaurants.

Finally, two other related company level variables of stock compensation and organizational structure reveal significance in their relationship to increased risk of fraud. Using the marginal effects equation, it can be said that each additional unit change in stock compensation yields an increase of about $41 \%$ in the likelihood of increased risk of fraud through a reported control deficiency for casual dining restaurants. Lastly, the significant 
relationship between increased risk of fraud and organizational structure can be analyzed accordingly. Using the marginal effects equation, it can be said that whether or not the CEO is also the Chairman of the Board indicates an increase of about 32\% in the likelihood of increased risk of fraud.

The results of the probit model for the casual dining restaurants provide an opportunity to explore this segment in greater detail in future research. This will be further explained in Chapter 5. Finally, the results for the fine dining restaurant segment will be provided for additional insight regarding the overall model.

\section{Fine Dining Restaurants Results}

Fine dining restaurants make up about $10 \%$ of total U.S. restaurant sales, and are characterized by full table service, extremely high food quality and price, and a formal ambience (Ban, 2012). When analyzing this segment from the presented data, the population includes 10 companies over a 10 year period, providing 1,200 total data points. Unit root tests are performed as described in the previous section for the overall model. The final unit root tests that reveal the optimal lag selection combined with the form of the data is presented in Table 34. Also, based on the principles of ARDL models as described, the variables are presented in mixed order for inclusion in the probit model because of differences in integrated order. For the fine dining restaurant segment, the variables are all stationary in level form, with the exception of debt and interest rate, which are stationary in the first difference. Therefore, the null hypothesis for each of the variables is rejected; there is no unit root. Additionally, lags are incorporated and optimized at the minimized AIC level for each of the variables and presented in Table 34. 
Table 34: Fine Dining Final Unit Root Tests

\begin{tabular}{|c|c|c|c|c|c|}
\hline & & Level Form & $\begin{array}{l}\text { Level } \\
\text { Form }\end{array}$ & $\begin{array}{c}\text { 1st } \\
\text { Difference }\end{array}$ & $\begin{array}{c}\text { 1st } \\
\text { Difference }\end{array}$ \\
\hline Variable & Lags & $\begin{array}{l}\text { (w/out } \\
\text { trend) }\end{array}$ & (w/trend) & $\begin{array}{l}\text { (w/out } \\
\text { trend) }\end{array}$ & (w/trend) \\
\hline $\begin{array}{l}\text { Company Size (natural } \\
\text { log) }\end{array}$ & 1 & $-3.0444 *$ & $-5.0217 *$ & $-5.7459 *$ & $-5.0982 *$ \\
\hline Debt & 1 & 3.5704 & $-1.8874^{*}$ & $-2.6454^{*}$ & $-26.7077^{*}$ \\
\hline Employee Turnover & 2 & $-2.6114^{*}$ & $-3.1954 *$ & -1.2989 & $-1.8403 *$ \\
\hline International Sales Growth & 2 & $-3.0914^{*}$ & 0.2470 & 1.3839 & $-4.2458 *$ \\
\hline Stock Compensation & 1 & $-4.7720 *$ & 1.7185 & 0.6881 & $-5.8812 *$ \\
\hline Return on Assets & 1 & $-4.9564 *$ & $-5.2738 *$ & $-10.6007^{*}$ & $-7.4457 *$ \\
\hline Interest Rate & 1 & 0.2338 & -1.5901 & $-5.5427^{*}$ & $-5.9713^{*}$ \\
\hline Inflation Rate & 1 & $-1.9750 *$ & -0.9765 & $-2.0798 *$ & 1.2516 \\
\hline Unemployment Rate & 1 & $-5.5729 *$ & $-5.1388 *$ & $-4.2388 *$ & $-4.9216^{*}$ \\
\hline
\end{tabular}

*significant at the $\mathrm{p}<.05$ level

Because the overall probit model indicated the use of random effects instead of fixed effects, this same methodology is applied to the probit model for casual dining restaurants, in order to maintain consistency in reporting results and to control estimator bias. As noted in Table 35, the overall probit model for the fine dining segment is not significant since $\mathrm{p}>.05$; which is evidenced by a chi-square value of .8153 . The chi-square value is utilized in analysis instead of the F-statistic because of the determined selection of a random effects model (Baltagi, 2008). Additionally, the model also provides the intra-class correlation, rho, indicating the percent of variance that is due to differences across panels (companies). This value is .0254548, which means that the variance between companies is only $2.5 \%$. This makes intuitive sense because the restaurants all belong to the same competitive set, or category. Table 35 provides the details regarding significance for each of the variables in the model. 
Table 35: Fine Dining Final Probit Model (form and identified lags included)

\begin{tabular}{|l|c|c|r|c|}
\hline \multicolumn{1}{|c|}{ Variable } & Coefficient & Standard Error & Z-score & p-value \\
\hline L.Company Size (natural log) & .0670734 & .144654 & 0.46 & 0.643 \\
\hline DL.Debt & -.7577061 & .9422958 & -0.80 & 0.421 \\
\hline L2.Employee Turnover & -3.195315 & 2.249279 & -1.42 & 0.155 \\
\hline Recession & -.0821283 & .3390444 & -0.24 & 0.809 \\
\hline L2.International Sales Growth & -4.024476 & 2.713959 & -1.48 & 0.138 \\
\hline L.Stock Compensation & .1733885 & .3349882 & 0.52 & 0.605 \\
\hline L.Return on Assets & -4.506085 & 3.838069 & -1.17 & 0.240 \\
\hline DL.Interest Rate & 14.82901 & 25.60644 & 0.58 & 0.563 \\
\hline L.Inflation Rate & -21.32659 & 20.13765 & -1.06 & 0.290 \\
\hline L.Unemployment Rate & 4.708055 & 8.830545 & 0.53 & 0.594 \\
\hline Organizational Structure & .0898714 & .3814851 & 0.24 & 0.814 \\
\hline
\end{tabular}

*Significant at $\mathrm{p}<.05$ level

$* *$ Significant at $\mathrm{p}<.1$ level

The above results reveal that the model as a whole is not a significant fit to the data since $\mathrm{p}>.05$. These results therefore indicate that variables related to the model for fine dining restaurants do not have a significant impact on the increased risk of fraud as evidenced by an incidence of a reported internal control deficiency. This is interesting to note because the original probit model for all restaurant companies determined that all of the macroeconomic factors are significant. This may suggest that the fine dining segment has not been affected by the macroeconomic conditions and related company factors due to their smaller size in the industry.

The results of the probit model for the fine dining restaurants provide an opportunity to explore this segment in greater detail in future research. This will be further explained in Chapter 5. 


\section{$\underline{\text { Conclusion }}$}

The results of the applied probit model reveal for the entire population set of publicly traded restaurant companies that the macroeconomic factors of the Recession, interest rate, inflation rate and unemployment rate all have a significant impact on the increased risk of fraud, as evidenced through a reported internal control deficiency. These factors all impact demand by consumers for all types of restaurants, and are often noted as risk factors in management's discussion and analysis (FASAB, 1999). Therefore, it can be said that the results of this study empirically support the intuition that changes in macroeconomic conditions may impact increased risk of fraud for companies in the restaurant industry. From a practical standpoint, these results may support the position that management may not have control over factors like macroeconomic conditions that in turn, may increase the likelihood of fraud (Wang, 2012). As noted in Chapter 2, these factors are linked to the "opportunity" construct of the fraud triangle.

The likelihood of increased risk of fraud is evidenced through the mathematical function that applies the probability values from the results of the model. Under these parameters, the probability of increased fraud risk ranges from 43 - 68 percent, depending on the macroeconomic variable, for the overall population of restaurant companies. As supported by the variance in company size and the large intra-class correlation, additional results were provided for each of the restaurant segments in the overall population of 40 companies. These results provided an explanation as to the differences between each of the companies, and empirically supported intuition that different types of restaurant companies may experience significance for different variables. An elaboration of these results will be conveyed for the overall model and provide a platform for future research in Chapter 5. 


\section{CHAPTER 5: CONCLUSIONS AND IMPLICATIONS}

\section{Introduction}

The following chapter provides a discussion of the major findings and a summary of results, in addition to detailed interpretations of the research objectives. Theoretical and practical implications are also presented, considering both the fraud triangle framework and the restaurant industry as a whole. Finally, the chapter concludes with suggestions for future research and acknowledges limitations of the study.

\section{Overview of the Study}

The main objective of this study was to determine whether or not there are factors or variables that have a significant impact on increased risk of fraud as evidenced via a reported internal control deficiency by publicly traded restaurant companies. Ultimately, the overall significance of the model provides evidence that the Sarbanes-Oxley Act continues to identify areas of increased fraud risk for publicly traded restaurant companies. The study draws on the fraud triangle as the theoretical framework that supports the selection of both financial and nonfinancial variables as conditions that increase the likelihood of increased fraud risk. Therefore, the purpose of the study has been two-fold: (1) to first identify the optimal conditions (variables) that may prompt fraudulent behavior for publicly traded restaurant companies; and (2) to identify the relationship between these variables and increased risk of fraud. The dual purpose of the study has been accomplished through specific analysis of the relationships between the variables through application of a probit model. Each of the presented objectives with the corresponding hypothesis is presented in the next sections. 


\section{Objective One: Sarbanes-Oxley Act}

The first objective of the study was to determine whether or not the Sarbanes-Oxley Act has a significant impact on detecting increased risk of fraud in the restaurant industry through the conditions associated with a reported internal control deficiency, supported by the fraud triangle theoretical framework. It has been noted that internal control is the first line of defense for an organization against fraud (Arad \& Jamshedy-Navid, 2010), so when deficiencies are reported in company SEC filings as part of compliance efforts with the Sarbanes-Oxley Act, the results of the study indicate that executive management should focus on the factors identified in the model in order to reduce the likelihood of fraud. The first hypothesis stated that the Sarbanes-Oxley Act of 2002 has had a significant impact on highlighting areas of increased risk of fraud for publicly traded U.S. restaurant companies. Therefore, the null hypothesis asserted that there was no relationship between increased risk of fraud and the Sarbanes-Oxley Act, and the alternate hypothesis mandated that there is a significant relationship between increased risk of fraud and the Sarbanes-Oxley Act:

$\mathbf{H}_{\mathbf{0}}=$ There is no relationship between increased risk of fraud and the Sarbanes-Oxley Act.

$\mathbf{H}_{\mathbf{1}}=$ There is a significant relationship between increased risk of fraud and the SarbanesOxley Act.

Given that the overall model was significant at the $\mathrm{p}<.05$ level, it can be said that the Sarbanes-Oxley Act has a significant impact on highlighting areas of increased risk of fraud for the restaurant industry, when considering specific factors or variables that are linked to the fraud triangle. The null hypothesis is therefore rejected, and the alternate hypothesis cannot be rejected. 
These results are supported by literature as noted in Chapter 1. The Sarbanes-Oxley Act was always intended to restore public confidence in the reliability of financial statements of publicly traded companies (Hess, 2007). By requiring executive management to take responsibility for the processes in their organization and assess the internal controls in place, accountability is established and results are provided to the general public. When deficiencies are reported, this provides evidence that internal control systems are vulnerable, and the propensity for fraud increases significantly (Baker, 1998; Geller, 1991; Rezaee, 2005). Therefore, it can be said that the results of this study confirm work completed by Ge \& McVay (2005) and Ashbaugh-Skaife et al., (2006). Ideally, companies would prefer to report that their internal controls over financial reporting are effective and do not have any reported deficiencies, which would support the null hypothesis that there is no relationship between increased risk of fraud and the Sarbanes-Oxley Act. However, based on the overall model significance, this study supports the claim that increased risk of fraud occurs when deficiencies are reported. Inherently, the model additionally supports the claim that despite the Act, reported deficiencies will ultimately occur when certain conditions are present in the business environment. For example, macroeconomic conditions such as the Recession, interest, inflation, and unemployment rates were found to be significant contributors to increased fraud risk for publicly traded restaurant companies. These triggers provide insight into the main conditions that executive managers should pay attention to in order to manage opportunities for fraud risk. Additionally, it is noted that typical financial measures and financial characteristics such as company size and debt are not contributors to increased fraud risk. The indication that only macroeconomic conditions are significant provides powerful support for understanding the conditions and events that may 
impact consumer spending in publicly traded restaurant companies. These conclusions and implications regarding these conditions will be explored later in the chapter.

The implications from the significance of the overall model is apparent when considering the business processes that exist the industry, the susceptibility of the industry to consumer demand changes and the theoretical framework of the fraud triangle. Essentially, from a managerial and practical perspective, the results suggest that corporate governance structure and internal control processes for restaurant companies may be at an increased risk for manipulation/fraud despite the Sarbanes-Oxley Act’s attempt to promote stronger internal controls and accountability in company processes. Additionally, at least two legs of the fraud triangle framework, pressure and opportunity, are supported through the results, providing evidence that managers may be impacted by macroeconomic conditions that act as catalysts for increased probability of fraud. For example, literature supports both pressure and opportunity as risk factors for fraud, and define both as the "force behind the motivation for behavior" and the “environment or temporary circumstance that allows fraud to be committed”, respectively (Albrecht, 2003; Jensen, 1993; Wells, 1997; Cressey, 1973). Specifically, the macroeconomic conditions of the Recession, interest, inflation and unemployment rates are defined through both pressure and opportunity constructs, as noted in the literature review. Rationalization is the third leg of the fraud triangle, and has been defined through literature as the frame of mind that allows management to justify dishonest actions (Cressey, 1973). It should be noted that the results did not indicate that variables linked to rationalization are significant elements in increased probability of fraud for publicly traded restaurant companies. Implications for each of the significant variables as previously identified through the constructs of pressure, opportunity, and rationalization will be discussed in subsequent sections of the chapter. 


\section{Objective \#2: Company Size}

As revealed in Chapter 4, it has been noted that while company size was positively correlated to the incidence of a reported deficiency for all companies, the relationship was not statistically significant. Therefore, the null hypothesis cannot be rejected, and it can be stated that there is no relationship between increased risk of fraud and company size for all publicly traded restaurant companies. The null hypothesis and alternative hypothesis are presented below:

$\mathbf{H}_{\mathbf{0}}=$ There is no relationship between increased risk of fraud and company size.

$\mathbf{H}_{\mathbf{1}}=$ There is a significant relationship between increased risk of fraud and company size. $\operatorname{Pr}\left(\mathrm{Y}=1 \mid \mathrm{X}_{1}\right)=\Phi\left(\mathrm{X}_{1} \beta\right)$

The implication that the null hypothesis cannot be rejected disconfirms previous research conducted by Ge and McVay (2005), who determined that companies with deficiencies are often less profitable and smaller than those companies that have not disclosed deficiencies. In comparison, it should also be noted that Beneish (1999) determined that companies most likely to manipulate financial statements consist of those that are growing rapidly and thus reporting higher margins, instead of the smaller companies as determined by Ge \& McVay (2005). Therefore, the results seem to imply that while changes in company size may be an indicator of increased fraud risk for other types of companies, it appears that this variable by itself is not conducive to increased fraud risk for restaurant companies. Stated another way, the results seem to indicate that it doesn't matter how big or small a company is over time, rather, the results reveal that indicators of fraud are a complex web of a multitude of factors that rely on opportunity, intent and justification (Yu, 2008; Cressey, 1973). The results therefore suggest that other factors may also be linked to incidences of reported deficiencies. In the context of the 
proposed model, a positive correlation with size indicates that it should still be considered as a factor, however, perhaps it should be considered in conjunction with other factors. In addition, since the model captured company size at specific points in time for each company over ten years, the dynamic aspect of the variable is not considered (e.g., changes in company size over time). The specific growth rate for companies combined with other factors may be an additional element that might provide support for company size as a factor in increased risk of fraud, however, company size by itself is not considered to be a risk factor.

One literature stream that supports this line of thinking is derived from research completed by Aherns \& Chapman (2004), who found that company size by itself was not an important indicator of fraud, rather, the system that management used to capture the revenue coupled with changes in food cost over time may contribute to increased fraud risk. While the current study didn’t specifically examine systems, it stands to reason that when systems controls are weak, the opportunity for revenue manipulation increases (Wanhill, 1994). Supporting Aherns \& Chapman (2004) and Wanhill (1994), it appears that both researchers are implying the essence of the fraud triangle theory: if management intends to commit fraud, and the conditions are right, then it is likely to occur (Cressey. 1973). Supporting this notion, as echoed by many industry practitioners after the ENRON scandal, Alex Plavsic, head of the forensic team for KPMG, said: “There was a lot of emphasis around risk, systems and controls [after Enron]. Ultimately the real issue is how you get people in your business behaving properly and ethically.” While company size doesn’t appear to be a main risk factor pointing to increased fraud risk for publicly traded restaurant companies, these results provide at least the beginnings of a road map for risk factors of increased fraud risk that executive leadership may be able to utilize. 
In conclusion, given the findings of this study and the overall conflicting opinions regarding the implications of company size on reported internal control deficiencies in literature, it makes sense to conclude that company size does not impact increased risk of fraud for publicly traded restaurant companies. Areas for future research in this area could include a deeper dive into systems for capturing revenue for publicly traded restaurants in conjunction with a review of food cost changes over time. The review of the systems may provide insight into actual changes in the businesses that affect company size. Given the positive correlation for company size found in this study, perhaps additional considerations like company size growth rate combined with other factors will provide a significant relationship for increased fraud risk. Additionally, there may also be certain repeating instances of fraud associated with varying types of company sizes, so research regarding patterns based size may provide additional insight in this area for publicly traded restaurant companies.

\section{Objective \#3: Debt}

Chapter 4 indicated that debt was negatively correlated to the incidence of a reported internal control deficiency and it is not statistically significant. Based on these results, the null hypothesis cannot be rejected, and there is no relationship between increased risk of fraud and amount of debt for publicly traded restaurant companies. Previous studies that investigated firm debt leverage revealed that companies that were constrained by debt covenants were at an increased risk for misstatements (Efendi, et al, 2007; Persons, 1995). The results of this study do not support these previous findings, but may be explained from both a practical and theoretical vantage point, considering other relevant literature streams in this area. 
First, it is important to recognize that debt covenants often work in tandem with other financing and operating components of the business (Ritter, 2003). While debt financing increases liabilities on the balance sheet, it also allows for business growth and development, which may be reflected through increased profit and appreciating assets (Ho, 2012). For example, restaurant companies that obtain a line of credit for the purpose of expanding operations domestically or overseas are looking for a payoff through increased profits relating to new restaurant builds while preserving their own capital for other needs (Kim \& Gu, 2006; Ritter, 2003). During an upswing of business, the investment in debt financing could prove to be quite lucrative in the long run. Therefore, because of the positive ways that debt financing can help a business, it may not be an appropriate indicator of increased fraud risk for publicly traded restaurant companies. It appears that past research notes that disruptions in financial markets, poor performance and timing of construction loans and development are the main concerns with why debt financing has been associated with increased fraud risk. In other words, in times of poor performance, debt financing could be a catalyst for increased fraud risk (Raab et al., 2007). However, when companies note an increase in performance in conjunction with debt financing, there may be a better environment of controls, and pressure as it relates to the fraud triangle framework may be alleviated. Additionally, there may be more controls instilled by the banks, who wish to protect their own lending power by selectively choosing only the companies with the highest credit ratings. Therefore, the results of the study seem to suggest that other factors that relate to debt financing, such as development plans and performance, need to be considered when evaluating the impact on increased risk of fraud.

From a theoretical perspective, debt has been linked closely to the construct of pressure (Sidel, 2007) in the fraud triangle framework. However, the results suggest that the amount of 
corporate debt does not increase fraud risk for the total amount of companies in the restaurant industry, insinuating that it is not a factor of consideration. Aside from the practical considerations as noted above, additional research completed by Thorburn (2000) suggests that because the effects of corporate debt pressures are often long term pressures that aren't felt until closer to 15 or 20 year maturity dates, the incidence of a reported deficiency may not be realized as a factor until this particular time frame. Because the sample time period only includes the ten years since the implementation of the Sarbanes-Oxley Act, the time frame may be too short to accurately reflect the significance of debt on increased fraud risk.

Regardless, like with company size and other management controlled variables, intent and opportunity play an important role in predicting the likelihood of fraud. It can therefore be inferred from the results of the study that debt by itself is not an indicator of increased risk of fraud for the complete population of publicly traded restaurant companies, but considering the effects along with other financial characteristics may produce red flags of concern. Additionally, like with company size, the dynamic aspect of the variable was not considered. The model captured the amount of debt at specific moments of time instead of comparing the changes over time. Therefore, the specific rate of debt in conjunction with other variables might be an indicator of increased fraud risk. In summary, management might not consider the amount of incurred debt when evaluating the company for likelihood of increased fraud risk.

\section{Objective \#4: Employee Turnover}

Similar to the debt variable, annual employee turnover for publicly traded restaurant companies was determined to be negatively correlated and not statistically significant to an incident of a reported internal control deficiency, as revealed in Chapter 4. Thus, the null 
hypothesis cannot be rejected, and it can be stated that there is no relationship between increased risk of fraud and employee turnover. As noted in Chapter 2, literature has suggested that turnover creates instability in the business and job functions which in turn may result in increased fraud risk (Allen, 2008). However, in light of the presented results, it should also be noted that within the restaurant industry, turnover is a common and accepted practice (Gustafson, 2002). While turnover is generally thought to be a negative outcome for the restaurant industry through performance and a lost investment in human capital (Ongori, 2007), the annual rates of turnover do not appear to have an effect on reported internal control deficiencies.

There are several reasons that employee turnover rates might not have an impact on reported internal control deficiencies. First, from a practical perspective, it is important to note that most of the turnover rates for restaurant companies are attributed to the hourly employee, where employees in this category that are involved in processes relating to financial controls are not as voluminous (NRA, 2014). Most of the hourly restaurant employees are comprised of student and part-time workers, and encompass approximately $70-80 \%$ of the restaurant company workforce (Dess et al. 2001). Therefore, it can be inferred that the turnover rate numbers are not representative of the population of employees with responsibility for internal controls over financial reporting.

However, at the corporate level, literature dictates that organizational instability and high rates of employee turnover are synonymous (Ongori, 2007). Therefore, in situations where companies are not stable, employees tend to quit and look for stability elsewhere so they may be comfortable with their career progression (Saks, 1996). Conversely, there are indications that employees are more likely to stay when there is a predictable and expected work environment (Zuber, 2001). Additionally, it is noted that in companies with a high level of inefficiency that 
there is also a high level of staff turnover that is realized due to the changes in management structure or performance (Ongori, 2007; Alexander et al., 1994). Costly et al. (1987) pointed out that a high turnover rate may indicate a lack of company policies regarding recruitment, supervisory and grievance procedures. Additionally, the lack of structure at the top may contribute to a lack of motivation for all employees. All these factors contribute to high employee turnover in the sense that when there is no purpose for work and no governance, employees who value a position or career will eventually decide to quit (Trevor, 2001).

Even though these described factors provide the rationale for why employee turnover increases and may provide insight into the current state of a company based on changing turnover rates, they do not address the employees who are still voluntarily employed with the company in question. It is insinuated from literature that the results of high turnover provide opportunities for increased risk of fraud by those employees still with the company, which in turn supports the opportunity leg of the fraud triangle framework. And while it intuitively makes sense that broken systems and lack of policies provide opportunities for fraud and internal control deficiencies, the lack of significance in the results provides evidence that employee turnover is not an important risk factor when predicting the likelihood of increased risk of fraud for publicly traded restaurant companies. In summary, it can be implied that executive management might not consider internal company changes when evaluating the company for likelihood of increased fraud risk.

\section{Objective \#5: Organizational Structure}

As determined in Chapter 4, a restaurant company’s organizational structure does not appear to be a significant factor in the likelihood of increased risk of fraud. Specifically, the 
results determined that risk of fraud does not increase based on whether or not the CEO is also the Chairman of the Board. Additionally, organizational structure is negatively correlated to an incidence of a reported deficiency, which means that the null hypothesis cannot be rejected and it can be said that there is no relationship between increased risk of fraud and whether or not the CEO is also Chairman of the Board.

It is well known that in many public firms, the Chief Executive Officer (CEO) holds the top position representing management, while the Board of Directors exists to provide oversight to corporate activities set forth by management and to protect the interests of shareholders (Booth et al., 2002). At the helm of the Board of Directors is the Chairman, who has power over the general direction of the board. As noted, in numerous companies, the CEO may also serve as the Chairman of the Board of Directors, especially as a company takes on growth initiatives (Boyd, 1995), or if the company is new to market and just establishing a Board. In fact, the CEO may retain the Chairman role for several years before it moves to someone else.

Literature in this area contends that holding both roles may reduce the effectiveness of the board and create a conflict of interest, particularly when it comes to voting on executive compensation. For example, the Board typically votes for the compensation of executive management, and when the CEO is also Chairman of the Board, the "Chairman" is technically voting for his/her own compensation. Additionally, having both positions attributed to one person may compromise the overall integrity of the company (Boyd, 1995). Specifically, having the CEO as the Chairman of the Board enables the effect of having one person as the dominant decision maker, which in turn could promote aggressive accounting practices and instill a culture of poor governance and susceptibility to fraud (Beasley, 1996). 
As noted in Chapter 2, the study proposed that having the CEO as the Chairman of the Board may increase the risk of fraud. While literature clearly supports the case for conflicts of interest and less favorable conditions, it doesn't necessarily point to increased risk of fraud as a result of the dual role of the CEO and Chairman. Further, as suggested by the results of the study, there is no relationship and a negative correlation, which creates further support that organizational structure does not have an impact on increased fraud risk for all publicly traded restaurant companies. Providing further evidence that supports these results, Agrawal et al., (1999) looked at actual fraud instances that occurred in various public companies and whether or not the organizational structure changed as a result of the fraud. The results of their study found little systemic evidence that companies with suspected or actual fraud change the governance leadership after the fraud. Thus, these findings indicate that even when fraud occurs in a company, leadership and organizational structure changes do not reduce the incidence of fraud or have any other beneficial effect on the company (Jensen, 1993; Agrawal, 1999).

One reason why organizational structure changes should not be considered as an indicator of fraud includes consideration of existing internal control deficiencies. As noted by Jensen (1993), a typical corporation's internal controls are often too expensive to change at the executive management level. Likewise, this implies that when there is an internal control deficiency, it usually relates to a violation of a business process or procedure by management which requires a process adjustment. Since most of the time there is no value in changing executive leadership as a result of the deficiency (Agrawal et al., 1999), it stands to reason that organizational structure should not be viewed as an indicator of increased likelihood of fraud. From a theoretical standpoint, the “opportunity” resulting from the CEO and Chairman of the Board holding a dual role is not significant. 


\section{Objective \#6: International Sales Growth}

Chapter 4 revealed that while international sales growth is positively correlated to an incidence of a reported internal control deficiency, the relationship between the two is not statistically significant. Thus, the null hypothesis cannot be rejected and it can be said that there is no relationship between increased risk of fraud and international sales growth. Previous research conducted by Albrecht (2002) revealed that opportunity for fraud increases as companies grow international operations. Additionally, Kim and Gu (2003) supported this claim through research detailing the risks of international growth, providing evidence that international economic and political conditions coupled with foreign currency fluctuations and changing consumer tastes may increase the risk of fraud.

While there are risks in expanding operations overseas, the results of the study imply that this is not an area that executive managers should be concerned with as it relates to increased fraud risk. International growth through franchise partnerships is among the most common strategy employed in order to maximize a company’s financial performance (Koh et al., 2009). And most often, publicly traded restaurant companies expand internationally through franchisee partnerships when they experience the right mix of size, growth rate as it relates to agency cost, brand name capital and risk-sharing considerations (Koh, 2002). Additionally, a study by Hsu and Jang (2009) demonstrated that franchised restaurant companies had significantly higher profitability than non-franchised restaurant companies, and that an optimal franchise proportion exists for all companies in the public sector. The implication from Hsu and Jang's (2009) study suggests that franchise opportunities occur when a company is already experiencing favorable profit margins, which is not deemed to be a favorable environment for fraudulent conditions, based on past literature in this area. Drawing on a study completed by Lafontaine and 
Bhattacharya (1995), empirical literature further suggests that international sales growth through franchising actually lowers financial risk by improving cash flow and providing higher returns on investment. Therefore, from a practical perspective, executive management should feel free to move forward with international growth plans as long as the correct mix of size, risk-sharing and review of costs are considered.

From a theoretical perspective, the results imply that opportunities stemming from international sales growth do not increase fraud risk. In fact, even though risk exists when entering into franchisee partners, it is not enough to warrant concern regarding fraud by executive management. Additionally, to the companies experiencing high international growth rates, franchising actually means diversification of risks by increasing the number of locations through partner's investments. From a strategic opportunity standpoint, this could mean faster network expansion and a better opportunity to focus on changing market needs, which might lead to a reduced effect from competitors (Lee, 1999).

Overall, from both a practical business perspective and related opportunity according to the fraud triangle theoretical framework, executive management should be mindful of growth strategy through international operations so as not to expand too quickly, which may lead to additional risk and opportunity for breakdowns in controls, since a positive correlation exists between international sales growth and incidences of internal control deficiencies. However, publicly traded restaurant companies may take comfort that growth plans might provide a means of achieving strategic priorities while still protecting the company from weaknesses in the internal control structure for publicly traded restaurant companies. 


\section{Objective \#7: Stock Compensation}

Results from chapter four indicate that there is a negative correlation between executive stock compensation and an incidence of an internal control deficiency. Additionally, the relationship between the two variables is not significant, suggesting that there is no relationship between increased risk of fraud and an incidence of an internal control deficiency. These results imply that executive stock compensation is not a consideration of increased fraud risk for publicly traded restaurant companies, which makes sense provide that the model also found that organizational structure was not a significant factor for fraud risk for restaurant companies.

The lack of significance for executive stock compensation is somewhat surprising, given past empirical literature that found evidence linking hefty performance-based executive compensation packages to leadership charged with fraud or mismanaging the companies they

lead. For example, Bromley and Harrast (2011) studied companies that were forced to restate their financial statements compared to similar companies that did not run into such problems. The report found that companies who offer big compensation in the form of executive stock options are more likely to have a going concern; or experience a discontinuation in operations. Additionally, companies where leadership received $92 \%$ or more of their pay in options were more likely to misstate their financials within five years. Also, pressure to misstate financials increases when company performance falls short compared to competitors; and companies that produce strong financials in one year have a propensity for misstatements in the next year, specifically as long as big compensation packages are offered (Mehran, 1995). Furthermore, another study by Moody's found that companies with the highest paid executive leadership, adjusted for things like financial performance and company size, had increased risk of defaulting 
on commercial debt or suffering major downgrades in bond and debt offerings (Johnson \& Ryan, 2003).

While some of this past literature makes an appropriate case for reviewing high executive compensation as an indicator of fraud risk, a study by Markham (2007) makes the point that regulation in this area has suggested that SEC regulation for executive compensation may not be beneficial to the public or the corporate environment, and that corporate focus should continue to be on the other types of regulations that protect shareholder interests, like company operating performance. This is based on the results of the study that proposed that while executive compensation structures for companies that commit fraud were high, those fraud firms represent a small fraction of the population of firms from which the sample is drawn. This implies that the overwhelming majority of firms have structures that are not too high, that is, they do not induce executives to commit fraud (Erickson et al. 2003).

Additionally, while the other studies point to links between executive management compensation and increased risk of fraud, the literature does not address the relationship among differing industry groups (Markham, 2007). As of the current date, a study has not been completed that investigates the relationship between increased risk of fraud and executive compensation specifically for publicly traded restaurant companies. Therefore, based on the results of the current study, it is suggested that publicly traded restaurant companies do not experience the same empirical results as the past studies found. One possible explanation of this is the heavy reliance on consumer demand for drivers of restaurant profitability. As noted by Johnson et al. (2005), operating performance measures suggests that increased fraud risk occurs following declines in operating performance. Given the sensitivity of the restaurant industry to performance changes based on consumer demand, the effects on performance may not have been 
statistically significant enough to indicate internal control deficiencies have occurred as changes are noted to executive compensation performance. Also, the current study seems to mirror Markham's (2007) results that only found a small population of fraud firms with high executive compensation.

Finally, this research objective should be analyzed from a theoretical standpoint of the fraud triangle. While pressure is a supported construct that may lead to increased fraud risk, executive compensation is not a supported pressure that leads to fraud, as evidenced by the results of this study. It is therefore proposed that other pressures such as operating performance should be considered in conjunction with executive compensation in order to support the parameters of the fraud triangle for publicly traded restaurant companies, as evidenced by research completed by Markham (2007) and Johnson et al. (2005).

\section{Objective \#8: Return on Assets}

Return on assets was noted in chapter four to be positively correlated but not statistically significant to incidences of internal control deficiencies. Thus, the null hypothesis could not be rejected and it was determined that there is no relationship between increased fraud risk and return on assets over time for publicly traded restaurant companies. As discussed in chapter two, return on assets is often utilized as a proxy for measuring performance targets to determine how efficiently assets have been utilized (Dechow et al., 1996; Rosner, 2003). In the context of the restaurant industry, ROA can help showcase the ability of restaurant companies to meet performance and bonus targets (Alalehto, 2000).

While pressure to meet targets has been defined from a theoretical standpoint as a common example of financial pressure and systematic risk that may lead to increased fraud, the 
restaurant industry (represented in this sample) overall does not view this variable as an indicator of increased fraud risk. The implications of this are a result of the competing theories regarding how operating efficiency affects systemic risk. As such, Logue and Merville (1972) and Scherrer and Mathison (1996) determined that high profitability or high operating efficiency lowered systematic risk, suggesting that stable cash flow reduces risk of fraud and volatility in stock price. In contrast, Merlicher (1974) and Idol (1978) pointed out that systematic risk, and therefore fraud risk, were positively related to return on assets and other measures of profitability.

One possible explanation for the conflicting and competing theories may be explained by the incidence of other variables that might impact systematic risk and fraud risk. For example, fast growth has been hypothesized to increase systematic risk instead of lowering it (Patel \& Olsen, 1984). The "fast growth" companies therefore may face greater competition and pressure to meet expectations, as evidenced through fluctuating return on assets. This would have the effect of increased risk of fraud through incidences of reported internal control deficiencies. Additionally, fast growth may create a lag time for control systems as the pressure to meet demand becomes the prime driving force (Patel \& Olsen, 1984). Borde (1998) also supported this hypothesis through a study that revealed that increased restaurant earnings before income and taxes was noted to increase systematic risk.

Clearly, it can be said that empirical findings regarding the impact of profitability on systematic risk and fraud risk are inconclusive. Researchers are indicating that operating efficiency as measured through return on assets may positively or negatively impact systematic risk and increased risk of fraud. Similar to other company specific variables presented in the overall model, it is suggested that there is a delicate balance of financial and non-financial 
variables that may impact the probability of increased likelihood of fraud. For example, if a company grows too fast or too slow, or has too much or too little debt, the impact on fraud risk may be negligible.

From a theoretical standpoint, the fraud triangle leg of pressure does not appear to be impacted by return on assets for publicly traded restaurant companies. This isn't too surprising given the implications as described above, however, it also makes sense given the other profitability measures tested in the model. Company size as measured through profit margin was also not statistically significant, however, it was also positively correlated to increased fraud risk. These findings supports the claims made by Patel \& Olsen (1984) and Merlicher (1974), which provide evidence that variables are positively related. While pressure is still a relative leg of the fraud triangle, the variable return on assets does not appear to be a significant concern for executive managers when trying to predict increased likelihood of fraud.

In summary, it can be said that the company specific variables are not significant indicators of increased likelihood of fraud as evidenced through an incidence of a reported internal control deficiency. As mentioned in the previous analysis of the other variables, the results imply overall that there is a delicate balance of company specific variables that may increase fraud risk when evaluated in tandem. In the case of the restaurant industry, all company specific variables were not significant for the time period 2004-2013. However, the last objective of the study addresses the macroeconomic conditions, which have been revealed to have a significant impact, which provides additional support to the fraud triangle theoretical framework and offers managerial implications. 


\section{Objective \#9: Recession and Macroeconomic Factors}

The first part of this study focused on the reported results for company specific variables and analyzed such variables for the total forty companies in the public company restaurant data set. While the company level variables did not produce significant results in the model, the remaining macroeconomic variables were indeed significant. These variables include coding for the Recession, as well as the existing interest, unemployment and inflation rates. Since the reported values for these independent variables are the same across all companies, the results provide reliability and consistency in terms of analysis and conclusion.

First, it is important to discuss the properties of these four variables in relation to the restaurant industry and other variables in the data set. The Recession, interest, unemployment and inflation rates are macroeconomic conditions or trends that have an impact on restaurant companies and are typically related in some fashion (Loebbecke et al., 1989). They cannot be controlled or ignored by any one company, and they all relate to and ultimately impact the demand by consumers for the restaurant industry (Summers \& Sweeney, 1998). In fact, publicly traded restaurant companies usually disclose information relating to these variables in their “Management's Discussion and Analysis” section in their 10-K annual report filings in order to provide shareholders with relevant information that may affect their business (Allen, 2008).

A typical cause of falling into a Recession is often rises in prices of goods and services over time (or inflation). The higher the rate of inflation, the smaller the percentage of goods and services that can be purchased with the same amount of money (Morah, 2012). In an inflationary environment, consumers tend to cut out leisure spending such as dining out, reduce overall spending, and begin to save more. Then, as a result of the lack of demand for services, businesses respond by cutting expenses and reducing workforce needs. Then, unemployment 
rates begin to rise. As a Recession deepens, the restaurant industry usually feels the effects of this first as consumers pull back from spending money on eating out (Allen, 2008). Likewise, interest rates respond to the Recession in much the same way - as consumers save, there is a greater supply of money to lend compared to the demand to borrow. In order to increase the demand to borrow money, interest rates drop.

This relationship is important to understand because the core of the restaurant industry is dependent on consumer patronage (Yap, 2008). As demand for the industry lessens, restaurants undoubtedly experience a decline in performance. Consequently, restaurant industry revenue has fallen at an average annual rate of .1\% to $\$ 54.6$ billion over the 5 years to 2012. (Hiemstra \& Kosiba, 1994). A study completed by Hiemstra \& Kosiba (1994) supports this notion by finding that the decline in demand for the restaurant industry could largely be explained by changes in prices and income due to the Recession, in addition to changes in tax, unemployment and inflation rates.

Additionally, as the results indicate in the study, the effects of these macroeconomic conditions also may have an impact on the likelihood of increased fraud risk. It appears that while management can't control the effects of the conditions, the industry has responded directly by posting incidences of reported internal control deficiencies. Thus, it is likely that these macroeconomic variables create essentially "tipping points" for which enhanced likelihood of errors or fraud are magnified during this period. This is explained empirically through the marginal effects calculations which determined that the Recession had the highest probability of increased fraud risk at 30\%, followed by interest, inflation and unemployment rates.

There are a couple reasons that may explain this phenomenon of increased fraud risk as a result of the macroeconomic conditions. First, it appears that the effects of the macroeconomic 
conditions actually have an indirect effect on the individual companies through operational performance changes, employee turnover changes, and changes in debt structure. Restaurant companies as a whole are so dependent on consumers to run their business, that as the core business starts to decline, the increased pressure combined with opportunity allows for risk of fraud to increase. Second, as a result of the effects of changing macroeconomic conditions, companies in the restaurant industry respond to internal changes by cutting costs and changing processes to compensate for dwindling consumer demands. As demonstrated through the fraud triangle framework, both of these reasons adequately demonstrate the ability of the constructs of the fraud triangle to highlight the causes of increased fraud risk.

\section{Conclusions Regarding the Overall Model}

As noted in Chapter 4, the results of the overall model provide an opportunity to further disaggregate the data in order to look at specific segments of companies in the restaurant industry. This is justified through the analysis of the variance in the overall model (53\%), as well as the wide distribution of standard deviations for company size, which indicates that several types of restaurants exist in the dataset with varying profit margins (Parsa et. al, 2005; Jennings, 2012). The overall model in the aggregate, while indicative of significance through the signs of each of the coefficients, provides evidence that the variance combined with the outliers indicates that disaggregation by restaurant segment is necessary to provide more robust results.

The related results from the disaggregation of the model by restaurant sub-segment implies that the characteristics of separate restaurant segments are significant when considering reported internal control deficiencies. For example, international sales growth, return on assets and executive stock compensation are significant risk factors of fraud for fast casual restaurants, 
while debt and the interest rate are significant risk factors for quick service restaurants.

Additionally, casual dining restaurants appear to be the most sensitive to increased fraud risk, as debt, the Recession, executive stock compensation, interest rate and organizational structure all may play a role in contributing to increased fraud risk through reported internal control deficiencies. Finally, fine dining restaurants revealed that all the variables pointed to equal risk meaning that one particular condition was not more important or significant than another for the sample of restaurants studied.

These results provide compelling evidence for future research which may help discern which characteristics for each type of restaurant segment are the most significant indicators for increased fraud risk. While the overall model provides that macroeconomic conditions should be viewed carefully when reported internal control deficiencies are reported, the additional specific characteristics of each restaurant company notes that the model is different according to type of restaurant. Regardless, the overall model provides implications for both theory and practice in the realm of predicting the likelihood of fraud for publicly traded restaurant companies on the whole.

\section{Theoretical Implications}

As noted in the literature review, there are three main constructs that contribute to the risk of fraud in an organization, and this study indicates a slight variation to Cressey’s (1973) hypothesis that all three constructs must exist together, in equal weight, for fraud to occur. This study actually revealed that the constructs of pressure and opportunity are supported through the significance of the macroeconomic (external) conditions in the model and not the internal variables. External pressure to meet targets as a result of declining performance from 
Recessionary time periods in conjunction with opportunities that stem from changes in interest, inflation and unemployment rates provide support for the application of this theoretical model to the restaurant industry. While rationalization is more difficult to measure and does not show significance as measured by executive stock compensation, it is noted through evaluation of the impact of the Sarbanes-Oxley Act in the overall model that executive managers often justify their actions through corporate governance actions. As internal control deficiencies are realized and reported by external auditors, the Act provides insight regarding management's commitment to running the company ethically and adhering to process controls. As more deficiencies are noted over time, the greater the exposure to increased risk of fraud.

Overall, it is noted that from a theoretical perspective, the fraud triangle is contextual when applied to the restaurant industry because only the variables that are outside of managements control were significant. However, once the data was disaggregated, the framework revealed a mix of both internal and external factors that held significance. For example, for the casual dining segment, it was revealed that debt, stock compensation and organizational structure, combined with the Recession and interest rates revealed significance. This provides for additional considerations in future research for building a model that is segmented by type of restaurant company. While this study focused on testing and evaluating the framework to the aggregate industry instead of building, the empirical evidence provides some support for building a future model at the disaggregated level in order to evaluate the risk of fraud.

The contribution of this study therefore supports part of Cressey's general framework as well as the AICPA's use of the fraud triangle to identify fraud red flags. Finally, this study contributes to the effectiveness of the fraud triangle framework by supporting the framework 
through the identification of conditions that may lead to reported deficiencies. Figure 13 provides the components of the fraud triangle framework as suggested by the overall model presented.

\section{The Fraud Triangle}

\section{Opportunity}

\section{Ability to carry out} misappropriation of cash or organizational assets.

\section{Rationalization}

Justification of

dishonest actions.

\section{FRAUD}

Figure 13: Components of the Fraud Triangle

Additionally, the study supports organizational theory as suggested by Langevoort (2007) in the context of securities fraud. Essentially, Langevoort uses organizational theory to support the fraud triangle framework by drawing on the motivations of executive management. Langevoort (2007) states that motivation must be a contributing factor to fraud, and that executive management must feel the pressure to lie or conceal information. This implies that as long as executive management is aligned with the long-term interests of the company, then fraud is unlikely to occur. This is further supported by Arlen and Carney (1994) who make a case that 
when faced with a going concern or insolvency issue for future company performance, executive management will be incentivized to commit fraud or misstate financials in order to avoid a threatened loss of salary, job or reputation. This notion supports the fraud triangle framework of pressure, opportunity and rationalization by viewing the executive management as stewards of the culture and backbone of the organization. When the organization is threatened, executive management may find motivation for intentional deception (Arlen \& Carney, 1994; Langevoort, 2007).

\section{Managerial Implications}

The main practical, managerial contribution of this study highlights the risk factors that the executive management of publicly traded restaurant companies should focus on in order to mitigate increased risk of fraud. First, from a practical standpoint, the effects of a Recession and fluctuating interest, inflation and unemployment rates study contribute to the current body of literature regarding fraud and the effectiveness of the Sarbanes-Oxley Act on deterring fraud risk. By focusing on the changing macroeconomic conditions that may have an empirical effect on demand, executive leadership will be able to streamline processes to avoid incidences of reporting internal control deficiencies when exposed to the macroeconomic conditions. For example, revenue recognition processes should be scrutinized as a Recessionary time period is realized for the restaurant industry. This will ease the burden of reporting on internal controls and allow managers to focus on the most meaningful processes in order to reduce noted deficiencies.

The importance of this contribution is evident, when considering that the cost of complying with the Sarbanes-Oxley disclosure requirements is tremendous. Compliance with 
section 404 is arguably one of the most controversial areas of the Sarbanes-Oxley Act, largely due to the opinions that the costs of compliance far outweigh the benefits. For example, a study in 2005 estimated that Fortune 1000 firms expended an average of \$5.9 million to comply with the internal control reporting requirements in their first year of compliance with section 404 of the Act (De Franco, 2005; Gupta \& Nayar, 2006; Hammersley et al., 2008). Given the high costs of compliance, it is necessary to have a road map that will provide managers with the suggestion to focus on internal controls when faced with declining conditions as a result of changing macroeconomic conditions.

In addition to the high costs of compliance, it is also important to recognize additional managerial characteristics that may heighten the effects of the macroeconomic conditions on increased fraud risk. For example, it is well known in organizational behavior research that structure and processes shape how executive management is making sense of what is happening around them (Rubin, 1996). Never is this more important or evident than in times when the economy is in a Recession. As indicated by the results of the study, however, many times executive management does not recognize the problems associated with the macroeconomic conditions because of systematic perceptual filters that play the crucial role in the functioning of the company. For example, executive management only has available a certain amount of information to make decisions, and that information is often decentralized and therefore poses a challenge to coherent corporate decision-making (Arrow, 1974). In the restaurant industry in particular, information is also not readily quantifiable, which makes it even more difficult to transform into meaningful and timely information for executive management. Particular examples include consumer insights and how well new promotions are received and moved throughout the market. 
All of these managerial characteristics creates a situation where management is not fully conscious of their bias towards optimism, which may also be shaped by corporate culture and the strong desire to appear to be in control of all areas of the business (Bainbridge, 1996). It is clear that companies operate in a complex web of relationships with a lot of different stakeholders. This complex web combined with the characteristics described all create a perfect managerial storm for increased risk of fraud. And, according to the model, the managerial factors are only exacerbated by the presence of macroeconomic factors.

For the first time, this study offers publicly traded restaurant companies with guidance towards a more thorough understanding of the specific conditions that might contribute to fraudulent behavior and increased risk of fraud. Additionally, the identified conditions could help managers to improve internal control when a high risk factor is realized. The contribution of this study may allow restaurant companies to deter activities that may result in increased risk of fraud.

\section{$\underline{\text { Limitations }}$}

First, it is important to recognize that the Sarbanes-Oxley Act was put in place to regulate publicly traded companies only. Therefore, for purposes of this study, privately traded companies are excluded. This is a limitation of the study because the results may indicate a problem that is more or less pervasive since the sample is representative of a small number of companies in the United States. For example, since private companies aren’t subject to the Act, their governance procedures may be lacking completely, providing evidence of fraud that isn’t regulated. Additionally, the model is limited in application because it does not take into account fluctuations among the variables over time. Although the model compares data points to 
industry medians over time, the model is static in that it reports data at specific points in time but it does not calculate or account for the differences in the amounts between time periods. This could create a situation in which the changes in the variables are actually a result of the variables impacting each other instead of changing independently over time. Lagging the variables helps to remove these effects but the variables may still be exogenous when faced with changing financial conditions over time. Future research may address the changes in the variables over time and may therefore provide additional insight. Finally, it should be noted that reported internal control deficiencies are indicative of increased fraud risk, but not necessarily conclusive that fraud has occurred. Therefore, just because a company has reported a deficiency, it does not indicate fraud, necessarily. The study therefore precludes the ability to conclude that fraud is always a result of an internal control deficiency.

\section{Future Research}

Since the study revealed that the macroeconomic conditions were significant for the entire population of restaurant companies, an area of future research might explore the relevance of the co alignment model (Olsen \& Roper, 1998) to strategic management decisions in order to reduce the risk of fraud. The co alignment model has typically been utilized to make strategic management decisions for improving performance, based on the elements of environmental events, strategic choice, firm structure and firm performance (Olsen, West \& Tse, 1998). By applying the co-alignment model to the identified variables, a new application for management to reduce instances of fraud might be revealed.

While the evaluation of the entire population of restaurant companies did not provide significant results at the company level, an opportunity became apparent to further segregate the 
restaurant companies by restaurant segment, in order to evaluate the impact of the variables within a smaller, similar group. Chapter four provided results for quick service, fast casual, casual dining/full service, and fine dining. Each of the segments revealed significance for different company level variables, which provides support for future research in the area of analysis by segment. The results of the probit models for each of the segments implies that characteristics of each of the segments warrants further research into why the "red flags" might differ. By analyzing model differences for each case of restaurants, perhaps different aspects of the business may be highlighted for mitigation of fraud. Thus, this area of future research may explore why certain segments of the restaurant industry are more susceptible to internal factors compared to others.

When considering the model, while this study utilized past literature as a basis for selecting the variables to measure the constructs, a future research study may incorporate a confirmatory factory analysis to explore other variables that might provide more insight into factors that increase the risk of fraud for the restaurant industry. For example, competitiveness is increasing among restaurant companies and may prove to be an additional pressure that might impact increased fraud risk.

Additionally, it should be noted that the study is complex and relies on construct measurement as supported by financial and non-financial variables. One main component that could contribute to the body of research in this area is perceptions of corporate governance by the employees of the organization. Since rationalization is often the most difficult to measure and relies on the intent and justification, a future study of perceptions of how ethical management is might provide further credit to this main construct. 


\section{LIST OF REFERENCES}

Ahrens, T., \& Chapman, C. S. (2004). Accounting for Flexibility and Efficiency: A Field Study of Management Control Systems in a Restaurant Chain*. Contemporary accounting research, 21(2), 271-301.

AICPA, (2009). Management override of internal controls: the achilles' heel of fraud prevention. New York, NY 10036-8775.

Ainsworth, R. (2010). Zappers-Retail VAT Fraud.

Allen, C. (2008). Restaurant Industry bears brunt of recession. Retrieved from Decision Analyst website. http://www.decisionanalyst.com/publ_data/2008/restaurant.dai

Arad, H. \& Jamshedy-Navid. (2010). A clear look at internal controls: theory and concepts. SSRN 2009 Top 10 Paper, Retrieved from http://ssrn.com/abstract=1342048

Ashbaugh-Skaife, H., Collins, D., Kinney, W., \& LaFond, R. (2006), “The Effect of Internal Control Deficiencies on Firm Risk and Cost of Equity Capital,” Working Paper.

Baker, K. (1998). Internal control and audit issues in the hospitality industry. Retrieved May 2, 2010, $3^{\text {rd }}$ International Conference: Tourism and Hotel Industry in Indo-China \& Southeast Asia: Development, Marketing, and Sustainability, June, 1998.

Bernardi, R. A., \& Pincus, K. V. (1996). The relationship between materiality thresholds and judgments of fraud risk. Managerial Finance, 22(9), 1-15.

Boulton, D. L. (2013). New Menu labeling requirements for food chains: possible impact on small business restaurants. In Allied Academies International Internet Conference (Vol. 15, p. 111).

Booth, J. R., Cornett, M. M., \& Tehranian, H. (2002). Boards of directors, ownership, and regulation. Journal of Banking \& Finance, 26(10), 1973-1996. 
Boyd, B. K. (1995). CEO duality and firm performance: A contingency model. Strategic Management Journal, 16(4), 301-312.

Bryan, S. H., \& Lilien, S. B. (2005). Characteristics of firms with material weaknesses in internal control: an assessment of Section 404 of Sarbanes Oxley. Available at SSRN 682363.

Business Wire (2009). Three top economists agree 2009 worst financial crisis since great depression; risks increase if right steps are not taken. [Available Online] http://www.businesswire.com/portal/site/home/permalink/?ndmViewId=news_view\&ne wsId=20090213005161\&newsLang=en

Canina, L. \& Carvell, S. (2005). Lodging demand for urban hotels in major metropolitan markets. Journal of Hospitality \& Tourism Research, 29(3), 291-311.

Card, D. \& Krueger, A. (2001). Minimum wages and employment: a case study of the fast food industry in New Jersey and Pennsylvania. National Bureau of Economic Research (Cambridge, MA) Working Paper No. 4509.

Chatwin, R. (2000). Optimal dynamic pricing of perishable products with stochastic demand and a finite set of prices. European Journal of Operational Research, 125(1), 149-174.

Chauvin, K. \& Hirschey, M. (1993). Advertising, r\&d expenditures, and the market value of the firm. Financial Management, Winter, 128-140.

Chon, K. \& Singh, A. (1993). Current economic issues facing the US lodging industry. International Journal of Contemporary Hospitality Management, 5(3), 3-9.

Chen, C., \& Schwartz, Z. (2008). Room rate patterns and customers’ propensity to book a hotel room.Journal of Hospitality and Tourism Research, 32(3), 287-306.

Coates, J. C. (2007). The goals and promise of the Sarbanes-Oxley Act. The Journal of Economic Perspectives, 91-116. 
Corgel, J. (2004) Focus on hospitality: predictive powers of hotel cycles. Real Estate Issues, 28(4), 32-36.

Committee of Sponsoring Organizations of the Treadway Commission (COSO), (1992). Internal Control-Integrated Framework. New York: American Institute of Certified Public Accountants.

Committee of Sponsoring Organizations of the Treadway Commission (COSO), (2000). Internal Control-Integrated Framework. New York: American Institute of Certified Public Accountants.

Cross, R., Higbie, J., \& Cross, D. (2009). Revenue management's renaissance: A rebirth of the art and science of profitable revenue generation. Cornell Hospitality Quarterly, 50(1), 5681.

Davis, S. \& Albright, J. (2000). The changing organisational structure and individual responsibilities of managerial accountants: a case study. Journal of Managerial Issues, $12(4), 446-64$.

Defranco, A. L. \&Lattin, T. W. (2006).Hospitality Financial Management. Hoboken, New Jersey: John Wiley \& Sons, Inc.

Dick, A. \& Basu, K. (1994). Customer loyalty: toward and integrated conceptual framework. Journal of the Academy of Market Science, 22(2), 99-113.

Doyle, J., Ge, W., \& McVay, S. (2007a). Accruals quality and internal control over financial reporting. The Accounting Review, 82(5), 1141-1170.

Doyle, J., Ge, W., \& McVay, S. (2007b). Determinants of weaknesses in internal control over financial reporting. Journal of Accounting and Economics, 44(1-2), 193-223. 
Durbin, J., (1970). Testing for serial correlation in least squares regression when some of the regressors are lagged dependent variables. Econometrica, 38, pp410-421.

Fenich, G. (2008). ‘Chapter 4: Meeting and Conventions Venues’ $2^{\text {nd }}$ edn. Upper Sadle River, NJ: Prentice-Hall, Inc.

Finch, J., Becherer, R., \&Casavant, R. (1998).An option-based approach for pricing perishable services assets. The Journal of Services Marketing, 12(6), 473-483.

Foster A. \&Wohlberg, A. (2006). Hotel spas as independent profit centers.http://www.pkfc.com/en/pkfhome/freestuff/industryreports/IR2006_04A.aspx

Frechtling, C. (2001). Forecasting Tourism Demand: Methods and Strategies. Woburn, MA: Reed Educational and Professional Publishing, Ltd.

Free, C., Stein, M., \& Macintosh, N. (2007). Management controls: The organizational fraud triangle of leadership, culture and control in Enron. Ivey Business Journal, 71(6), 1-10.

Fikes, E. M. (2009). Dishonest associates in the workplace: The correlation between motivation and opportunity in retail among employee theft.

Garber, A., \& Walkup, C. (2004). Theft protection plan key to locking in profits. Nation’s Restaurant News, 38, 21.

Garg, A. (1999). U.S. Patent No. 6,009,407. Washington, DC: U.S. Patent and Trademark Office.

Ge, W. \& McVay, S. (2005). The disclosure of material weaknesses in internal control after the Sarbanes-Oxley act. Accounting Horizons, 19(3), 137-158.

Geller, N. (1991). Rule out fraud and theft: controlling your food-service operation. Cornell Hotel and Restaurant Administration Quarterly, 32(4), 55. 
Geller, A. N., Ilvento, C. L., \& Schmidgall, R. S. (1990). The hotel controller revisited. The Cornell Hotel and Restaurant Administration Quarterly, 31(3), 91-97.

Geiger, M. \& Taylor, P. (2003). CEO and CFO certifications of financial information. Accounting Horizons, 17(4), 357-368.

Gustafson, C. M. (2002). Employee turnover: a study of private clubs in the USA. International Journal of Contemporary Hospitality Management, 14(3), 106-113.

Hammersley, J., Myers, L. \& Shakespeare, C. (2008). Market reactions to the disclosure of internal weaknesses and to the characteristics of those weaknesses under section 302 of the Sarbanes Oxley Act of 2002.

Hess, D. (2007). A business ethics perspective on Sarbanes-Oxley and the organizational sentencing guidelines. Michigan Law Review, 1781-1816.

Ho, Z. P. (2012). An application of new approach for dynamic orders selection to maximize restaurant operational profits. Advanced Materials Research, 472, 380-385.

Hogan, J. (2009). Effective sales management: short and long-term planning, forecasting, and expense budgeting (part 1 of 2). [Available online] http://www.hospitalitynet.org/news/154000320/4042741.search?query=how+hotel+mana ger $\% 27 \mathrm{~s}+$ forecast + sales

Hogan, C. E., \& Wilkins, M. S. (2008). Evidence on the Audit Risk Model: Do Auditors Increase Audit Fees in the Presence of Internal Control Deficiencies?*. Contemporary Accounting Research, 25(1), 219-242.

Hope, J., \& Fraser, R. (2003). Who needs budgets?. Harvard Business Review, 81(2), 108-15.

Karpoff, J. M., Lee, D. S., \& Martin, G. S. (2008). The consequences to managers for cooking the books. Journal of Financial Economics, 88, 193-215. 
Kim, H., \& Gu, Z. (2006). Predicting restaurant bankruptcy: a logit model in comparison with a discriminant model. Journal of Hospitality \& Tourism Research, 30(4), 474-493.

Kim, J. B., Song, B. Y., \& Zhang, L. (2011). Internal control weakness and bank loan contracting: Evidence from SOX Section 404 disclosures. The Accounting Review, 86(4), 1157-1188.

Krippel, G. L., Henderson, L. R., Keene, M. A., Levi, M., \& Converse, K. (2008). Employee theft and Coastal Carolina hospitality industry: Incidence, detection, and response (Survey Results 2000, 2005). Tourism and Hospitality Research, 8 (3), 226-238.

Krishnan, J. (2005). Audit committee quality and internal control: An empirical analysis. The accounting review, 80(2), 649-675

Krishnan, G. V., \& Visvanathan, G. (2007). Reporting Internal Control Deficiencies in the PostSarbanes-Oxley Era: The Role of Auditors and Corporate Governance. International Journal of Auditing, 11(2), 73-90.

Kuma, M. (2012). Market access and value chain analysis of dairy industry in Ethiopia: The case of Wolaita Zone. PhD Dissertation in Agriculture (Agricultural Economics). Haramaya, Ethiopia: Haramaya University.

Langevoort, D. C. (2006). SEC as a Lawmaker: Choices about Investor Protection in the Face of Uncertainty, The. Wash. UL Rev., 84, 1591.

Levisohn, B. (2009). Experts Say Fraud Likely to Rise. Business Week Online [serial online]. January 12, 2009: 14-14. Available from: Business Source Complete, Ipswich, MA. Accessed February 18.

Lord \& Benoit, LLC. (2007). The Lord \& Benoit Report: Do the Benefits of 404 Exceed the Costs? Worcester, Massachusetts, United States. 
Maijoor, S. (2000). The internal control explosion. International Journal of Auditing, 4(1), 101109.

Mak, J. (2003). Tourism and the Economy. Hawaii: University of Hawaii Press.

Masson, R., Mudambi, R. \& Reynolds, R. (1994).Oligopolistic product withholding in ricardian markets. Bulletin of Economic Research,46(1), 71-79.

Mattila, A. 2006. Affective commitment and its impact on guest loyalty and frequency reward programs. Cornell Hotel and Restaurant Administration Quarterly 47 (2): 174-81.

Martinek, K. (2005). Outbreak of Vibrio parahaemolyticus Gastroenteritis Associated with Alaskan Oysters. The New England Journal of Medicine, 353: 1463-1470.

Matovic, D. (2002). The competitive market structure of the U.S. lodging industry and its impact on the financial performance of hotel brands. Unpublished doctoral dissertation, Virginia Polytechnic Institute and State University. Blacksburg, Virginia.

Meredith, J. \& Roth, A. (1998). Operations management in the USA. International Journal of Operations \& Production Management, 18(7), 668-674.

Mulherin, J. Harold \& Boone, Audra L. (2000). Comparing Acquisitions and Divestitures (March 2000). Available at SSRN: http://ssrn.com/abstract=218145 or http://dx.doi.org/10.2139/ssrn.218145

Muth, J. (1961). Rational expectations and the theory of price movements. Econometrica, 29(3), 315-335.

New York Times (2014). 4 Accused in Law Firm Fraud. Retrieved February 20, 2014.

Nicolaisen, D. T. (2004). Keynote speech at 11th annual midwestern financial reporting symposium. Chicago, IL, October 7, 2004. 
Nicolau, J. (2005). Leveraging profit from the fixed-variable cost ratio: The case of new hotels in Spain. Tourism Management, 26(1), 105 -111.

Oliver, R. (1999). Whence consumer loyalty? Journal of Marketing, 63(1), 33-44.

Olsen, M. \& Roper, A. (1998). Research in strategic management in the hospitality industry. International Journal of Hospitality Management, 17, 111- 124.

Olsen, M. D., West, J., \& Tse, E. C. (1998). Strategic management in the hospitality industry (2nd ed.). New York, NY: John Wiley and Sons, Inc.

O’Neill, John W., Bjorn Hanson, and Anna S. Mattila. 2008. The relationship of sales and marketing expenses to hotel performance in the United States. Cornell Hospitality Quarterly 49 (4): 355-63.

Pany, K. J., \& Whittington, O. R. (2001). Research implications of the Auditing Standard Board's current agenda. Accounting Horizons, 15(4), 401-411.

Public Company Accounting Oversight Board (PCAOB, 2004). Auditing Standard No. 2 - An Audit of internal control over financial reporting performed in conjunction with an audit of financial statements.

Raab, C., Shoemaker, S., \& Mayer, K. J. (2007). Activity-based costing: a more accurate way to estimate the costs for a restaurant menu. International Journal of Hospitality \& Tourism Administration, 8(3), 1-15.

Rajopadhye, M., Ghalia, M., \& Wang, P. (2001). Forecasting uncertain hotel room demand. Information Sciences, 132(1), 1-11.

Reilly, F., A. McGann, and R. Marquardrat. 1977. Advertising decision and stockholders wealth. Journal of Advertising Research 17:49-56. 
Rezaee, Z. (2005). Causes, consequences and deterrence of financial statement fraud. Critical Perspectives on Accounting, 16(3), 277-298.

Ritter, J. R. (2003). Behavioral finance. Pacific-Basin Finance Journal, 11(4), 429-437.

Rui, H., \& Yip, G. S. (2008). Foreign acquisitions by Chinese firms: A strategic intent perspective. Journal of World Business, 43(2), 213-226.

Rutherford, D. (2002). Hotel Management and Operations, $3^{\text {rd }}$ edn. Wiley: New York.

Schmidgall, R. (2006). Hospitality Industry Managerial Accounting, 6th edn. Lansing:

Educational Institute of the American Hotel \& Lodging Association.

Schwartz, Z. \& Cohen, E. (2004). Hotel revenue-management forecasting: evidence of expertjudgement bias. Cornell Hotel and Restaurant Administration Quarterly, 45(1), 85-98.

Schwartz, Z. \& Hiemstra, S. (1997). Improving the accuracy of hotel reservations forecasting: curves similarity approach. Journal of Travel Research, 36(1), 3-14.

SEC, (2002). Certification of disclosure in companies' quarterly and annual reports, final rule 33-8124, (August 29), Washington, D.C.

SEC (2004). Management's reports on internal control over financial reporting and certification of disclosure in exchange act periodic reports-frequently asked questions, (October 6) Washington, D.C.

SEC (2008). Study of the Sarbanes-Oxley Act of 2002 Section 404 Internal Control over Financial Reporting Requirements.

SEC (2014). Management's reports on internal control over financial reporting and certification of disclosure in exchange act periodic reports-frequently asked questions, (October 6) Washington, D.C. 
Shetty, M. (2008). The lodging industry market structure. Retrieved from Hotel News Resource website: http://www.hotelnewsresource.com

Sinclair, T. \& Stabler, M. (1997).The Economics of Tourism. London: Routledge.

Srinivasan, M., \& Chandra, A. (2014). Assessing the Impact of Sarbanes-Oxley Act on the Logistics Industry. Transportation Journal, 53(1), 44-78.

Steed, E. \& Gu, Z. (2008). Hotel management company forecasting and budgeting practices: a survey-based analysis. International Journal of Contemporary Hospitality Management, 21(6), 676-697.

Tellis, G. (1986). Beyond the many faces of price: An integration of pricing strategies. Journal of Marketing, 50(4), 146-160.

Thorburn, K. S. (2000). Bankruptcy auctions: costs, debt recovery, and firm survival. Journal of financial economics, 58(3), 337-368.

Vanhove, N. (2005). The Economics of Tourism Destinations. London:Butterworth-Heinemann.

Vallens, A. \& Cook, G. (2001). The importance of reputation. RISK MANAGEMENT-NEW YORK-, 55(4), 36.

Vinod, B. (2004). Unlocking the value of revenue management in the hotel industry. Journal of Revenue and Pricing Management, 3(2), 178-190.

Wanhill, S. R. (1994). The economics of restaurant fraud. International Journal of Hospitality Management, 13(3), 265-273.

Weatherford, L. \& Kimes, S. (2003). A comparison of forecasting methods for hotel revenue management. International Journal of Forecasting, 19(2), 401-415.

Wheaton, W. \&Rossoff, L. (1998). The cyclic behavior of the U.S. lodging industry. Real Estate Economics 26(1), 67-82. 
Whitfield, C. (2013). Guess who's eating your profits...The manager's essential guide to restaurant and bar loss prevention and investigations. Author House: Bloomington, IN.

Woodworth, R. (2009). Falling industry profits. Cornell Hospitality Quarterly, 50(1), 15-18.

Zimmerman, J. L. (2003), Accounting for Decision Making and Control, 4th ed., McGraw-Hill Higher Education, New York, NY.

Zorn, C. (2001). Generalized Estimating Equation Models for Correlated Data: A Review with Applications. American Journal of Political Science, 45(April), 470-90. 